\title{
The Yin and Yang of ERBB4: Tumor Suppressor and Oncoprotein
}

Lauren M. Lucas, Vipasha Dwivedi, Jared I. Senfeld, Richard L. Cullum, Christopher P. Mill, J. Tyler Piazza, Ianthe N. Bryant, Laura J. Cook, S. Tyler Miller, James H. Lott IV, Connor M. Kelley, Elizabeth L. Knerr, Jessica A. Markham, David P. Kaufmann, Megan A. Jacobi, Jianzhong Shen, and David J. Riese II

Department of Drug Discovery and Development, Harrison School of Pharmacy (L.M.L., V.D., J.I.S., R.L.C., C.P.M., J.T.P., L.J.C., S.T.M., J.H.L., C.M.K., E.L.K., J.A.M., D.P.K., M.A.J., J.S., D.J.R.), and Department of Chemical Engineering, Samuel Ginn College of Engineering (R.L.C.), Auburn University, Auburn, Alabama; The University of Texas M.D. Anderson Cancer Center, Houston, Texas (C.P.M.); Office of the

Executive Vice President for Research and Partnerships, Purdue University, West Lafayette, Indiana (I.N.B.); and Cancer Biology and Immunology Program, O'Neal Comprehensive Cancer Center, The University of Alabama at Birmingham, Birmingham, Alabama (D.J.R.)

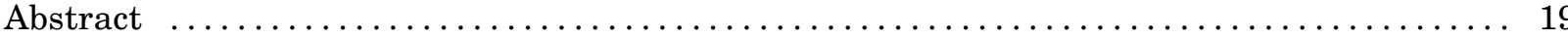

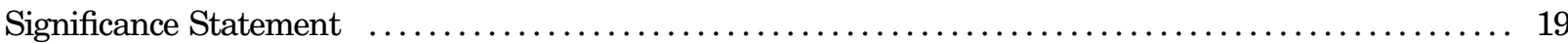

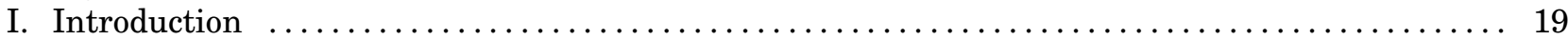

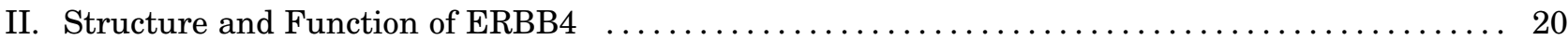

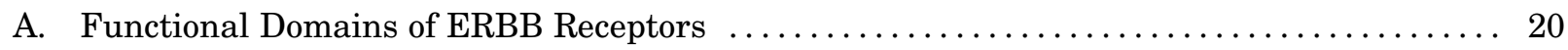

B. General Principles of Ligand-Induced ERBB Receptor Dimerization $\ldots \ldots \ldots \ldots \ldots \ldots \ldots$

C. General Principles of ERBB Receptor Tyrosine Phosphorylation $\ldots \ldots \ldots \ldots \ldots \ldots \ldots \ldots 21$

D. Canonical ERBB4 Signaling Relies on ERBB4 Tyrosine Phosphorylation ............ 22

E. Differences in Phosphorylation Sites Enable ERBB Receptor Signaling Specificity ....... 23

F. Differences in Ligand Potency and Intrinsic Activity Enable ERBB Receptor Signaling

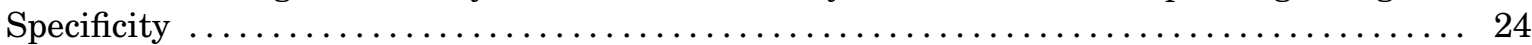

G. ERBB Receptor Homodimers and Heterodimers Enable Signaling Specificity .......... 25

H. Trafficking of the ERBB4 Cytoplasmic Domain Enables Noncanonical Signaling in the Nucleus and the Mitochondria, Thereby Contributing to Apoptosis and Other Effects . . 26

I. Transcriptional Splicing Isoforms of ERBB4 Confer Signaling Specificity . . . . . . . . . . . 29

J. Summary and Implications for ERBB4 Function in Human Malignancies . .......... 30

III. Tumors in Which ERBB4 Appears to Function as a Tumor Suppressor $\ldots \ldots \ldots \ldots \ldots \ldots \ldots \ldots 30$

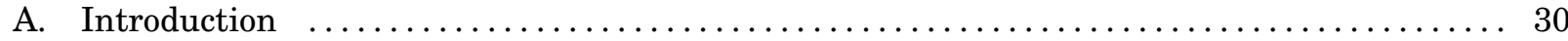

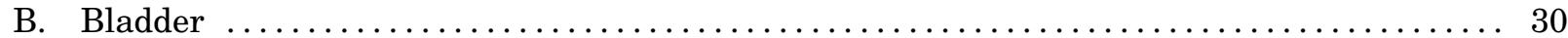

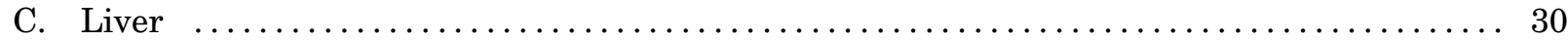

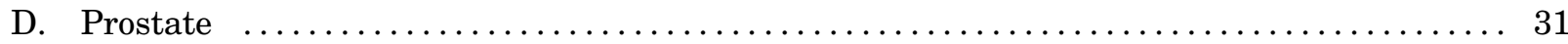

IV. Tumors in Which ERBB4 Appears to Function as an Oncoprotein $\ldots \ldots \ldots \ldots \ldots \ldots \ldots \ldots \ldots . \ldots \ldots$

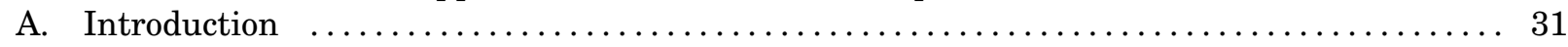

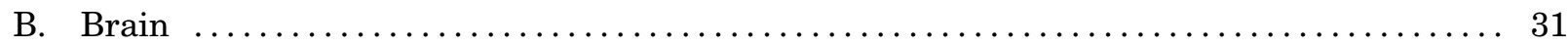

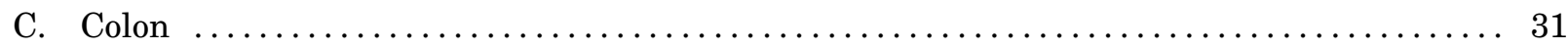

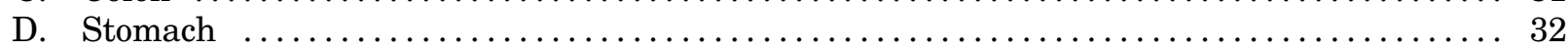

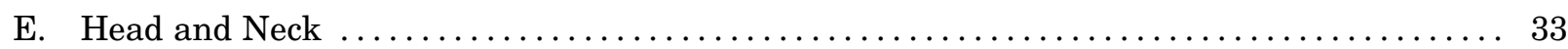

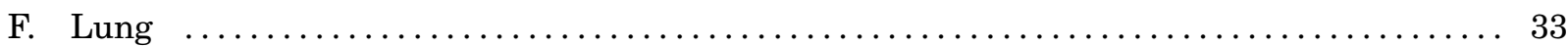

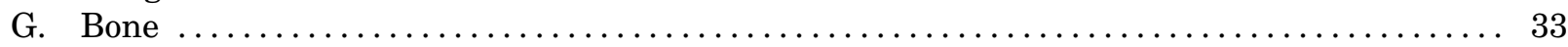

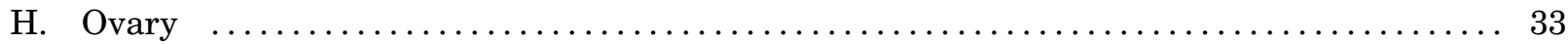

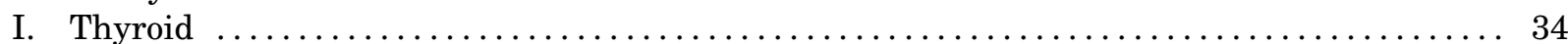

Address correspondence to: Dr. David J. Riese II, Department of Drug Discovery and Development, Harrison School of Pharmacy, Auburn University, 3211g Walker Bldg., Auburn, AL 36849-5501. E-mail: driese@auburn.edu

Research in the Riese laboratory has been funded by an Auburn University Research Initiative in Cancer (AURIC) fellowship to R.L.C., an AURIC grant to D.J.R., a US Department of Education GAANN Graduate Fellowship Program in Biological \& Pharmaceutical Engineering Award P200A120244 to Auburn University, an Auburn University Presidential Graduate Research Fellowship to L.M.L., an Auburn University Intramural Grants Program award to D.J.R., and other support from the Auburn University Department of Drug Discovery and Development and the Auburn University Harrison School of Pharmacy.

D.J.R. is a consultant for Eli Lilly and Company, Bristol-Myers Squibb, and ImClone, LLC. R.L.C. is an employee of Abbott Laboratories. The funders had no role in preparation of the manuscript.

dx.doi.org/10.1124/pharmrev.121.000381. 


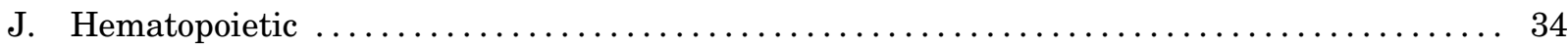

V. Tumors in Which ERBB4 Appears to Function as an Oncoprotein and as a Tumor Suppressor . 36

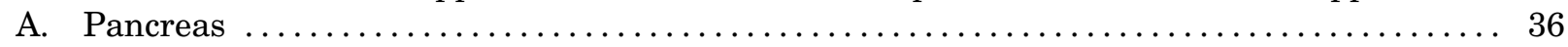

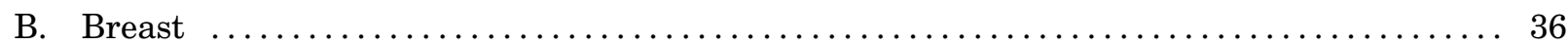

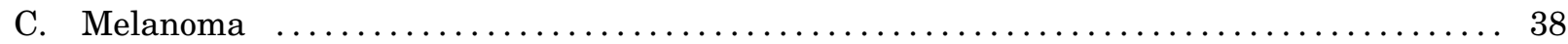

VI. Implications for Staging and Treating Human Tumors $\ldots \ldots \ldots \ldots \ldots \ldots \ldots \ldots \ldots \ldots \ldots \ldots$

A. Determination of whether ERBB4 Functions as a Tumor Suppressor or as an Oncoprotein 39

B. Identification of ERBB4 Mutants that Serve as Biomarkers through Their Function as

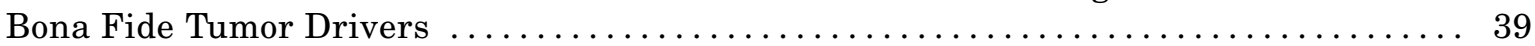

C. Potential Therapeutic Approaches for Tumors that Harbor Tumor Driver Mutations in

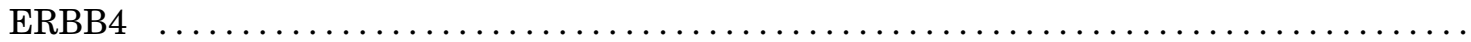

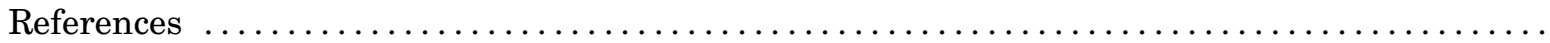

Abstract-ERBB4 (HER4) is a member of the ERBB family of receptor tyrosine kinases, a family that includes the epidermal growth factor receptor (EGFR/ERBB1/HER1), ERBB2 (Neu/HER2), and ERBB3 (HER3). EGFR and ERBB2 are oncoproteins and validated targets for therapeutic intervention in a variety of solid tumors. In contrast, the role that ERBB4 plays in human malignancies is ambiguous. Thus, here we review the literature regarding ERBB4 function in human malignancies. We review the mechanisms of ERBB4 signaling with an emphasis on mechanisms of signaling specificity. In the context of this signaling specificity, we discuss the hypothesis that ERBB4 appears to function as a tumor suppressor protein and as an oncoprotein. Next, we review the literature that describes the role of ERBB4 in tumors of the bladder, liver, prostate, brain, colon, stomach, lung, bone, ovary, thyroid, hematopoietic tissues, pancreas, breast, skin, head, and neck. Whenever possible, we discuss the possibility that ERBB4 mutants function as biomarkers in these tumors. Finally, we discuss the potential roles of ERBB4 mutants in the staging of human tumors and how ERBB4 function may dictate the treatment of human tumors.

Significance Statement_-This articles reviews ERBB4 function in the context of the mechanistic model that ERBB4 homodimers function as tumor suppressors, whereas ERBB4-EGFR or ERBB4-ERBB2 heterodimers act as oncogenes. Thus, this review serves as a mechanistic framework for clinicians and scientists to consider the role of ERBB4 and $E R B B 4$ mutants in staging and treating human tumors.

\section{Introduction}

ERBB4 (HER4) is a member of the ERBB family of receptor tyrosine kinases, a family that includes the epidermal growth factor receptor (EGFR/ERBB1/HER1), ERBB2 (Neu/HER2), and ERBB3 (HER3) (Carraway et al., 1997; Gullick and Srinivasan, 1998; Riese and Stern, 1998; Olayioye et al., 2000; Schlessinger, 2000; Yarden and Sliwkowski, 2001; Burgess et al., 2003; Earp et al., 2003; Holbro and Hynes, 2004; Zaczek et al., 2005; Citri and Yarden, 2006; Britsch, 2007; Karamouzis et al., 2007; Riese et al., 2007; Burgess, 2008; Mei and Xiong, 2008; Bose and Zhang, 2009; Lemmon, 2009; Wilson et al., 2009; Lemmon and Schlessinger, 2010; Rudloff and Samuels, 2010; Easty et al., 2011; Eccles, 2011; Arteaga and Engelman, 2014; Bessman et al., 2014; Lemmon et al., 2014; Riese and Cullum, 2014; Roskoski, 2014; Alaoui-Jamali et al., 2015; Appert-Collin et al., 2015; Kennedy et al., 2016; Mishra et al., 2017; Wang, 2017). EGFR and ERBB2 are extensively studied oncoproteins and are well validated targets for therapeutic intervention in various solid tumors. ERBB3 also appears to function as an oncoprotein, although its role in human malignancies appears to be more limited than the roles of EGFR or ERBB2. In contrast, the role that ERBB4 plays in human malignancies is ambiguous (Klijn et al., 1992; Lupu et al., 1992; Tripathy and Benz, 1992; Hynes and Stern, 1994; Lupu et al., 1995; Carraway et al., 1997;
Gullick and Srinivasan, 1998; Riese and Stern, 1998; Olayioye et al., 2000; Schlessinger, 2000; Bowers et al., 2001; Hynes et al., 2001; Yarden and Sliwkowski, 2001; Anderson and Ahmad, 2002; Zhou and Carpenter, 2002; Carpenter, 2003a; Earp et al., 2003; Holbro and Hynes, 2004; Roskoski, 2004; Hynes and Lane, 2005; Zaczek et al., 2005; Citri and Yarden, 2006; Engelman and Cantley, 2006; Hynes and Schlange, 2006; Nicholas et al., 2006; Schlessinger and Lemmon, 2006; Breuleux, 2007; Karamouzis et al., 2007; Riese et al., 2007; Burgess, 2008; Black and Dinney, 2008; Chuu et al., 2008; Jones, 2008; Lafky et al., 2008; Muraoka-Cook et al., 2008; Paatero and Elenius, 2008; Roepstorff et al., 2008; Sorkin and Goh, 2008; Stern, 2008; Uberall et al., 2008; Lemmon, 2009; Wilson et al., 2009; Carraway, 2010; Hollmen and Elenius, 2010; Koutras et al., 2010; Lemmon and Schlessinger, 2010; Rudloff and Samuels, 2010; Easty et al., 2011; Eccles, 2011; Veikkolainen et al., 2011; Lindet et al., 2012; Khelwatty et al., 2013; Arteaga and Engelman, 2014; Gala and Chandarlapaty, 2014; Ma et al., 2014; Modjtahedi et al., 2014; Appert-Collin et al., 2015; Feldinger and Kong, 2015; Cao et al., 2016; Kennedy et al., 2016; Lemmon et al., 2016; Sacco and Worden, 2016; Wang et al., 2016; Kourie et al., 2017; Mishra et al., 2017; Mota et al., 2017; Lyu et al., 2018; Arienti et al., 2019; Black et al., 2019; Jordan et al., 2019; Maennling et al., 2019; Wang et al., 2019; Segers et al., 
2020). Some data indicate that ERBB4 functions as an oncoprotein, making it a potential target for therapeutic intervention. Other data indicate that ERBB4 functions as a tumor suppressor and is therefore unsuited for direct therapeutic intervention.

Genome-wide, next-generation sequencing of tumor cell transcripts has identified mutations and changes in gene expression that are characteristics of tumor genesis and progression. This has enabled a revolution in mechanism-based targeted chemotherapy. However, the absence of a clear-cut understanding of the role that ERBB4 plays in human malignancies has hindered the translation of ERBB4 expression and $E R B B 4$ mutation data into clinical practice.

Hence, here we will review ERBB4 function, including mechanisms by which biochemical and biologic responses to ERBB4 signaling are specified. We will emphasize the mechanistic model that ERBB4 homodimerization and heterodimerization can be coupled to distinct biochemical responses, thereby enabling ERBB4 homodimers to function as tumor suppressors and ERBB4 heterodimers to function as oncoproteins. We will review past efforts to characterize the role of ERBB4 in human malignancies in the context of this mechanistic model, and we will discuss the implications of this model in the staging and treatment of human tumors.

\section{Structure and Function of ERBB4}

\section{A. Functional Domains of ERBB Receptors}

The four ERBB family receptors share structural homology (Fig. 1). They each contain a large, amino-terminal, extracellular region comprised of four subdomains (I-IV) involved in ligand binding and receptor dimerization. Adjacent to the extracellular domain is a single-pass, hydrophobic transmembrane domain. Carboxyl terminal to the transmembrane domain is a cytoplasmic tyrosine kinase domain and a tail region that features numerous tyrosine residues that serve as sites of phosphorylation (Carraway et al., 1997; Gullick and
Srinivasan, 1998; Riese and Stern, 1998; Olayioye et al., 2000; Hynes et al., 2001; Burgess et al., 2003; Holbro and Hynes, 2004; Roskoski, 2004, 2014; Britsch, 2007; Burgess, 2008; Lemmon et al., 2014; AlaouiJamali et al., 2015; Appert-Collin et al., 2015; Wang, 2017; Maennling et al., 2019).

\section{B. General Principles of Ligand-Induced ERBB Receptor Dimerization}

The ligands for ERBB receptors are members of the epidermal growth factor (EGF) family of peptide growth factors. No ligand has been identified for ERBB2, whereas multiple EGF family members (discussed in Section II.F) bind to EGFR, ERBB3, and ERBB4 (Fig. 2). In the absence of a cognate ligand, most EGFR, ERBB3, and ERBB4 molecules on the cell surface exist in a closed conformation that features intramolecular interactions between extracellular subdomains (ECDs) II and IV (Fig. 1). This conformation buries the receptor dimerization motifs found in ECDs II and IV and increases the distance between the ligand-binding motifs found in ECDs I and III. This spatial distance prevents ligand molecules from simultaneously binding the ligand-binding motifs found in ECDs I and III. Thus, in the closed conformational state, EGFR, ERBB3, and ERBB4 bind ligands with low affinity and fail to dimerize and signal.

In the absence of ligand, a small fraction of EGFR, ERBB3, and ERBB4 molecules on the cell surface exist in an open conformation that lacks the interactions between ECDs II and IV. This conformation exposes the receptor dimerization motifs found in ECDs II and IV. Therefore, this open conformation permits ligand-independent receptor dimerization and signaling, particularly during extreme receptor overexpression $\left(\geq 10^{\wedge} 6\right.$ receptor molecules/cell); this overexpression enables stochastic dimerization of two receptor molecules in the open conformation (note that extreme receptor overexpression is observed in some types of human tumors, as will be discussed in later sections). However, to reiterate, EGFR, ERBB3,

ABBREVIATIONS: ADAM17, TNF converting enzyme; AKT, protein kinase; ALCL, anaplastic large-cell lymphoma; AREG, amphiregulin; ATM, ataxia telangiectasia mutated; BAK, Bcl-2 homologous antagonist/killer; BAPC, anaphase-promoting complex; BAX, Bcl-2-associated X protein; BCBL, Casitas B-lineage lymphoma E3 ubiquitin ligase; BH3, Bcl2 homology 3 domain; BRAF, v-Raf murine sarcoma viral oncogene homolog; BTC, betacellulin; CRC, colorectal cancer; CT, carboxyl terminal; Cyt1/Cyt2, cytoplasmic domain isoforms of ERBB4 that arise through alternative splicing of the ERBB4 transcript; ECD, extracellular subdomain of ERBB4; EGF, epidermal growth factor; EGFR, ERBB1; ER, estrogen receptor; G2/M, transition between the G2 and M phases of the cell cycle; GRB, growth factor receptor-bound; HBEGF, heparin-binding EGF-like growth factor; HCC, hepatocellular carcinoma; HPV, human papillomavirus; HNSCC, head and neck squamous cell carcinoma; 4ICD, soluble form of the ERBB4 cytoplasmic (intracellular) domain; ITCH, itchy E3 ubiquitin protein ligase; $\mathrm{JMa} / \mathrm{JMb}$, extracellular juxtamembrane isoforms of ERBB4 that arise through alternative splicing of the ERBB4 transcript; KRAS, Kirsten RAS; MDM2, mouse double minute 2 homolog; miR, microRNA; MMTV, mouse mammary tumor virus promoter; NRG, neuregulin; OMM, mitochondrial outer membrane; p85, regulatory subunit of phosphatidylinositol 3-kinase; PAY, proline-proline-alanine-tyrosine; PDAC, pancreatic ductal adenocarcinoma; PDZ, structural motif first described in postsynaptic density protein 95 (PSD-95), Dlg1, and Zo-1 and involved in interactions of membrane-bound receptors with cytoskeletal proteins; PI3K, phosphatidylinositol 3-kinase; PKB, protein kinase $\mathrm{BP}$; PR, progesterone receptor; RAS, rat sarcoma virus; RIP, regulated intramembrane proteolysis; SRC, Rous sarcoma virus protein tyrosine kinase; SKCM, skin cutaneous melanoma; STAD, stomach adenocarcinoma; STAT, signal transducer and activator of transcription; TCGA, The Cancer Genome Atlas; TGFA, transforming growth factor $\alpha$; TNBC, triple-negative breast cancer; TNF, tumor necrosis factor; WWOX, tumor suppressor oxidoreductase; YAP1, Yes-associated protein 1. 


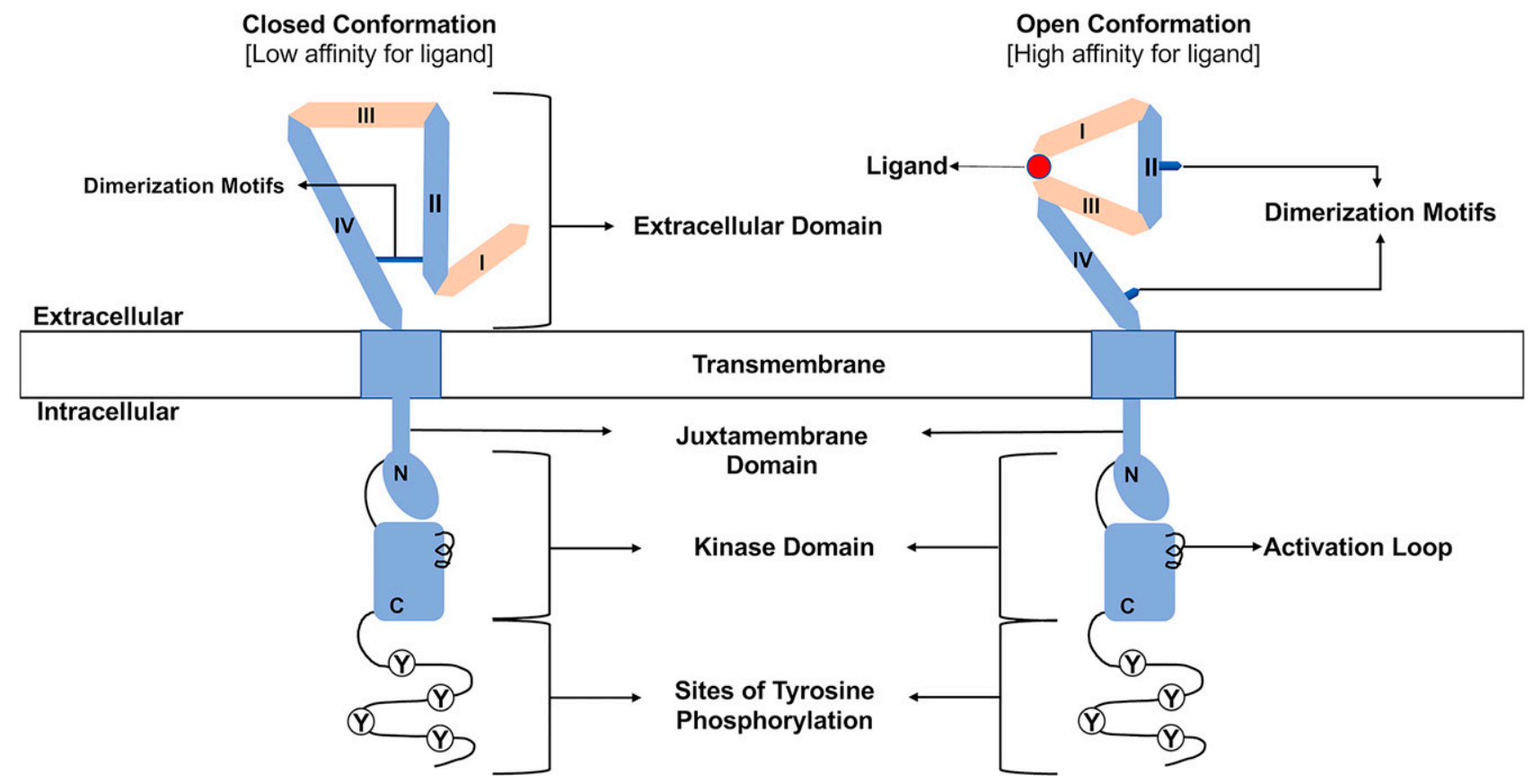

Fig. 1. Organization of ERBB receptors. The amino-terminal extracellular region consists of four subdomains (I-IV) responsible for ligand binding and receptor dimerization. Note the dimerization motifs in subdomains II and IV that stabilize the intramolecular interactions characteristic of the closed conformation and enable the intermolecular interactions necessary for dimerization of two receptor molecules that exist in the open conformation. A hydrophobic transmembrane domain lies between the extracellular region and the cytoplasmic tyrosine kinase domain. This kinase domain can be divided into amino-terminal $(\mathrm{N})$ and carboxyl-terminal (C) lobes. Several sites of tyrosine phosphorylation $(\mathrm{Y})$ reside at the carboxyl terminus of these receptors. Finally, note that ligand binding stabilizes a receptor molecule in the open conformation.

and ERBB4 molecules exist in an equilibrium between the closed and open conformations that strongly favors the closed conformation, thereby limiting ligand-independent receptor signaling under physiologic levels of expression.

When EGFR, ERBB3, or ERBB4 molecules are in the open conformation, there is a relatively small distance between ECDs I and III, such that it permits simultaneous, high-affinity binding of a single-ligand molecule to the ligand-binding sites of both subdomains (Fig. 1). Ligand binding stabilizes the receptor molecule in the open conformation, thereby facilitating receptor dimerization and signaling (Fig. 2) (Lemmon et al., 1997, 2014; Riese and Stern, 1998; Cho and Leahy, 2002; Garrett et al., 2002; Burgess et al., 2003; Ferguson et al., 2003, 2020; Holbro and Hynes, 2004; Roskoski, 2004, 2014; Bouyain et al., 2005; Dawson et al., 2005; Citri and Yarden, 2006; Ozcan et al., 2006; Britsch, 2007; Riese et al., 2007; Lemmon, 2009; Lemmon and Schlessinger, 2010; Rudloff and Samuels, 2010; Alaoui-Jamali et al., 2015; Appert-Collin et al., 2015; Feldinger and Kong, 2015; Kennedy et al., 2016; Wang, 2017; Maennling et al., 2019).

The effects of ligand binding on ERBB4 dimerization and signaling have been modeled by the constitutive dimerization and phosphorylation of the synthetic ERBB4 Q646C (Penington et al., 2002) and I658E (Vidal et al., 2007) mutants. The Q646C mutant, which undergoes homodimerization but not heterodimerization with other ERBB receptors, is functionally distinct from constitutively active $E R B B 2$ mutants in that it does not cause malignant growth transformation of fibroblasts. Instead, the Q646C mutant inhibits clonogenic proliferation by various human breast, prostate, and pancreatic tumor cell lines (Penington et al., 2002; Williams et al., 2003; Gallo et al., 2006, 2013; Pitfield et al., 2006; Mill et al., 2011a). Likewise, the I658E mutant promotes apoptosis in numerous human breast, prostate, and ovarian tumor cell lines (Vidal et al., 2007). Consequently, these mutants indicate that ERBB4 homodimers function as tumor suppressors in a variety of contexts. We will discuss this general principle in more detail throughout this review.

\section{General Principles of ERBB Receptor Tyrosine Phosphorylation}

The dimerization of the extracellular subdomains of two ERBB receptor molecules causes dimerization of the intracellular subdomains of those molecules (Fig. 2). The extracellular domains of two receptor molecules form a symmetrical dimer. In contrast, the intracellular domains form an asymmetric dimer in which one monomer (the "regulatory/substrate monomer") causes a conformational change in the other monomer (the "catalytic monomer"). This change in conformation activates the tyrosine kinase activity of the catalytic monomer, resulting in phosphorylation of tyrosine residues of the regulatory/substrate monomer. The carboxyl terminus of each ERBB receptor molecule contains multiple tyrosine residues, and this region is relatively unstructured. Thus, ERBB4 receptor 


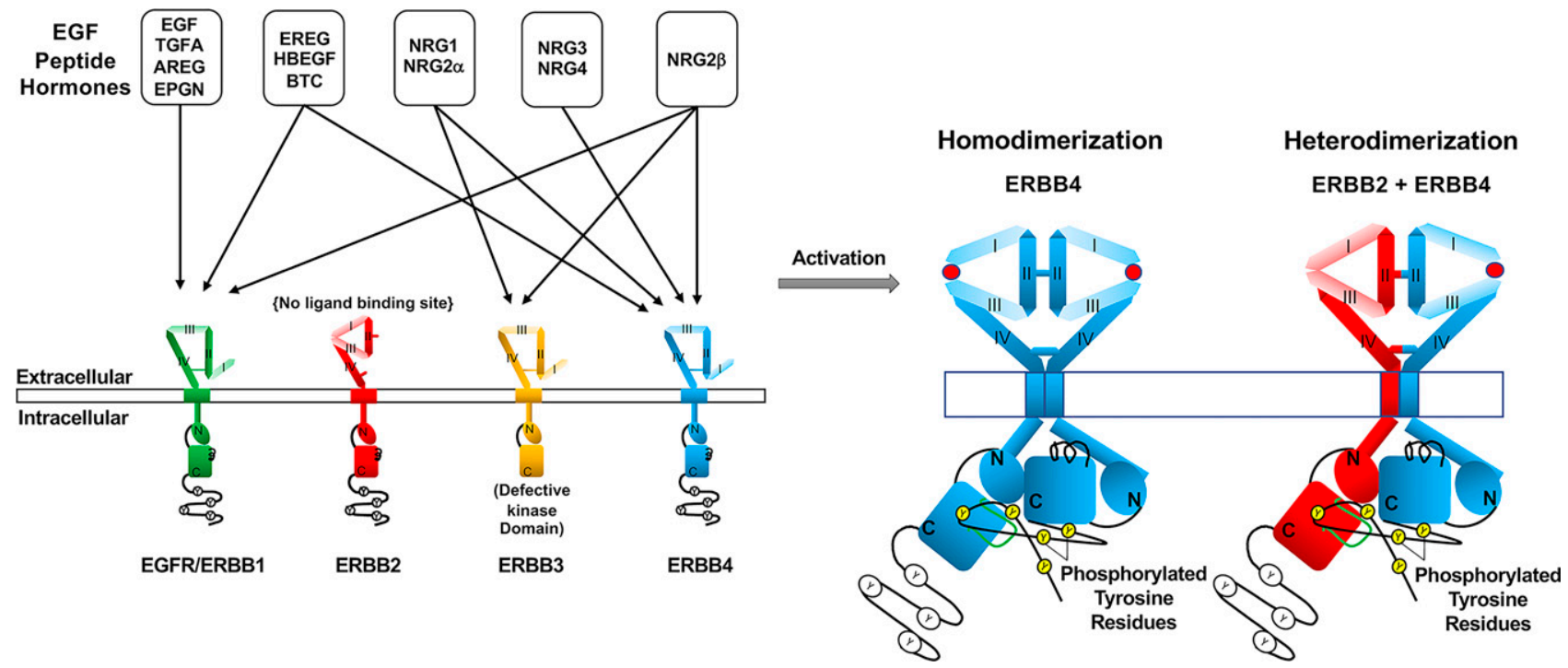

Fig. 2. Ligand-induced ERBB receptor signaling. Eleven members of the EGF family of peptide growth factors bind to EGFR, ERBB3, and ERBB4. Some EGF family members bind to multiple ERBB family receptors, but no EGF family member binds to ERBB2. The binding of an EGF family hormone to a receptor stabilizes the extracellular domain of the receptor in an open conformation that enables receptor dimerization. ERBB receptors can either homodimerize or heterodimerize. The symmetrical dimerization of the extracellular region of two ERBB receptors causes asymmetric dimerization of the cytoplasmic regions. This asymmetric dimerization enables the kinase domain of one monomer to allosterically stimulate the kinase activity of the other monomer. This results in transphosphorylation of one monomer by the other on tyrosine residues.

dimerization and signaling features phosphorylation of multiple tyrosine residues within a population of receptor molecules (Fig. 3) (Carraway and Cantley, 1994; Jeffrey et al., 1995; Carraway et al., 1997; Olayioye et al., 2000; Bowers et al., 2001; Yarden and Sliwkowski, 2001; Landau et al., 2004; Jones et al., 2006; Zhang et al., 2006; Britsch, 2007; Qiu et al., 2008; Bose and Zhang, 2009; Foley et al., 2010; Lemmon and Schlessinger, 2010; Lemmon et al., 2014; Riese and Cullum, 2014; Roskoski, 2014; Alaoui-Jamali et al., 2015; Kovacs et al., 2015; Kennedy et al., 2016; Mishra et al., 2017; Wang, 2017; Black et al., 2019; Segers et al., 2020).

\section{Canonical ERBB4 Signaling Relies on ERBB4 Tyrosine Phosphorylation}

The phosphorylation of ERBB receptors creates binding sites for numerous cytoplasmic signaling proteins that possess SRC homology domain 2 or (to a lesser extent) phosphotyrosine binding domain domains. The binding of these signaling proteins can trigger numerous intracellular signaling cascades, resulting in a wide range of phenotypes. The recognition of a specific site of tyrosine phosphorylation of an ERBB receptor by a specific cytoplasmic protein that possesses an SRC homology domain 2 or phosphotyrosine binding domain is dependent in part on the ERBB receptor amino-acid residues immediately adjacent to the phosphorylated tyrosine residue. Therefore, different sites of tyrosine phosphorylation can couple to different cytoplasmic signaling effectors, resulting in distinct phenotypes (Fig. 3) (Carraway and Cantley, 1994; Carraway et al., 1997; Olayioye et al., 2000; Yarden and Sliwkowski, 2001;
Schlessinger and Lemmon, 2003; Holbro and Hynes, 2004; Schulze et al., 2005; Zaczek et al., 2005; Citri and Yarden, 2006; Jones et al., 2006; Kaushansky et al., 2008; Lemmon and Schlessinger, 2010; Eccles, 2011; Riese and Cullum, 2014; Roskoski, 2014; Kovacs et al., 2015; Wang, 2017; Black et al., 2019; Segers et al., 2020).

Mass spectrometry, high-performance liquid chromatography, and other analytical approaches have identified candidate sites of ERBB4 tyrosine phosphorylation. Protein microarrays and other methods have identified cytoplasmic signaling proteins that bind to 21 of these sites of phosphorylation (Fig. 3) (Schulze et al., 2005; Kaushansky et al., 2008; Segers et al., 2020). Additional putative ERBB4 signaling modulators and effectors that appear to bind the ERBB4 cytoplasmic domain independent of specific sites of tyrosine phosphorylation have been identified (Fig. 4). Altogether, an incomplete list of the proteins that apparently mediate ERBB4 function via physical and functional interactions with the ERBB4 cytoplasmic domain includes the Rous sarcoma virus protein tyrosine kinase (SRC); the Abelson-related protein tyrosine kinase (ABL2); the spleen-associated protein tyrosine kinase (SYK); the Janus kinase 1 (JAK1); protein tyrosine phosphatase non-receptor type 11 (PTPN11); phospholipase C gamma-2 (PLCG2); phosphatidylinositol 4,5bisphosphate 3-kinase catalytic subunit alpha isoform (PIK3CA) via its p85 regulatory subunit; the Casitas Blineage lymphoma ubiquitin ligase $(\mathrm{CBL})$; the second guanine nucleotide exchange factor named after the sixth letter of the Greek alphabet (VAV2); the rat sarcoma virus protein (RAS) GTPase activating protein 


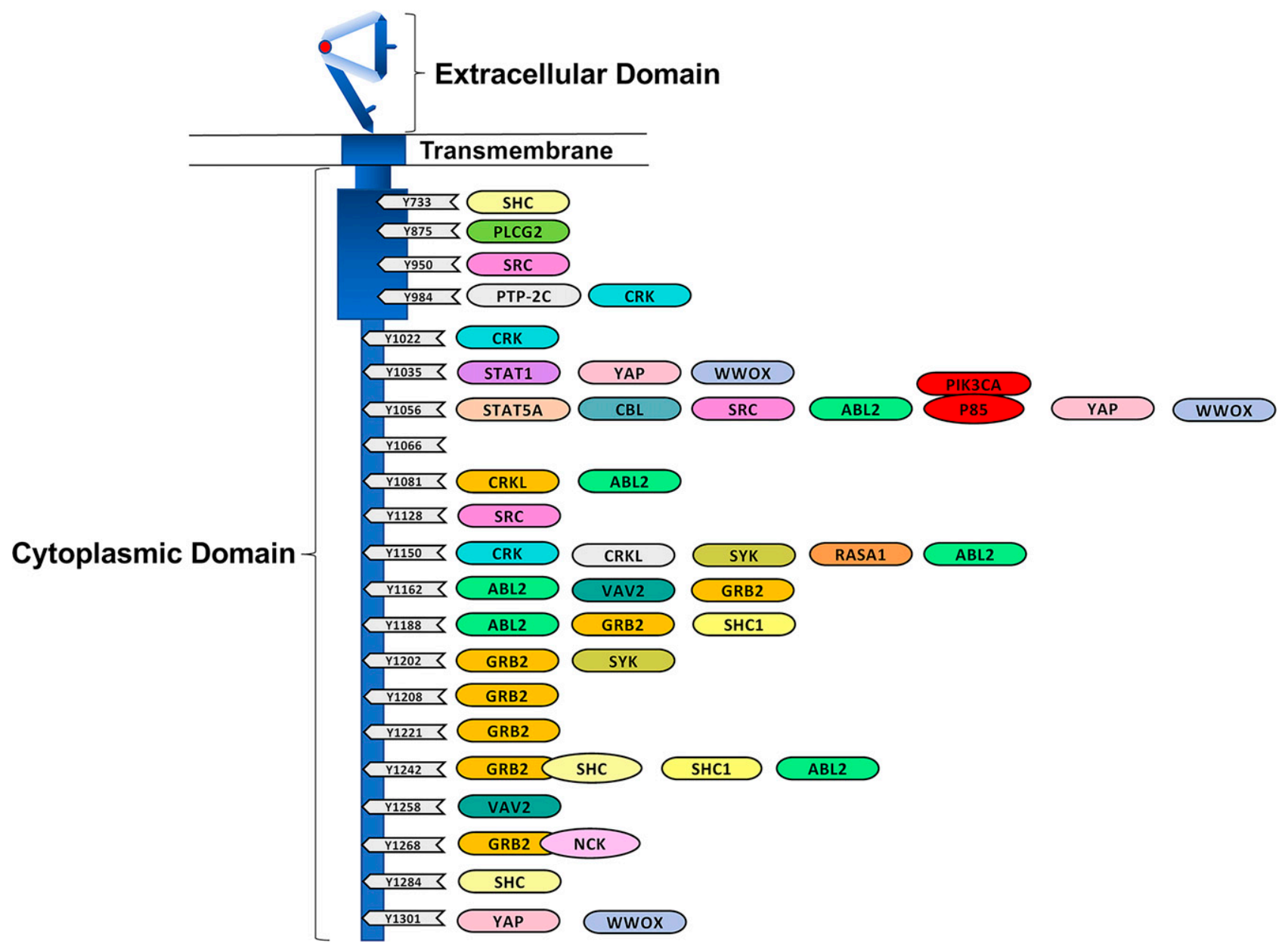

Fig. 3. The cytoplasmic domain of ERBB4 possesses several candidate and validated sites of tyrosine phosphorylation. These sites of ERBB4 tyrosine phosphorylation are depicted along with candidate and validated effector proteins that directly or indirectly interact with these phosphorylation sites. The cytoplasmic domain is not depicted to scale.

RASA1; the signal transducer and activator transcription factors STAT1 and STAT5a; the Yes-associated protein 1 (YAP1); the tumor suppressor oxidoreductase WWOX; postsynpatic density protein 95 (PSD-95), which binds the PDZ-domain recognition motif at the carboxyl terminus of ERBB4; and several adapter proteins, including the SRC homology domain 2-containing transforming protein (SHC1), growth factor receptorbound protein 2 (GRB2), growth factor receptor-bound protein 7 (GRB7), CT10 regulator of kinase (CRK), and the CRK-like protein (CRKL) (Culouscou et al., 1995; Sepp-Lorenzino et al., 1996; Elenius et al., 1997b; Fiddes et al., 1998; Olayioye et al., 1998; Pinkas-Kramarski et al., 1998b; Wang et al., 1998; Elenius et al., 1999; Jones et al., 1999; Olayioye et al., 1999; Garcia et al., 2000; Huang et al., 2000, 2002; Sweeney et al., 2000; Puricelli et al., 2002; Carpenter, 2003a,b; Schulze et al., 2005; Chuu et al., 2008; Kaushansky et al., 2008; Ishibashi et al., 2013; Roskoski, 2014; Li et al., 2015; Wang, 2017; Segers et al., 2020). Section II.H, which is focused on signaling by the soluble ERBB4 cytoplasmic domain (4ICD), further discusses ERBB4 signaling effectors, some of which are not mentioned in Section II.D.

\section{E. Differences in Phosphorylation Sites Enable ERBB Receptor Signaling Specificity}

EGFR and ERBB2 do not possess a phosphorylation site that enables direct binding of the p85 regulatory subunit of phosphatidylinositol 3-kinase (PI3K); in contrast, both ERBB3 and ERBB4 do possess at least one phosphorylation site that enables direct binding of p85 and activation of PI3K signaling (Yarden and Sliwkowski, 2001; Citri and Yarden, 2006; Arteaga and Engelman, 2014). Similarly, an EGFR phosphorylation site binds to the ubiquitin ligase CBL, resulting in CBLdependent EGFR downregulation. In contrast, ERBB4 does not appear to directly bind CBL but instead requires the adaptor protein GRB2 for CBL binding (Carraway and Sweeney, 2001; Citri and Yarden, 2006; Carraway, 2010; Kiuchi et al., 2014; Roskoski, 2014). These differences in coupling to signaling effectors may account for some of the specificity in receptor coupling to biochemical pathways and biologic responses. For example, signaling by EGFR or ERBB2 homodimers typically causes increased cell survival or proliferation, whereas signaling by ERBB4 homodimers typically results in tumor suppression (Riese et al., 1996a,b; Muthuswamy 


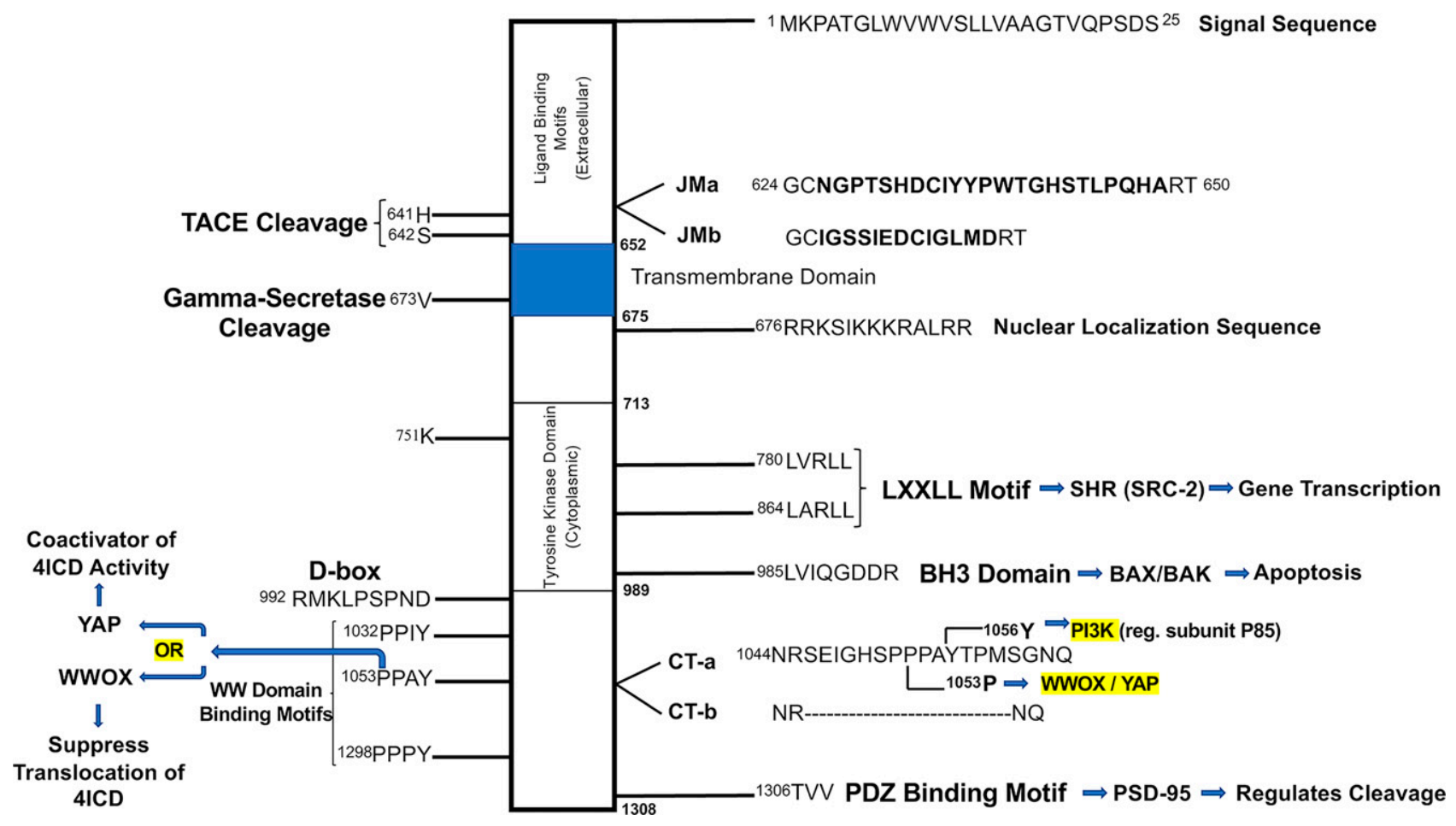

Fig. 4. Additional motifs and effectors that modulate and mediate ERBB4 signaling. The cytoplasmic region of ERBB4 is depicted along with the differences in the amino-acid sequence of the four ERBB4 splicing isoforms. Sites of ERBB4 functional motifs are indicated, along with the particular downstream signaling effectors that bind to these sites. The cytoplasmic region is not depicted to scale.

et al., 1999; Sartor et al., 2001; Penington et al., 2002; Earp et al., 2003).

\section{F. Differences in Ligand Potency and Intrinsic Activity Enable ERBB Receptor Signaling Specificity}

The EGF family of peptide growth factors (Fig. 2) consists of 11 family members, each encoded by a distinct gene: amphiregulin (AREG), betacellulin (BTC), EGF, epigen, epiregulin (EREG), heparin-binding EGFlike growth factor (HBEGF), neuregulin1 (NRG1), neuregulin2 (NRG2), neuregulin3 (NRG3), neuregulin4 (NRG4), and transforming growth factor $\alpha$ (TGFA). Moreover, there are multiple, functionally distinct splicing isoforms of both neuregulin1 and neuregulin2. Several of these ligands exhibit differences in receptor binding affinity. For example, NRG1 binds to ERBB3 and ERBB4; EREG, HBEGF, and BTC bind to EGFR and ERBB4; and NRG3 and NRG4 bind only to ERBB4 (Fig. 2) (Alimandi et al., 1997; Pinkas-Kramarski et al., 1998a; Olayioye et al., 2000; Hynes et al., 2001; Carpenter, 2003a; Zaczek et al., 2005; Karamouzis et al., 2007; Wilson et al., 2009; Eccles, 2011; Veikkolainen et al., 2011; Arteaga and Engelman, 2014; Dahlhoff et al., 2014; Macdonald-Obermann and Pike, 2014; Riese and Cullum, 2014; Roskoski, 2014; Feldinger and Kong, 2015; Arienti et al., 2019; Black et al., 2019; Maennling et al., 2019; Segers et al., 2020).

Moreover, saturating concentrations of different ligands at the same receptor may elicit distinct effects (Wilson et al., 2009). For example, a saturating concentration of
EREG, AREG, or TGFA stimulates greater EGFR coupling to cell proliferation than a saturating concentration of EGF. This difference appears to reflect that, unlike AREG, EGF stimulates EGFR phosphorylation at Tyr1045, a canonical binding site for the E3 ubiquitin protein ligase $\mathrm{CBL}$; thus, compared with AREG, EGF causes greater EGFR ubiquitination and downregulation and diminished EGFR signaling duration. Consistent with this model, the EGFR Y1045F mutant causes EGF to exhibit greater intrinsic activity but does not affect the intrinsic activity of AREG. Indeed, in the presence of the EGFR Y1045F mutant, EGF and AREG exhibit roughly equal intrinsic activity (Levkowitz et al., 1998; Shelly et al., 1998; Komurasaki et al., 2002; Joslin et al., 2007; Gilmore et al., 2008, 2009; Stern et al., 2008; Jansen et al., 2009; Roepstorff et al., 2009; Willmarth et al., 2009; Wilson et al., 2009; Ahsan et al., 2010; Foley et al., 2010; Wilson et al., 2012a; Macdonald-Obermann and Pike, 2014; Riese and Cullum, 2014; Lemmon et al., 2016; Wee and Wang, 2018).

As noted elsewhere, subtle differences in the structure of receptor monomers within a receptor dimer or subtle differences in the juxtapositioning of receptor monomers within a receptor dimer appear to determine which receptor tyrosine residues become phosphorylated, how receptors are processed after ligand engagement, the identity and duration of downstream 
signaling events, and which biologic responses result from these actions. Consistent with this model, EGF and TGFA induce distinct conformations of the EGFR intracellular region (Wilson et al., 2009; Foley et al., 2010; Scheck et al., 2012; Bessman et al., 2014). Similarly, EREG and EGF induce distinct conformations of the EGFR extracellular region. Moreover, EREG induces less stable EGFR dimers than does EGF. These differences may account for the failure of EREG to stimulate EGFR phosphorylation at Tyr1045 and the fact that EREG stimulates EGFR signaling of greater duration than does EGF (Freed et al., 2017).

Noteworthy differences in ligand efficacy can also be observed among the ERBB4 ligands (Wilson et al., 2009). NRG2 encodes two distinct sets of splicing isoforms that display substantial differences in the aminoacid sequence of the EGF homology domain, which is responsible for receptor binding. The isoform NRG2 $\beta$ binds to ERBB3 and ERBB4 with relatively high affinity, potently stimulates phosphorylation of both receptors (the former in the context of an ERBB3-ERBB2 heterodimer), and stimulates coupling of ERBB3-ERBB2 heterodimers or ERBB4-EGFR heterodimers to cell survival and proliferation. In contrast, NRG $2 \alpha$ binds to ERBB3 and ERBB4 with relatively low affinity and stimulates phosphorylation of both receptors with relatively low potency. Moreover, a saturating concentration of NRG2 $\alpha$ fails to stimulate the coupling of ERBB3-ERBB2 heterodimers or ERBB4-EGFR heterodimers to cell proliferation. The failure of NRG2 $\alpha$ to stimulate the coupling of ERBB3-ERBB2 heterodimers and ERBB4-EGFR heterodimers to cell proliferation is not due to a failure of NRG2 $\alpha$ to bind to ERBB3 or ERBB4, respectively. Indeed, NRG $2 \alpha$ competitively antagonizes the action of NRG2 $\beta$ at either ERBB3 or ERBB4 (Hobbs et al., 2002; Cote et al., 2005; Gilmore et al., 2006; Wilson et al., 2007, 2009, 2012b; Eckert et al., 2009).

Consistent with the current mechanistic explanation for differences in EGFR ligand efficacy, it has been postulated that NRG2 $\alpha$ and NRG2 $\beta$ cause ERBB4 to dimerize in slightly different conformations, resulting in the phosphorylation of different sets of tyrosine residues and differential coupling to downstream signaling effectors (Sweeney et al., 2000; Wilson et al., 2009). This mechanistic model is consistent with the observation that NRG2 $\beta$ stimulates ERBB4-EGFR heterodimers to couple to PI3K signaling via phosphorylation of ERBB4 Tyr1056 by EGFR; in contrast, NRG $2 \alpha$ fails to stimulate PI3K signaling, presumably due to a failure of NRG $2 \alpha$ to stimulate ERBB4 phosphorylation at Tyr1056 (Cote et al., 2005; Eckert et al., 2009; Wilson et al., 2012b). Moreover, this mechanistic model is consistent with the observation that altering the juxtapositioning of ERBB2 monomers within an ERBB2 homodimer affects the ability of these homodimers to stimulate malignant growth transformation (Burke and Stern, 1998; Wilson et al., 2009); likewise, this mechanistic model is consistent with the observation that altering the juxtapositioning of ERBB4 monomers within an ERBB4 homodimer affects the ability of these homodimers to function as tumor suppressors (Williams et al., 2003; Gallo et al., 2006; Pitfield et al., 2006; Wilson et al., 2009).

\section{G. ERBB Receptor Homodimers and Heterodimers Enable Signaling Specificity}

As noted earlier, ligand binding and stabilization of the receptor extracellular domain in the open conformation enables dimerization with another receptor molecule in the open conformation. Under many conditions, homodimerization predominates as the presence of a ligand increases the availability of its cognate receptor in the open conformation. However, heterodimerization of a liganded receptor to an unliganded receptor can occur, particularly when the unliganded receptor is overexpressed; overexpression increases the concentration of the unliganded receptor in the open conformation. Similarly, because the structure of the ERBB2 extracellular domain resembles the open (ligand-bound) conformation of the EGFR, ERBB3, and ERBB4 extracellular domains (Fig. 2), ERBB2 is a preferred heterodimerization partner for the other three receptors (Graus-Porta et al., 1997; Yarden and Sliwkowski, 2001; Burgess et al., 2003; Garrett et al., 2003; Eccles, 2011; Roskoski, 2014; Wang, 2017). This heterodimerization is particularly important for ERBB2 signaling, as ERBB2 lacks a cognate ligand. Heterodimerization is also particularly important for ERBB3 signaling, as ERBB3 possesses markedly impaired kinase activity (Stern and Kamps, 1988; Wada et al., 1990; Carraway and Cantley, 1994; Olayioye et al., 2000; Bowers et al., 2001; Hynes et al., 2001; Yarden and Sliwkowski, 2001; Burgess et al., 2003; Earp et al., 2003; Zaczek et al., 2005; Citri and Yarden, 2006; Karamouzis et al., 2007; Mei and Xiong, 2008; Lemmon, 2009; Rudloff and Samuels, 2010; Eccles, 2011; Veikkolainen et al., 2011; Roskoski, 2014; Wang, 2017).

Receptor heterodimerization has profound functional implications; it is well established that the homodimer of a particular ERBB family member activates different signaling pathways and biologic effects than does a heterodimer containing (in part) the same particular ERBB family member. For example, heterodimerization of ERBB2 or EGFR with ERBB4 modifies the biologic response to ERBB4 ligands, illustrating that signaling by ERBB4 homodimers is different from signaling by ERBB4-EGFR or ERBB4-ERBB2 heterodimers (Beerli et al., 1995; Riese et al., 1995; Cohen et al., 1996; Karunagaran et al., 1996; Riese et al., 1996a; Zhang et al., 1996; Carraway et al., 1997; Chang et al., 1997; Graus-Porta et al., 1997; Weiss et al., 1997; Fitzpatrick et al., 1998; Pinkas-Kramarski et al., 1998b; Riese et al., 1998; Shelly et al., 1998; Wang et al., 1998; 
Hynes et al., 2001; Hobbs et al., 2002; Carpenter, 2003a; Earp et al., 2003; Hobbs et al., 2004; Zaczek et al., 2005; Muraoka-Cook et al., 2006; Mill et al., 2011a,b; Wilson et al., 2012b; Segers et al., 2020). Moreover, as discussed in detail in Section II.B and Section II.H, homotypic ERBB4 signaling by the 4ICD or by the constitutively active ERBB4 Q646C or I658E mutants is coupled to apoptosis, growth inhibition, and tumor suppression (Penington et al., 2002; Williams et al., 2003; Vidal et al., 2005; Gallo et al., 2006, 2013; Naresh et al., 2006; Pitfield et al., 2006; Vidal et al., 2007; Mill et al., 2011a; Arienti et al., 2019). In contrast, heterotypic signaling by ERBB4-EGFR and ERBB4-ERBB2 heterodimers is coupled to oncogenic phenotypes, including cell proliferation, migration, invasion, and chemoresistance (Cohen et al., 1996; Riese et al., 1996a; Zhang et al., 1996; Carraway et al., 1997; Olayioye et al., 1999, 2000; Mill et al., 2011b).

\section{H. Trafficking of the ERBB4 Cytoplasmic Domain Enables Noncanonical Signaling in the Nucleus and the Mitochondria, Thereby Contributing to Apoptosis and Other Effects}

The binding of an ERBB4 full agonist (such as NRG1 $\beta$ or NRG2 $\beta$ ) to ERBB4 can also trigger noncanonical signaling, which is commonly referred to as regulated intramembrane proteolysis (Fig. 5) (Carpenter, 2003a,b; Junttila et al., 2005; Citri and Yarden, 2006; Sardi et al., 2006; Schlessinger and Lemmon, 2006; Mei and Xiong, 2008; Paatero and Elenius, 2008; Blobel et al., 2009; Veikkolainen et al., 2011; Roskoski, 2014; Wang, 2017). In the first step, the transmembrane metalloprotease tumor necrosis factor (TNF) $\alpha$-converting enzyme (ADAM17) cleaves the ERBB4 extracellular region near the transmembrane domain (between $\mathrm{H} 641$ and S642; Fig. 4), releasing the $120-\mathrm{kDa}$ extracellular region into the extracellular milieu (Vecchi and Carpenter, 1997; Rio et al., 2000; Zhou and Carpenter, 2000; Ni et al., 2001; Carpenter, 2003a,b; Cheng et al., 2003; Schlessinger and Lemmon, 2006; Blobel et al., 2009). Parenthetically, this soluble form of the extracellular region of ERBB4 can function as a ligand sink (Gilmore and Riese, 2004).

The remaining fragment of ERBB4, which consists of the transmembrane domain and the cytoplasmic domains, is cleaved by the gamma-secretase complex. The cleavage site appears to reside within the transmembrane domain, corresponding to the site of cleavage of Notch and the amyloid precursor protein by gamma-secretase (Fig. 4). This cleavage releases the 80-kDa cytoplasmic region of ERBB4 (the 4ICD) from the plasma membrane (Zhou and Carpenter, 2000; Ni et al., 2001, 2003; Lee et al., 2002a; Carpenter, 2003a,b; Linggi and Carpenter, 2006; Linggi et al., 2006; Naresh et al., 2006; Schlessinger and Lemmon, 2006; Greenwald and Kovall, 2013). This step requires the threonine-valine-valine (TVV) amino acid sequence (a PDZ recognition domain) present at the extreme carboxyl terminus of ERBB4 (Fig. 4) (Carpenter, 2003a; Ni et al., 2003; Blobel et al., 2009). This PDZ recognition domain may also mediate ERBB4 localization to basolateral membranes (Carraway and Sweeney, 2001). The PDZ recognition domain appears to be important to ERBB4 function; the addition of an epitope tag carboxyl-terminal to the TVV sequence disrupts the tumor suppressor activity of the ERBB4 Q646C mutant (Gallo et al., 2013).

The 4ICD induces growth arrest or apoptosis in a variety of tissues, including those of the breast (Zhu et al., 2006; Jones, 2008; Muraoka-Cook et al., 2008; Rokicki et al., 2010; Han et al., 2016; Arienti et al., 2019), brain (Sardi et al., 2006; Allison et al., 2011), and lung (Zscheppang et al., 2007; Liu et al., 2010; Hoeing et al., 2011). After release from the plasma membrane, the 4ICD traffics to the nucleus and alters patterns of gene expression that result in growth arrest (Srinivasan et al., 1999; Srinivasan et al., 2000; Ni et al., 2001; Lee et al., 2002a; Zhang et al., 2002; Carpenter, 2003b; Sardi et al., 2006; Blobel et al., 2009; Miller et al., 2017). Parenthetically, the trafficking of the 4ICD to the nucleus appears to be dependent on a putative nuclear localization sequence within the 4ICD (Fig. 4) (Ni et al., 2001; Lee et al., 2002a; Carpenter, 2003b; Williams et al., 2004; Gallo et al., 2013).

Nuclear 4ICD regulates gene transcription via various mechanisms ( $\mathrm{Ni}$ et al., 2001; Carpenter, 2003b; Wang, 2017; Wang et al., 2019), including trafficking binding partners to the nucleus (Carpenter, 2003b; Long et al., 2003; Segers et al., 2020). This activity appears to be regulated in part by LXXLL motifs within the 4ICD (Fig. 4), which have been shown in other contexts to mediate interactions with nuclear hormone receptors (Heery et al., 1997; Edwards, 2000; Savkur and Burris, 2004) and one of which is required for the tumor suppressor activity of the ERBB4 Q646C mutant (Gallo et al., 2013). The functions of several transcriptional regulatory proteins are in some cases dependent on physical and functional interactions with the 4ICD, including the estrogen receptor (ER) $\propto$ (Zhu et al., 2006; Blobel et al., 2009; Veikkolainen et al., 2011; Wang, 2017). Indeed, the 4ICD interacts with an ER $\alpha$ coactivator and increases the sensitivity of breast cancer cells to tamoxifen (Naresh et al., 2008; Wang et al., 2019). Additional transcriptional regulatory proteins whose functions are in some cases dependent on the 4ICD include the Yes-associated protein 1 (YAP1) (Komuro et al., 2003; Omerovic et al., 2004; Aqeilan et al., 2005; Citri and Yarden, 2006; Naresh et al., 2006; Blobel et al., 2009; Veikkolainen et al., 2011; Wang, 2017), STAT5a (Williams et al., 2004; Citri and Yarden, 2006; Blobel et al., 2009; Wang, 2017), eight twenty one 2 (ETO2) 

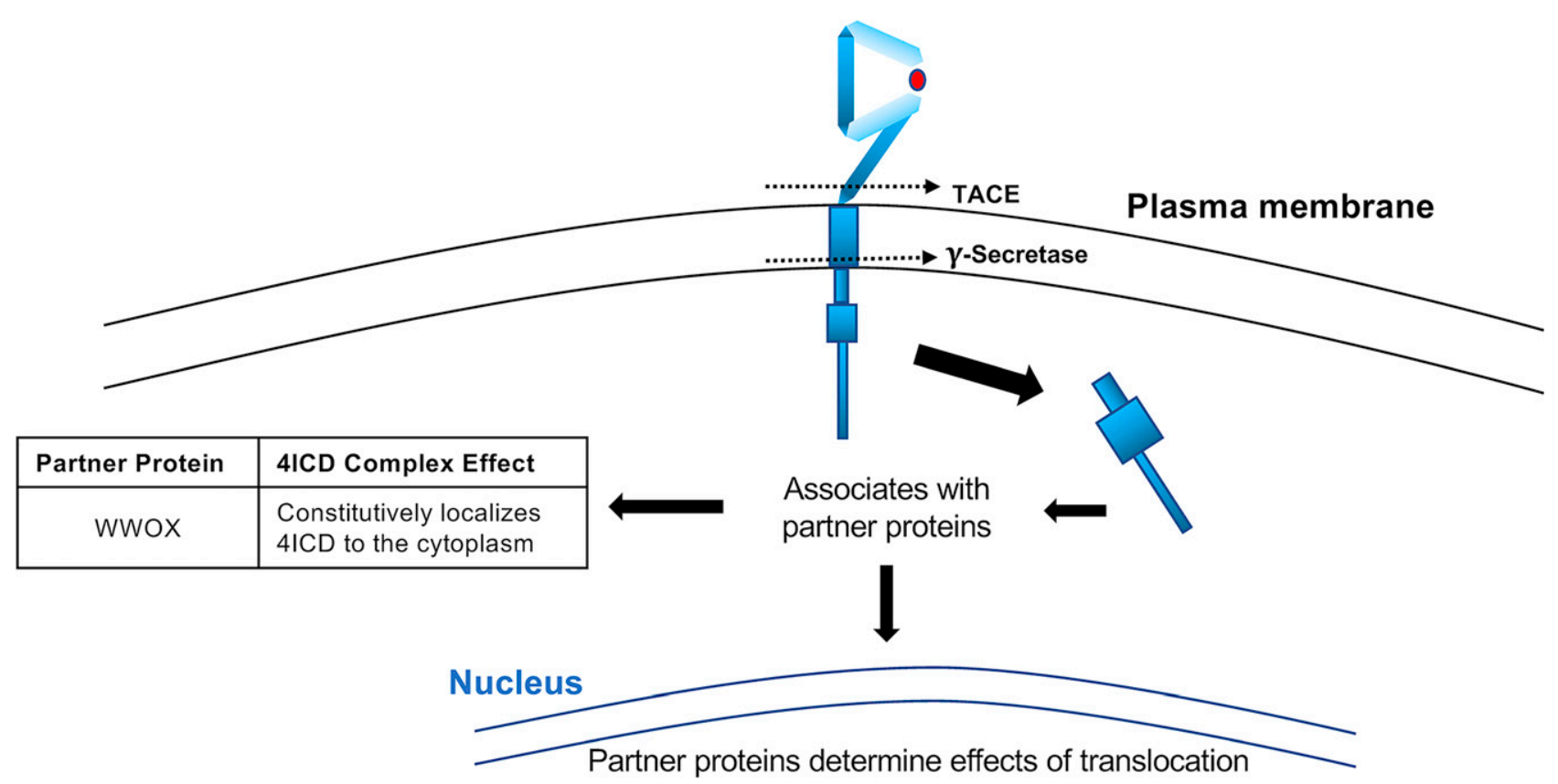

\begin{tabular}{|c|l|}
\hline Partner Protein & 4ICD Complex Effect \\
\hline ER $\alpha$ & $\begin{array}{l}\text { Increase gene expression associated with estrogen response } \\
\text { elements (EREs) }\end{array}$ \\
\hline STAT5a & Increase $\beta$-casenin gene transcription \\
\hline ETO2 & Inhibit cell differentiation \\
\hline $\begin{array}{c}\text { TAB2:NCoR } \\
\text { Complex }\end{array}$ & Repress gene promoters causing astrogenesis \\
\hline AP-2 & Increase PDGFRA gene transcription \\
\hline YAP1 & Activates 4ICD transcriptional activity \\
\hline Kap1 & Repress ERBB4 gene transcription \\
\hline MDM2 & $\begin{array}{l}\text { Indirect promotion of apoptosis by phosphorylation and subsequent } \\
\text { ubiquitination of MDM2 }\end{array}$ \\
\hline
\end{tabular}

Fig. 5. Interactions of the 4ICD with partner proteins. The intracellular region of ERBB4 (4ICD) is depicted, along with the various partner proteins that are known to interact with the 4ICD in the nucleus and the cytoplasm. The biologic effect of each 4ICD complex is listed. The figure is not drawn to scale.

(Linggi and Carpenter, 2006; Blobel et al., 2009; Veikkolainen et al., 2011; Wang, 2017), the transforming growth factor beta activated kinase 1 binding protein 2-nuclear receptor corepressor (TAB2NCoR) complex (Sardi et al., 2006; Schlessinger and Lemmon, 2006; Blobel et al., 2009; Veikkolainen et al., 2011; Wang, 2017), Krab-associated protein 1 (Gilmore-Hebert et al., 2010; Veikkolainen et al., 2011; Wang, 2017), and the activated enhancer-binding protein 2 (AP-2) (Sundvall et al., 2010; Veikkolainen et al., 2011; Wang, 2017) (Fig. 5).

WWOX binds to the proline-proline-alanine-tyrosine (PPAY) amino acid sequence found near the cytoplasmic carboxyl terminus of ERBB4 (Fig. 4), and increased ERBB4 tumor suppressor activity is associated with increased WWOX function (Aqeilan et al., 2007). Thus, it is not surprising that WWOX is also a tumor suppressor. WWOX appears to function in part by binding nuclear oncoproteins, including several transcription factors, and sequestering them in the cytoplasm (Aqeilan et al., 2005; Citri and Yarden, 2006; Blobel et al., 2009; Li et al., 2015; Pospiech et al., 2018); however, the tumor suppressor activity of WWOX may also be dependent on its 17b-hydroxysteroid dehydrogenase activity (Gluz et al., 2009; Krishnamurthy et al., 2012; Li et al., 2015; Pospiech et al., 2018). It has been reported that WWOX constitutively localizes the 4ICD to the cytoplasm (Aqeilan et al., 2007; Segers et al., 2020). However, this localization does not appear to solely account for the tumor suppressor activity of WWOX or ERBB4, as tumor suppression by ERBB4 seems to be dependent on 4ICD localization to the nucleus. Further complicating our understanding of the role that WWOX may 
play in mediating ERBB4 function, WWOX causes increased activity of the ataxia telangiectasia mutated (ATM) checkpoint kinase, leading to increased activity of the itchy E3 ubiquitin ligase (ITCH) and ubiquitination of Lys63 of WWOX. This results in increased nuclear translocation of WWOX and potentiation of further ATM activity in a positive feed-forward loop mechanism (Omerovic et al., 2007; Blobel et al., 2009; Schuchardt et al., 2013; Abu-Odeh et al., 2014; Aqeilan et al., 2014; Pospiech et al., 2018).

Our understanding of the functional consequences of ATM regulation by the AICD via WWOX and ITCH is impacted by the fact that the 4ICD causes G2/M cell cycle arrest and that this arrest is abrogated by 4ICD ubiquitination and degradation via interaction of the anaphase-promoting complex (APC) with a Dbox sequence of the 4ICD (Fig. 4) (Strunk et al., 2007; Segers et al., 2020). This abrogation of G2/M arrest by APC-4ICD interactions may be related to the observation that ERBB4 induces $\mathrm{G} 2 / \mathrm{M}$ arrest via a functional interaction with the breast cancer DNA repair associated 1 (BRCA1) protein (Muraoka-Cook et al., 2006; Segers et al., 2020). Moreover, our understanding of the role that WWOX plays in regulating ERBB4 function is also impacted by the fact that WWOX binding to ERBB4 inhibits YAP1 transcriptional activity (Aqeilan et al., 2005; Omerovic et al., 2007; Pospiech et al., 2018) as well as the fact that the 4ICD can also regulate the mouse double minute 2 (MDM2) E3 ubiquitin ligase (Arasada and Carpenter, 2005; Blobel et al., 2009), histone methylation, and human telomerase reverse transcriptase (Ishibashi et al., 2013; Segers et al., 2020). Finally, there are reports that the E3 ubiquitin ligases ITCH and WWP1 directly bind to and are specific for the ERBB4 Cyt1 isoforms and cause degradation of those isoforms. Furthermore, ITCH binds to the prolineproline-alanine-tyrosine-threonine-proline-methionine (PPAYTPM) amino acid sequence specific to Cyt1 (Fig. 4), suggesting that WWOX and ITCH compete for binding to ERBB4 (Omerovic et al., 2007; Sundvall et al., 2008; Li et al., 2009; Carraway, 2010).

The 4ICD may also trigger apoptosis by trafficking to the mitochondria and triggering the release of cytochrome C (Fig. 6) from the mitochondria, thereby stimulating programmed cell death. In some cases, ERBB4 expression and signaling are accompanied by mitochondrial accumulation of the 4ICD and binding of the proapoptotic Bcl-2 homologous antagonist/killer (BAK) protein to the 4ICD via the Bcl2 homology 3 (BH3)-like domain of the 4ICD (Fig. 4). This results in increased cytochrome $\mathrm{C}$ efflux (Naresh et al., 2006; Blobel et al., 2009; Miller et al., 2017; Arienti et al., 2019; Segers et al., 2020). This proposed mechanism is supported by the observation that when the ERBB4 V673I mutation abolishes ERBB4 cleavage by gamma- secretase, there is no accumulation of the 4ICD within the mitochondria, and the apoptotic activity associated with the 4ICD is abolished (Vidal et al., 2005).

When the proapoptotic Bcl-2-associated X (BAX) or BAK proteins oligomerize and permeabilize the mitochondrial outer membrane, cytochrome $\mathrm{C}$ is exported from the inner mitochondrial membrane via the phospholipid cardiolipin, which is followed by efflux from the outer mitochondrial membrane (OMM) and into the cytosol via BAK oligomers. Cytochrome $\mathrm{C}$ complexes with the apoptosis protease-activating factor 1 , causing its allosteric activation and oligomerization into an apoptosome. The activated cytochrome $\mathrm{C}$ cleaves nonmature caspase-3/9, which then triggers programmed cell death (Bossy-Wetzel et al., 1998; Zou et al., 1999; Garrido et al., 2006; Schug and Gottlieb, 2009). BH3-only proteins appear to stimulate mitochondrial-regulated apoptosis via indirect and direct mechanisms (Giam et al., 2008). In the indirect (or displacement) mechanism, BH3-only proteins bind Bcl-2 and related antiapoptotic proteins and inhibit their activity by sequestering them away from BAX or BAK, thereby allowing BAX or BAK oligomerization (Willis et al., 2007). The direct mechanism proposes that the BH3-only proteins directly interact with BAX or BAK, thereby stimulating their oligomerization and subsequent apoptotic signaling cascade (Kuwana et al., 2002; Letai et al., 2002).

The ERBB4 cytoplasmic region (4ICD) possesses a BH3-like domain (Fig. 4). This domain might allow the 4ICD to reside in the OMM, after which the BH3like domain could either directly or indirectly stimulate apoptosis (Naresh et al., 2006; Wilfling et al., 2012). This apoptosis is dependent on BAK but not BAX (Naresh et al., 2006). One explanation is that BAK is found at higher levels in the OMM than is BAX. This may reflect the fact that BAX exists predominately in the cytosol but is translocated to the mitochondria after apoptotic stimulation (Naresh et al., 2006; Wilfling et al., 2012; Edlich, 2015). Therefore, the 4ICD could directly stimulate BAK oligomerization within the OMM. The 4ICD could also indirectly stimulate BAK oligomerization by displacing the antiapoptotic BclXL, Bcl-w, myeloid leukemia cell differentiation (Mcl-1), or A1 proteins from BAK (Fig. 6).

The 4ICD may stimulate apoptosis via other mechanisms. For example, human MDM2 ubiquitinates TP53, thereby decreasing TP53 tumor suppressor activity and promoting cell survival. However, when 4ICD complexes with human MDM2, the complex is ubiquitinated and degraded, allowing for TP53 promotion of apoptotic pathways (Arasada and Carpenter, 2005; Veikkolainen et al., 2011). The array of direct and indirect tumor suppressor signaling pathways connected to 4ICD make elucidating the importance of the 

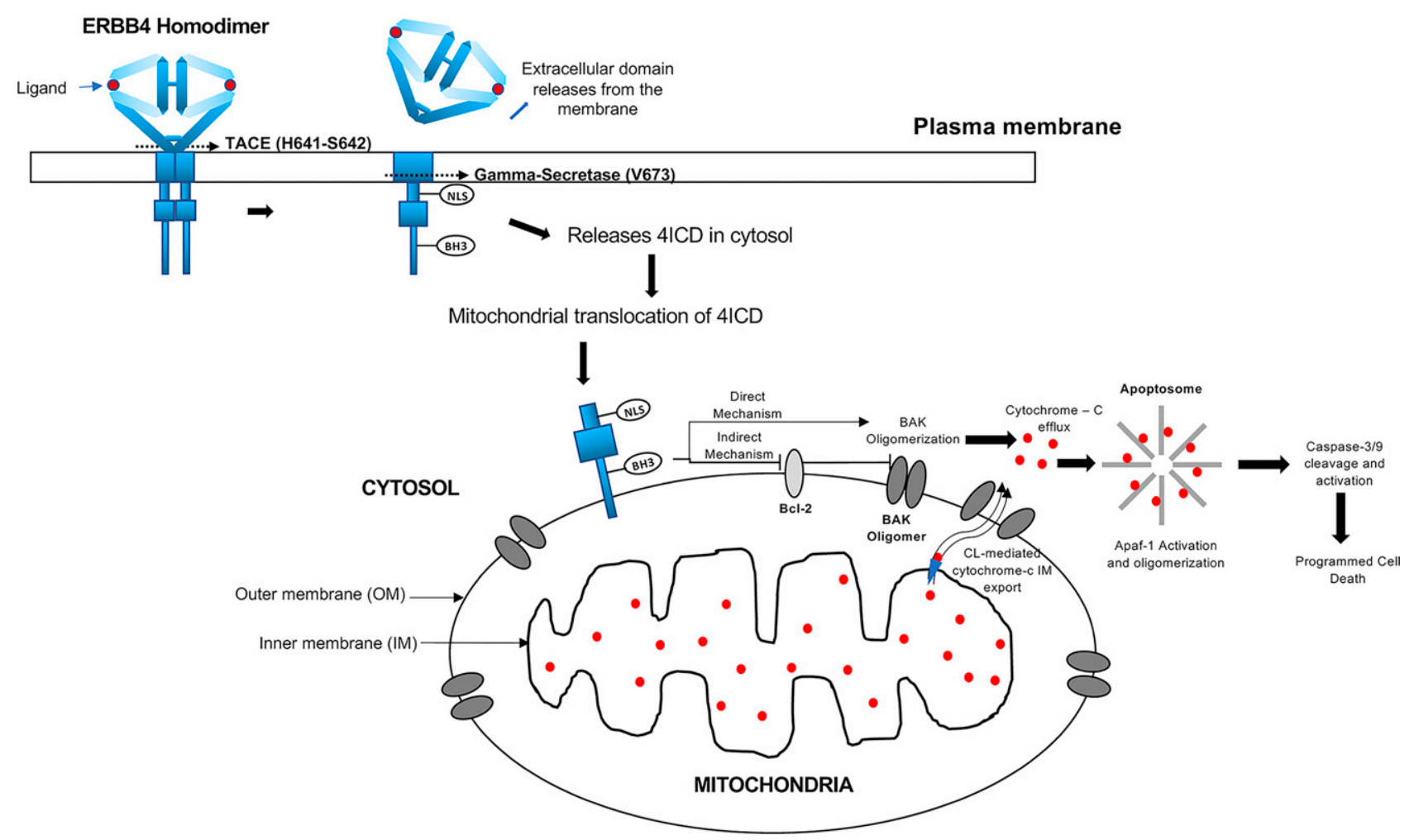

Fig. 6. The 4ICD regulates events in the mitochondria. The 4ICD translocates from the membrane to the outer mitochondrial membrane. Indirect and direct interactions of the 4ICD with BAK results in cytochrome $\mathrm{C}$ efflux and apoptotic cell death. The figure is not drawn to scale.

4ICD difficult but critical to validating ERBB4 as a target for cancer therapeutics.

\section{Transcriptional Splicing Isoforms of ERBB4 Confer Signaling Specificity}

ERBB4 signaling specificity can be conferred by alternative splicing of the ERBB4 transcript. There are two sites of alternative splicing, resulting in four different isoforms (Fig. 4) (Elenius et al., 1997a; Carpenter, 2003a; Junttila et al., 2005; Sardi et al., 2006; Schlessinger and Lemmon, 2006; Chuu et al., 2008; Mei and Xiong, 2008; Paatero and Elenius, 2008; Veikkolainen et al., 2011; Segers et al., 2020). The first alternative splicing site affects the sequence of the extracellular juxtamembrane region, resulting in $\mathrm{JMa}$ and $\mathrm{JMb}$ isoforms (Gilbertson et al., 2001). The second alternative splicing site affects the cytoplasmic region carboxyl terminal (CT) to the kinase domain, resulting in the Cyt1 (CT-a) and Cyt2 (CT-b) isoforms (Kainulainen et al., 2000). Thus, ERBB4 can be transcribed into four isoforms: JMa-Cyt1, JMa-Cyt2, JMb$\mathrm{Cyt1}$, and $\mathrm{JMb}-\mathrm{Cyt} 2$. The JMa-Cyt1 isoform is predominantly expressed and is considered the canonical ERBB4 transcript.

The ERBB4 transcriptional splicing isoforms possess distinct signaling activities. For example, the $\mathrm{JMb}$ isoforms lack the TNF converting enzyme cleavage site present in $\mathrm{JMa}$ isoforms. Hence, JMb isoforms cannot yield the 4ICD fragment whose intracellular trafficking is responsible for significant ERBB4 signaling activity (Rio et al., 2000; Sardi et al., 2006; Mei and Xiong, 2008; Paatero and Elenius, 2008; Segers et al., 2020) (see Section II.H for further details).

In contrast to the Cyt1 isoforms, the Cyt2 isoforms lack a short sequence of amino-acid residues from 1046 to 1061. This sequence includes a phosphorylation site (Tyr1056) that is part of a consensus sequence for binding the p85 regulatory subunit of PI3K (see Section II.F and Fig. 4 for further details). This sequence also contains a binding motif (PPAY) for proteins that contain a WW domain (see Section II.H and Fig. 4 for further details). Hence, as noted earlier, Cyt2 isoforms may be defective for coupling to PI3K signaling and WW proteins, including the WWOX tumor suppressor protein. These differences may be quantitative rather than absolute; WWOX binds to the Cyt2 isoform, albeit to a lesser extent than WWOX binding to the Cyt1 isoform (Kainulainen et al., 2000; Aqeilan et al., 2005; Mei and Xiong, 2008; Paatero and Elenius, 2008; Rudloff and Samuels, 2010; Schuchardt et al., 2013; Segers et al., 2020).

These and other differences in the signaling activities of the various ERBB4 isoforms also contribute to differences in biologic activities. For example, the JMa-Cyt2 isoform inhibits differentiation and promotes proliferation to a much greater extent than the $\mathrm{JMb}-$ Cyt2 isoform (Maatta et al., 2006; Sundvall et al., 2010; Veikkolainen et al., 2011). Furthermore, the region of 
ERBB4 that is specific to the Cyt1 isoforms (Fig. 4) and includes Tyr1056 is responsible for growth inhibition and differentiation of mammary ductal epithelial cells; this region is also required for the constitutively dimerized and active Q646C mutant of ERBB4 to function as a tumor suppressor (Muraoka-Cook et al., 2009; Wali et al., 2014; Segers et al., 2020). The Cyt1 isoform has recently been associated with an ERK-mediated negative-feedback mechanism that causes downregulation of ERBB4 activity (Haryuni et al., 2019).

However, the region of ERBB4 that is specific to Cyt1 isoforms and includes Tyr1056 is also required for the oncogenic activities of ERBB4, presumably through the action of ERBB4-EGFR or ERBB4-ERBB2 heterodimers (Junttila et al., 2005; Wali et al., 2014; Segers et al., 2020). Indeed, the 4ICD is associated with both tumor suppression and malignant phenotypes (see Section II.H for further details) (Junttila et al., 2005; Fujiwara et al., 2014); these functions suggest that ERBB4 homodimerization and heterodimerization cause differential phosphorylation of the ERBB4 cytoplasmic domain and differential association with effector proteins, resulting in distinct biologic responses.

\section{J. Summary and Implications for ERBB4 Function in Human Malignancies}

It appears that ERBB4 homodimers function as tumor suppressors, whereas ERBB4-EGFR and ERBB4-ERBB2 heterodimers function as oncoproteins. However, these do not appear to be absolute relationships, as the function of ERBB4 homodimers and heterodimers can be influenced by the involvement of ERBB4 splicing isoforms and of ERBB4 ligands, each of which can confer signaling and biologic specificity. Nonetheless, in contexts in which ERBB4 heterodimers predominate over ERBB4 homodimers, one would expect that increases in ERBB4 or ligand expression and ERBB4 gain-of-function mutants would be associated with malignancies or more aggressive tumor phenotypes. Conversely, in contexts in which ERBB4 homodimers predominate over ERBB4 heterodimers, one would expect that decreases in ERBB4 or ligand expression and ERBB4 loss-of-function mutants would be associated with malignancies or more aggressive tumor phenotypes. Below we will describe how ERBB4 expression, ligand expression, and ERBB4 mutations align with this mechanistic model for ERBB4 function in different types of tumors.

\section{Tumors in Which ERBB4 Appears to Function as a Tumor Suppressor}

\section{A. Introduction}

In the following subsections, we will discuss the different types of tumors in which ERBB4 appears to function as a tumor suppressor. In these types of tumors, ERBB4 expression is typically low. Likewise, only a small fraction of cell lines established from these types of tumors exhibits detectable ERBB4 transcription. In many instances, a decrease in ERBB4 copy number underlies the low level of ERBB4 expression (Segers et al., 2020). Loss-of-function mutations in ERBB4 are a potential mechanism for disrupting ERBB4 tumor suppressor activity. However, loss-of-function mutations in ERBB4 have yet to be validated as bona fide tumor drivers.

\section{B. Bladder}

In general, ERBB4 expression is lower in transitional cell carcinomas than in normal urothelium (Rotterud et al., 2007). Low ERBB4 expression is associated with high-grade tumors and shorter survival (Black and Dinney, 2008; Kassouf et al., 2008; Segers et al., 2020). Likewise, elevated ERBB4 expression in urothelial tumors is associated with lowergrade tumors, less invasive tumors, and a more favorable prognosis (Memon et al., 2004; Memon et al., 2006; Black and Dinney, 2008; Segers et al., 2020). These data suggest that ERBB4 functions as a tumor suppressor in these tumors. Superficially, this hypothesis appears to be at odds with the observation that EREG expression is elevated in bladder cancer samples and that EREG overexpression is associated with increased metastatic potential (Thogersen et al., 2001; Nicholson et al., 2004; Riese and Cullum, 2014). However, given that EREG is a high-affinity ligand for both EGFR and ERBB4, it is possible that the oncogenic activity of EREG is mediated by EGFR rather than by ERBB4.

\section{Liver}

ERBB4 is expressed in 39\%-63\% of cholangiocarcinomas (tumors of the biliary tract), and this expression is associated with a more favorable prognosis in intrahepatic cholangiocarcinomas that lack EGFR expression (Ito et al., 2001b; Yang et al., 2014; Pellat et al., 2018; Segers et al., 2020). The loss of ERBB4 expression may play a role in the progression of benign hepatic lesions to hepatocellular carcinomas (HCCs) (Lee et al., 2007; Segers et al., 2020). This hypothesis is consistent with the observation that ERBB4-null hepatocytes exhibit a higher rate of proliferation than control hepatocytes (Liu et al., 2017; Segers et al., 2020) and is consistent with the observation that ERBB4 expression is frequently lower in HCCs than in the normal hepatocytes. There are contradictory results regarding the effect of ERBB4 expression on HCC outcome (Ito et al., 2001a; Uberall et al., 2008; Liu et al., 2017; Segers et al., 2020). Nonetheless, taken together these data indicate that ERBB4 is functioning as a tumor suppressor in intrahepatic cholangiocarcinomas and HCCs. 


\section{Prostate}

ERBB4 is strongly expressed by normal prostate luminal cells. In contrast, ERBB4 protein expression is detected in only $23 \%$ of prostate cancer specimens, and no human prostate cell lines tested to date exhibit detectable ERBB4 protein expression (Grasso et al., 1997; Uberall et al., 2008). Furthermore, the constitutively active $E R B B 4 \mathrm{Q} 646 \mathrm{C}$ and $\mathrm{I} 658 \mathrm{E}$ mutants function as tumor suppressors in human prostate cell lines (Williams et al., 2003; Vidal et al., 2007). Superficially, these results are at odds with the observation that exogenous ERBB4 expression in androgen-independent human prostate tumor cell lines causes resistance to tyrosine kinase inhibitors (Carrion-Salip et al., 2012). However, as noted elsewhere, heterodimerization of ERBB4 with EGFR or ERBB2 (as a result of chemotherapy-induced EGFR or ERBB2 overexpression) may enable ERBB4 to cause this chemoresistance.

\section{Tumors in Which ERBB4 Appears to Function as an Oncoprotein}

\section{A. Introduction}

There are multiple reports in which an ERBB4 ligand stimulates malignant phenotypes and chemoresistance of tumor cells (Yamano et al., 2010; Mill et al., 2011a; Sato et al., 2013; Dahlhoff et al., 2014; Riese and Cullum, 2014; Mota et al., 2017; Segers et al., 2020). However, many ERBB4 ligands also bind either EGFR or ERBB3. Moreover, ligand binding to ERBB4 can induce ERBB4 homodimerization or ERBB4 heterodimerization with other ERBB receptors. Thus, reports that an ERBB4 ligand stimulates malignant phenotypes and chemoresistance of tumor cell lines should not be viewed as strictly contradictory of the evidence that ERBB4 functions as a tumor suppressor. Indeed, in the following subsections, we will provide evidence that ERBB4-ERBB2 and ERBB4-EGFR heterodimers function as oncoproteins. Oncogenic activity of these heterodimers may result from overexpression of ERBB4, ERBB2, or EGFR or gain-of-function mutations in ERBB4, ERBB2, or EGFR.

\section{B. Brain}

ERBB4 overexpression is associated with a statistically insignificant decrease in overall survival among patients with childhood medulloblastoma. However, the combination of ERBB2 and ERBB4 overexpression is associated with a dramatic reduction in overall survival that is greater than the effects of ERBB2 alone (Gilbertson et al., 1997; Gilbertson et al., 1998; Gilbertson et al., 2001; Carpenter, 2003a; Rickert, 2004; Rickert and Paulus, 2005; Britsch, 2007). NRG1 $\beta$ and ERBB4 are expressed in the developing cerebellum, but ERBB2 is not. Taken together, these data suggest that ERBB2 overexpression acquired during tumorigenesis or tumor progression enables the pre-existing ERBB4 and NRG1 $\beta$ expression to drive signaling by oncogenic ERBB4-ERBB2 heterodimers and the development of medulloblastomas in the cerebellum (Gilbertson et al., 1998; Britsch, 2007).

Molecular profiling has enabled the assignment of medulloblastomas into four main subtypes: Wingless, Sonic Hedgehog, group 3, and group 4 (Northcott et al., 2012; Rahmann and Gilbertson, 2018). An integrative proteogenomic approach reveals that group 4 tumors commonly exhibit elevated expression of ERBB4 and its ligand NRG2 as well as hallmarks of elevated receptor tyrosine kinase signaling, including ERK and PI3K signaling. Surprisingly, this report did not indicate that ERBB2 expression was elevated in the group 4 tumors, raising questions about the mechanism by which ERBB4 may be coupled to tumorigenesis or tumor progression in group 4 medulloblastomas (Forget et al., 2018; Rahmann and Gilbertson, 2018).

ERBB2 and ERBB4 are coexpressed in most childhood ependymomas, and high levels of coexpression are associated with elevated tumor proliferation. Likewise, limited data suggest that elevated ERBB2 and ERBB4 coexpression is associated with less favorable clinical outcomes (Gilbertson et al., 2002; Carpenter, 2003a).

Limited evidence exists regarding the role of ERBB4 in glioblastomas. Elevated ERBB4 phosphorylation is associated with shorter survival in patients with glioblastoma (Donoghue et al., 2018; Segers et al., 2020). In contrast, $E R B B 4$ copy number is frequently reduced across glioblastoma cell lines (Jones et al., 2018; Segers et al., 2020). One possible explanation for these apparently contradictory results is that ERBB4 heterodimers may function as oncoproteins in glioblastoma, whereas ERBB4 homodimers may function as tumor suppressors in glioblastoma. There are reports that ERBB4 does not play a major role in gliomas (Berezowska and Schlegel, 2011). Moreover, ERBB4 expression is higher in low-grade (less aggressive) gliomas than in high-grade (more aggressive) gliomas. Thus, there is little evidence that ERBB4 functions as an oncoprotein in gliomas. In contrast, ERBB4 overexpression has been observed in meningiomas. This result suggests that ERBB4 is an oncoprotein in meningiomas (Andersson et al., 2004; Uberall et al., 2008).

\section{Colon}

EGFR is a well established colorectal cancer (CRC) biomarker and target for therapeutic intervention. In contrast, there is considerably less information about the role that ERBB4 plays in colorectal cancer (Khelwatty et al., 2013; Mitsui et al., 2014; Williams et al., 2015; Segers et al., 2020). Nonetheless, ERBB4 overexpression or elevated phosphorylation is observed in all stages of CRC and has been reported to be 
associated with more aggressive colorectal tumors, particularly metastatic behavior (Kountourakis et al., 2006; Baiocchi et al., 2009; Frey et al., 2010; Khelwatty et al., 2013; Mitsui et al., 2014; Williams et al., 2015; Mota et al., 2017; Segers et al., 2020). ERBB4 copy number does not appear to be altered in a significant fraction of CRC samples; therefore, overexpression of ERBB4 seems to reflect changes in transcription or protein stability (Segers et al., 2020).

Nonsynonymous ERBB4 mutations are found in $7.5 \%-11 \%$ of CRCs, and $\sim 1.5 \%$ of CRCs are predicted to harbor an ERBB4 tumor driver mutation (Mishra et al., 2017; Segers et al., 2020). Nonetheless, only a few ERBB4 mutations in CRC samples have been described (V721I, P854Q, D861Y, I1030M; Tables 1 and 2). Of these, the D861Y mutant exhibits reduced agonist-dependent and -independent tyrosine phosphorylation in a heterologous model system (Soung et al., 2006). On the surface, this finding is inconsistent with the hypothesis that ERBB4 functions as a tumor suppressor. However, given that these experiments were performed in the context of the noncanonical JMa-Cyt2 isoform, the relevance of this finding is unclear (Tvorogov et al., 2009).

ERBB4 signaling protects colon epithelial cells from TNF-induced apoptosis, and reduced ERBB4 expression is associated with decreased cell proliferation and increased apoptosis (Frey et al., 2009; Segers et al., 2020). Similarly, knockdown of ERBB4 expression in a CRC cell line inhibits anchorage-independent proliferation (Williams et al., 2015; Segers et al., 2020). Likewise, ectopic ERBB4 expression is associated with the development of resistance to EGFR inhibitors, such as cetuximab (Bae et al., 2014; Sun et al., 2017).

ERBB4 heterodimers may be responsible for the oncogenic activity of ERBB4, as EGFR is frequently expressed in colorectal tumors. Furthermore, ERBB4 is found in the membrane of CRC cells, which is suggestive of heterotypic signaling (Mitsui et al., 2014). In contrast, ERBB4 localization in the cytoplasm or nucleus is suggestive of homotypic signaling. Consistent with this model for ERBB4 function, coexpression of ERBB4 and ERBB2 (Lee et al., 2002b; Khelwatty et al., 2013) and coexpression of ERBB4 and ERBB3 are each associated with late-stage colorectal tumors (Ljuslinder et al., 2009; Khelwatty et al., 2013). A potential mechanism for the coexpression of ERBB3 and ERBB4 is revealed by Apc ${ }^{\text {Min }}$ transgenic mice in which ERBB3 is ablated in the intestine. Such animals exhibit a loss of ERBB4 expression and a dramatic reduction of intestinal tumors. Moreover, in a human colon cancer cell line containing a gain-of-function mutant Kirsten RAS $(K R A S)$ allele, reduced ERBB3 expression is associated with decreased ERBB4 expression and small interfering RNA against either ERBB3 or ERBB4 results in increased apoptosis. Thus, either ERBB4EGFR or ERBB4-ERBB4 heterodimers have been postulated to be responsible for the oncogenic activity of ERBB4 in colorectal tumors (Lee et al., 2009). The functional difference between ERBB4 homodimers and ERBB4 heterodimers may account for the observation that ERBB4 attenuates inflammation in colitis and may therefore function as a tumor suppressor in colitis-associated CRC (Schumacher et al., 2017; Segers et al., 2020). On the other hand, given that the promotion of colon adenoma to carcinoma by an intestine-specific KA11 C-terminal interacting tetraspanin (KITENIN) transgene (and $A p c^{M i n}$ ) is accompanied by elevated expression of the noncanonical $E R B B 4$ CT-b isoforms, it is possible that differences in ERBB4 function observed in the colonic epithelium are isoform-specific (Bae et al., 2016).

\section{Stomach}

$E R B B 4$ is frequently amplified in gastric cancer and is associated with advanced stage ( $\mathrm{He}$ et al., 2015; Arienti et al., 2019) and poorer prognosis (Shi et al., 2012; Qu et al., 2013; Segers et al., 2020). The microRNA (miR) miR-551b inhibits ERBB4 gene expression. Thus, low levels of miR-551b expression are associated with a poorer prognosis in gastric cancer patients (Song et al., 2017). Likewise, the irreversible pan-ERBB tyrosine kinase inhibitor dacomitinib yields some disease control in patients whose gastric tumors overexpress ERBB2, which is consistent with the hypothesis that ERBB4-ERBB2 heterodimers function as oncoproteins (Desai et al., 2013; Mishra et al., 2017).

There is limited evidence that $E R B B 4$ mutations may contribute to stomach cancer. The ERBB4 N548T mutation (Zang et al., 2012; Qu et al., 2013) and A773S mutation (Soung et al., 2006; Mishra et al., 2017) have each been found in a single gastric cancer sample. In a cohort of 294 stomach adenocarcinoma samples derived from northern Chinese patients, 20 samples contained one or more ERBB4 mutations (Table 2). One of these ERBB4 mutations alters an amino-acid codon (Arg106) that is also mutated in melanoma cases in The Cancer Genome Atlas Skin Cutaneous Melanoma (TCGA-SKCM) dataset and in stomach adenocarcinoma cases in the TCGA Stomach Adenocarcinoma (STAD) dataset (Chen et al., 2015). Altogether, the northern Chinese stomach adenocarcinoma datasets and the TCGA-STAD dataset contained 54 distinct ERBB4 missense mutations (Table 2 ). The same cohort of 294 northern Chinese gastric adenocarcinomas contains numerous samples that contain NRG1 mutations. Moreover, an NRG1 mutation is less common in samples that contain an ERBB4 mutation and vice versa (Chen et al., 2015). Taken together, these data suggest that increased ERBB4 signaling as 
a result of gain-of-function tumor driver mutations in the $N R G 1$ or $E R B B 4$ genes may contribute to gastric cancer genesis and/or progression.

\section{E. Head and Neck}

ERBB4 is overexpressed in a significant fraction of head and neck squamous cell carcinomas (HNSCCs). This overexpression is observed in both in situ and invasive tumors (Kalyankrishna and Grandis, 2006; Uberall et al., 2008). The overexpression of EGFR and its ligands has been well documented in head and neck cancers, but overexpression of EGFR ligands is more effective in predicting disease prognosis. For example, AREG, EGF, HBEGF, and BTC overexpression are each independently associated with reduced 5-year survival, although AREG overexpression is correlated with HBEGF overexpression (Kalyankrishna and Grandis, 2006; Uberall et al., 2008; Ahsan et al., 2010; Gao et al., 2016).

HNSCCs devoid of human papillomaviruses (HPVs) exhibit greater AREG expression than HPV-positive tumors (Gao et al., 2016). Similarly, HPV-negative tumors exhibit greater EREG expression than do HPVpositive tumors. HPV infection is associated with methylation of the EREG promoter and reduced EREG transcription; reversing this methylation causes increased EREG transcription (Khanal et al., 2020). Taken together, these data suggest that HPVs and EGF family members independently drive the genesis and progression of HNSCCs. Recall that BTC, EREG, and HBEGF are ligands for both EGFR and ERBB4. Moreover, ligand stimulation can cause EGFR heterodimerization with ERBB4. Therefore, it is plausible to postulate that ERBB4 potentiates EGFR function during the genesis and progression of HNSCCs.

\section{F. Lung}

ERBB4 expression is detected in several human lung cancer cell lines, and silencing ERBB4 decreases the viability of these cell lines. Ibrutinib, a broad-specificity tyrosine kinase inhibitor that has high affinity for the Bruton's tyrosine kinase also inhibits ERBB4, albeit with much less potency. Ibrutinib inhibits ERBB4 tyrosine phosphorylation in several human lung cancer cell lines and modestly inhibits proliferation by the H661 human lung cancer cell line in mouse xenografts. It is reasonable to postulate that the modest effect of ibrutinib on $\mathrm{H} 661$ cells in vivo may reflect the relatively low affinity of ibrutinib for ERBB4 (Rauf et al., 2018).

The Y285C, D595V, D931Y, and K935I ERBB4 mutants found in non-small cell lung carcinoma samples (Table 1) exhibit increased ligand-dependent and -independent tyrosine phosphorylation and increased heterodimerization with ERBB2. Furthermore, the Y285C, D595V, and K935I mutants caused increased survival of NIH 3T3 cells in the absence of serum. The ERBB4 G802dup mutation has been found in large-cell lung carcinomas (Table 1). The relevance of the G802dup mutation to lung cancer is unclear, particularly since it causes decreased ligand-dependent ERBB4 tyrosine phosphorylation. Additional ERBB4 missense mutations (N181S, T244R, R306S, V348L, H618P, R782Q, E810K, T926M; Table 2) have been identified in various forms of lung cancer, but it remains unclear whether these mutations are functionally significant (Soung et al., 2006; Ding et al., 2008; Tvorogov et al., 2009; Kurppa et al., 2016; Mishra et al., 2017; Segers et al., 2020).

Finally, overexpression of the EGFR and ERBB4 ligand EREG is frequently observed in lung adenocarcinomas and is associated with shorter disease-free survival and overall survival. For example, patients with lung adenocarcinoma with elevated EREG expression and an activating mutation in KRAS exhibit a poorer prognosis than patients who possessed only one of these factors (Sunaga et al., 2013; Sunaga and Kaira, 2015). If indeed EREG and an activated KRAS allele cooperate to drive more aggressive forms of lung adenocarcinoma, it is reasonable to postulate that EREG stimulation of EGFR coupling to RAS signaling is not sufficient for these adenocarcinomas and that EREG stimulation of ERBB4 signaling (via an ERBB4-EGFR heterodimer) is required for these aggressive tumors.

\section{G. Bone}

ERBB4 is constitutively phosphorylated in early passage human osteosarcoma cell lines. The 4ICD is observed in the nuclei of osteosarcoma clinical samples and cell lines, which is surprising given that the 4ICD is indicative of homotypic ERBB4 signaling and tumor suppressor activity. Furthermore, ERBB4 knockdown inhibits the proliferation and anchorage independence of osteosarcoma cell lines and increases the sensitivity of osteosarcoma cell lines to cytotoxic chemotherapeutic agents (Hughes et al., 2004, 2006; Wang et al., 2018, 2019).

\section{H. Ovary}

ERBB4 transcription and ERBB4 protein expression are higher in ovarian cancer samples than in borderline ovarian tumors or benign ovarian tumors. ERBB2 transcription and ERBB2 protein expression are likewise elevated but not EGFR transcription or EGFR protein expression (Steffensen et al., 2008; Wang, 2017). Taken together, these data suggest that ERBB4-ERBB2 heterodimers contribute to ovarian malignancies rather than ERBB4 homodimers or ERBB4-EGFR heterodimers. Overexpression of the ERBB4 JMa-Cyt1 isoform is associated with increased grade and poorer overall survival in patients with ovarian cancer (Paatero et al., 2013; Wang et al., 2019). This increase in endogenous ERBB4 
Table 1.

$E R B B 4$ missense mutations that are found in human tumor samples and whose function has been at least partially characterized.

\begin{tabular}{|c|c|c|c|c|}
\hline Mutation & ERBB4 Functional Region & Tumor Type & Effect & Reference(s) \\
\hline Y285C & ECD II & Lung & Gain of function & (Kurppa et al., 2016) \\
\hline E317K & ECD II & Melanoma & Gain of function & (Prickett et al., 2009) \\
\hline $\mathrm{E} 452 \mathrm{~K}$ & ECD III & Melanoma & Gain of function & (Prickett et al., 2009) \\
\hline E542K & ECD IV & Melanoma & Gain of function & (Prickett et al., 2009) \\
\hline R544W & ECD IV & Melanoma & Gain of function & (Prickett et al., 2009) \\
\hline E563K & ECD IV & Melanoma & Gain of function & (Prickett et al., 2009) \\
\hline D595V & ECD IV & Lung & Gain of function & (Kurppa et al., 2016) \\
\hline G802dup & Tyrosine kinase & Lung & Loss of function & (Soung et al., 2006; Tvorogov et al., 2009) \\
\hline E836K & Tyrosine kinase & Melanoma & Gain of function & (Prickett et al., 2009) \\
\hline D861Y & Tyrosine kinase & Colorectal & Loss of function & (Soung et al., 2006; Tvorogov et al., 2009) \\
\hline $\mathrm{E} 872 \mathrm{~K}$ & Tyrosine kinase & Melanoma & Gain of function & (Prickett et al., 2009) \\
\hline $\mathrm{E} 872 \mathrm{~K}$ & Tyrosine kinase & Breast & Unknown & (Soung et al., 2006; Tvorogov et al., 2009) \\
\hline D931Y & Tyrosine kinase & Lung & Gain of function & (Kurppa et al., 2016) \\
\hline K935I & Tyrosine kinase & Lung & Gain of function & (Kurppa et al., 2016) \\
\hline
\end{tabular}

expression appears to result from an increase in $E R B B 4$ copy number in ovarian tumor samples (Segers et al., 2020). The increase in ERBB4 copy number and consequent increase in ERBB4 JMa-Cyt1 transcription appear to be functionally significant; ectopic overexpression of the ERBB4 JMa-Cyt1 isoform increases the anchorageindependent growth of ovarian cancer cell lines, but the JMa-Cyt2 isoform does not (Paatero et al., 2013; Wang et al., 2019).

\section{Thyroid}

ERBB4, HBEGF, and NRG1 expression are increased in some thyroid cancers relative to non-neoplastic thyroid tissue. Immunohistochemical detection of the ERBB4 protein reveals increased expression of ERBB4 in both the cytoplasm and membrane in papillary thyroid carcinomas, suggesting that the ERBB4 protein is functional and mediates HBEGF and NRG action. Interestingly, there is some evidence that ERBB4 overexpression is inversely correlated with the V600E hotspot mutation in the v-Raf murine sarcoma viral oncogene homolog $\mathrm{B}(B R A F)$ gene, suggesting that ERBB4 and BRAF may independently drive tumor progression (Haugen et al., 1996; Fluge et al., 2000; Kato et al., 2004; Wiseman et al., 2008; Ota et al., 2013; Schulten et al., 2015; Zhang et al., 2018).

HBEGF and ERBB4 are overexpressed in malignant thyroid tissues relative to both benign thyroid tumors and normal thyroid tissue. In contrast, EGFR is overexpressed in both malignant and benign thyroid tumors. In vitro, HBEGF stimulates the motility of thyroid cancer cell lines. Treatment with the ERBB4 and EGFR tyrosine kinase inhibitor $N$-(3-chlorophenyl)-6,7-dimethoxy-4quinazolinamine attenuates this activity. Taken together, these data suggest that ERBB4 may heterodimerize with EGFR to mediate HBEGF-induced metastatic activity in thyroid cancers (Ota et al., 2013). Elevated ERBB4 expression in some papillary thyroid carcinoma cells appears to be the consequence of miR-326 downregulation. Indeed, ectopic expression of miR-326 in papillary thyroid carcinoma cell lines suppresses tumorigenesis in vivo. However, care must be taken not to overinterpret this result, as miR-326 also inhibits MAPK expression (Nie et al., 2020).

Finally, in a cohort of poorly differentiated thyroid carcinomas, nine different ERBB4 missense mutations were found (R106S, D113V, D165N, I166N, C213Y, G219D, E233G, C589Y, and C614Y; Table 2) (Gerber et al., 2018). The functional significance of these $E R B B 4$ mutants is not known; nonetheless, their existence is consistent with the hypothesis that $E R B B 4$ functions as an oncogene in thyroid cancers.

\section{J. Hematopoietic}

ERBB4 is not commonly believed to be expressed in normal cells of the hematopoietic lineage. ERBB4 knockout mice experience midembryonic lethality due to failed development of myocardial trabeculae (Gassmann et al., 1995). ERBB4 knockout mice in which ERBB4 expression in the heart is restored are viable at birth and exhibit normal cardiac development. However, these animals exhibit defects in mammary gland maturation, cranial neural crest migration, cranial nerve architecture, and cerebellum defects. Yet, there are no reports that these animals exhibit deficits in hematopoiesis or hematopoietic cell function (Tidcombe et al., 2003).

Thus, it is surprising that ERBB4 expression is observed during human erythroid cell maturation and that the irreversible ERBB tyrosine kinase inhibitor neratinib inhibits erythroid maturation in mice. Likewise, morpholino inhibition of ERBB4 in zebrafish embryos decreases embryonic erythropoiesis (Kinney et al., 2019a,b). Moreover, elevated expression of ERBB4 is detected in 24\% of anaplastic large-cell lymphomas (ALCLs) that lack a chromosomal translocation that affects the anaplastic lymphoma kinase gene. The ERBB4 protein expressed in these samples is truncated as a result of cryptic transcriptional promotion from within an intron in the ERBB4 gene. Most ALCLs that exhibit expression of the truncated ERBB4 exhibit a morphology reminiscent of Hodgkin lymphoma; this morphology is typically rare in ALCLs. Moreover, patients that are ERBB4-positive with ALCL 
Table 2

ERBB4 missense mutations that are found in human tumor samples, yet whose function is largely unknown.

\begin{tabular}{|c|c|c|c|}
\hline Mutation & ERBB4 Functional Region & Tumor Type & Reference(s) \\
\hline $\mathrm{A} 4 \mathrm{E}$ & Signal sequence & Gastric & (Chen et al., 2015) \\
\hline L39F & Unknown & Gastric & (Chen et al., 2015) \\
\hline L39F & Unknown & Melanoma & (Prickett et al., 2009) \\
\hline Y46C & Unknown & Gastric & (Chen et al., 2015) \\
\hline R50C & Unknown & Gastric & (Chen et al., 2015) \\
\hline L97P & ECD I & Gastric & (Chen et al., 2015) \\
\hline $\mathrm{R} 106 \mathrm{C}$ & ECD I & Gastric & (Chen et al., 2015) \\
\hline $\mathrm{R} 106 \mathrm{H}$ & ECD I & Gastric & (Chen et al., 2015) \\
\hline R106S & ECD I & Thyroid & (Gerber et al., 2018) \\
\hline $\mathrm{Y} 111 \mathrm{H}$ & ECD I & Melanoma & (Prickett et al., 2009) \\
\hline D113V & ECD I & Thyroid & (Gerber et al., 2018) \\
\hline D165N & ECD I & Thyroid & (Gerber et al., 2018) \\
\hline I166N & ECD I & Thyroid & (Gerber et al., 2018) \\
\hline P172S & Unknown & Gastric & (Chen et al., 2015) \\
\hline N181S & Unknown & Lung & (Kurppa et al., 2016) \\
\hline R196C & ECD II & Gastric & (Chen et al., 2015) \\
\hline C213Y & ECD II & Thyroid & (Gerber et al., 2018) \\
\hline C217R & ECD II & Gastric & (Chen et al., 2015) \\
\hline G219D & ECD II & Thyroid & (Gerber et al., 2018) \\
\hline V226I & ECD II & Gastric & (Chen et al., 2015) \\
\hline E233G & ECD II & Thyroid & (Gerber et al., 2018) \\
\hline G240R & ECD II & Gastric & (Chen et al., 2015) \\
\hline T244R & ECD II & Lung & (Kurppa et al., 2016) \\
\hline R306S & ECD II & Lung & (Kurppa et al., 2016) \\
\hline M313I & ECD II & Melanoma & (Prickett et al., 2009) \\
\hline S341L & Unknown & Melanoma & (Prickett et al., 2009) \\
\hline I353V & Unknown & Gastric & (Chen et al., 2015) \\
\hline V348L & Unknown & Lung & (Kurppa et al., 2016) \\
\hline N358K & ECD III & Gastric & (Chen et al., 2015) \\
\hline E387D & ECD III & Gastric & (Chen et al., 2015) \\
\hline R393W & ECD III & Gastric & (Chen et al., 2015) \\
\hline R393W & ECD III & Melanoma & (Prickett et al., 2009) \\
\hline F401S & ECD III & Gastric & (Chen et al., 2015) \\
\hline P409L & ECD III & Melanoma & (Prickett et al., 2009) \\
\hline S449Y & ECD III & Gastric & (Chen et al., 2015) \\
\hline L466M & ECD III & Gastric & (Chen et al., 2015) \\
\hline F478V & ECD III & Gastric & (Chen et al., 2015) \\
\hline R488W & Unknown & Gastric & (Chen et al., 2015) \\
\hline R491K & Unknown & Melanoma & (Prickett et al., 2009) \\
\hline E494G & Unknown & Gastric & (Chen et al., 2015) \\
\hline S522L & ECD IV & Gastric & (Chen et al., 2015) \\
\hline N548T & ECD IV & Gastric & (Qu et al., 2013; Zang et al., 2012) \\
\hline C589Y & ECD IV & Thyroid & (Gerber et al., 2018) \\
\hline D609N & ECD IV & Melanoma & (Prickett et al., 2009) \\
\hline $\mathrm{C} 614 \mathrm{Y}$ & ECD IV & Thyroid & (Gerber et al., 2018) \\
\hline H618P & ECD IV & Lung & (Kurppa et al., 2016) \\
\hline N626T & ECD IV & Gastric & (Chen et al., 2015) \\
\hline P700S & Unknown & Melanoma & (Prickett et al., 2009) \\
\hline L710R & Unknown & Gastric & (Chen et al., 2015) \\
\hline V721I & Tyrosine kinase & Colorectal & (Soung et al., 2006; Tvorogov et al., 2009) \\
\hline V744L & Tyrosine kinase & Gastric & (Chen et al., 2015) \\
\hline A773S & Tyrosine kinase & Gastric & (Soung et al., 2006; Tvorogov et al., 2009) \\
\hline $\mathrm{S} 774 \mathrm{G}$ & Tyrosine kinase & Gastric & (Chen et al., 2015) \\
\hline S774N & Tyrosine kinase & Gastric & (Chen et al., 2015) \\
\hline $\mathrm{R} 782 \mathrm{Q}$ & Tyrosine kinase/LXXLL motif & Lung & (Soung et al., 2006; Tvorogov et al., 2009) \\
\hline L798P & Tyrosine kinase & Gastric & (Chen et al., 2015) \\
\hline L798R & Tyrosine kinase & Gastric & (Chen et al., 2015) \\
\hline E810K & Tyrosine kinase & Lung & (Soung et al., 2006; Tvorogov et al., 2009) \\
\hline L821I & Tyrosine kinase & Gastric & (Chen et al., 2015) \\
\hline Y833C & Tyrosine kinase & Gastric & (Chen et al., 2015) \\
\hline V840I & Tyrosine kinase & Gastric & (Chen et al., 2015) \\
\hline P854Q & Tyrosine kinase & Colorectal & (Soung et al., 2006; Tvorogov et al., 2009) \\
\hline T898S & Tyrosine kinase & Gastric & (Chen et al., 2015) \\
\hline I910V & Tyrosine kinase & Gastric & (Chen et al., 2015) \\
\hline K919N & Tyrosine kinase & Gastric & (Chen et al., 2015) \\
\hline T926M & Tyrosine kinase & Lung & (Soung et al., 2006; Tvorogov et al., 2009) \\
\hline R927Q & Tyrosine kinase & Gastric & (Chen et al., 2015) \\
\hline G936R & Tyrosine kinase & Melanoma & (Prickett et al., 2009) \\
\hline P942S & Tyrosine kinase & Gastric & (Chen et al., 2015) \\
\hline R979Q & Tyrosine kinase & Gastric & (Chen et al., 2015) \\
\hline $\mathrm{K} 1002 \mathrm{R}$ & Unknown & Gastric & (Chen et al., 2015) \\
\hline I1030M & Unknown & Colorectal & (Parsons et al., 2005; Tvorogov et al., 2009) \\
\hline P1033S & WW domain binding motif? & Melanoma & (Prickett et al., 2009) \\
\hline Q1063K & Unknown & Gastric & (Chen et al., 2015) \\
\hline A1078T & Unknown & Gastric & (Chen et al., 2015) \\
\hline
\end{tabular}




\begin{tabular}{|c|c|c|c|}
\hline Mutation & ERBB4 Functional Region & $\begin{array}{l}\text { Continued } \\
\text { Tumor Type }\end{array}$ & Reference(s) \\
\hline F1102C & Unknown & Gastric & (Chen et al., 2015) \\
\hline H1118R & Unknown & Gastric & (Chen et al., 2015) \\
\hline P1132S & Unknown & Gastric & (Chen et al., 2015) \\
\hline $\mathrm{R} 1174 \mathrm{Q}$ & Unknown & Melanoma & (Prickett et al., 2009) \\
\hline $\mathrm{P} 1149 \mathrm{~T}$ & Unknown & Gastric & (Chen et al., 2015) \\
\hline Y1150C & Phosphorylation site? & Gastric & (Chen et al., 2015) \\
\hline K1160Q & Unknown & Gastric & (Chen et al., 2015) \\
\hline L1163P & Unknown & Gastric & (Chen et al., 2015) \\
\hline E1220A & Unknown & Gastric & (Chen et al., 2015) \\
\hline $\mathrm{K} 1223 \mathrm{M}$ & Unknown & Gastric & (Chen et al., 2015) \\
\hline $\mathrm{K} 1223 \mathrm{~T}$ & Unknown & Gastric & (Chen et al., 2015) \\
\hline $\mathrm{S} 1246 \mathrm{~N}$ & Unknown & Melanoma & (Prickett et al., 2009) \\
\hline R1257W & Unknown & Gastric & (Chen et al., 2015) \\
\hline $\mathrm{I} 1274 \mathrm{~F}$ & Unknown & Gastric & (Chen et al., 2015) \\
\hline
\end{tabular}

have overall survival rates inferior to those with the anaplastic lymphoma kinase translocation (Gaulard and de Leval, 2016; Scarfo et al., 2016).

The truncated ERBB4 protein, which consists of the carboxyl-terminal cytoplasmic domain and has an apparent molecular weight of $50 \mathrm{kDa}$, is constitutively tyrosine-phosphorylated. The truncated ERBB4 protein can transform the growth of NIH-3T3 fibroblasts. Patient-derived tumor cells that endogenously express the truncated ERBB4 protein were established. Neratinib kills these patient-derived tumor cells in ex vivo and in vivo settings (Gaulard and de Leval, 2016; Scarfo et al., 2016). Overall, these data suggest that $E R B B 4$ is an oncogene in a subset of ALCLs, although it is not apparent whether ERBB4 functions autonomously or through heterodimerization with another ERBB receptor.

\section{Tumors in Which ERBB4 Appears to Function as an Oncoprotein and as a Tumor Suppressor}

\section{A. Pancreas}

Elevated ERBB4 expression is associated with favorable tumor staging (Thybusch-Bernhardt et al., 2001; Segers et al., 2020). Similarly, relative to normal pancreatic tissue, malignant pancreatic tissue frequently exhibits reduced ERBB4 expression (te Velde et al., 2009; Mill et al., 2011a). Expression of the constitutively homodimerized and constitutively active $E R B B 4$ Q646C mutant inhibits clonogenic proliferation in pancreatic tumor cell lines that lack endogenous ERBB4 expression (Mill et al., 2011a). Taken together, these findings suggest that $E R B B 4$ functions as a pancreatic tumor suppressor gene.

In contrast, the expression of wild-type ERBB4 in the pancreatic tumor cell lines that lack endogenous ERBB4 expression enables the ERBB4 agonist NRG1 $\beta$ to stimulate anchorage-independent growth (Mill et al., 2011a). Likewise, the ERBB4 ligand BTC is overexpressed in pancreatic tumor cell lines and stimulates the proliferation of pancreatic tumor cell lines (Yokoyama et al., 1995; Mashima et al., 1996; Dunbar and Goddard, 2000;
Kawaguchi et al., 2000; Li et al., 2003; Dahlhoff et al., 2014).

Pancreatic fibrosis is a major component of several diseases of the pancreas, including pancreatic cancer. In a transgenic mouse, pancreatic-specific expression of Hbegf causes pancreatic fibrosis. This effect is significantly reduced in a bitransgenic mouse that possesses an EGFR mutant that exhibits a partial loss of tyrosine kinase activity (Blaine et al., 2009). However, this result may not mean that Hbegf functions solely through EGFR, as disrupting EGFR kinase activity causes reduced proliferative signaling by ERBB4EGFR heterodimers (Wilson et al., 2012b).

In a genetically engineered mouse, pancreas-specific knockout of BTC in the context of a KRAS G12D mutant results in decelerated progression of pancreatic ductal adenocarcinoma (PDAC). Similarly, pancreas-specific overexpression of $B T C$ in the context of a KRAS G12D mutant results in accelerated progression of PDAC. Knockout of EGFR, ERBB2, or ERBB4 diminishes this acceleration (Hedegger et al., 2020). These results suggest that ERBB4 functions as a PDAC oncoprotein in the context of a KRAS activating mutation through heterodimerization with another ERBB receptor (Mill et al., 2011a).

\section{B. Breast}

ERBB4 ligands inhibit proliferation and promote differentiation in several human breast cancer cell lines (Sartor et al., 2001; Carpenter, 2003a; MuraokaCook et al., 2006; Karamouzis et al., 2007; Uberall et al., 2008; Arienti et al., 2019; Segers et al., 2020). These data are consistent with the observation that ERBB4 signaling contributes to mammary gland differentiation rather than expansion (Schroeder and Lee, 1998; Jones et al., 1999; Carpenter, 2003a; Long et al., 2003; Tidcombe et al., 2003; Eccles, 2011; Segers et al., 2020). This inhibition of proliferation and contribution to differentiation appear to be specific for the $E R B B 4$ isoform; in transgenic mice, breast-specific expression of the canonical CT-a isoform of the 4ICD causes decreased proliferation of the ductal epithelium and lactogenic differentiation, whereas 
breast-specific expression of the CT-b isoform of the 4ICD causes epithelial hyperplasia (Muraoka-Cook et al., 2009).

Reduced ERBB4 expression is predictive of recurrence of ductal carcinoma in situ (Barnes et al., 2005; Uberall et al., 2008; Lyu et al., 2018) and reduced overall survival among patients with breast cancer (Das et al., 2010; Wang et al., 2019). Similarly, ERBB4 overexpression is associated with improved relapse-free survival (Pawlowski et al., 2000; Wang et al., 2016; Segers et al., 2020), disease-free survival (Koutras et al., 2008; Sassen et al., 2008), and overall survival (Pawlowski et al., 2000; Witton et al., 2003; Junttila et al., 2005; Koutras et al., 2008; Sassen et al., 2008). ERBB4 expression is positively correlated with estrogen receptor (ER) and progesterone receptor (PR) expression, raising some concern about ERBB4 status being an independent predictor of breast cancer outcome (Bacus et al., 1996; Knowlden et al., 1998; Pawlowski et al., 2000). Indeed, ERBB4 overexpression more strongly correlates with a favorable outcome in ER/PR-positive breast cancer cases than in ER/PR-negative breast cancer cases (Junttila et al., 2005). One potential explanation for this observation is that homotypic ERBB4 signaling by the 4ICD mediates tamoxifen-induced apoptosis (Naresh et al., 2008). The expression of ERBB4 and the tumor suppressor WWOX are both significantly lower in breast tumors derived from lymph node metastases than in the matched primary tumors (Aqeilan et al., 2007; Pospiech et al., 2018). It has been proposed that the loss of ERBB4 expression observed in malignant samples is due to ERBB4 promoter hypermethylation, as treatment of the BT20 human breast tumor cell line with a DNA demethylating agent causes decreased methylation of the ERBB4 promoter, increased ERBB4 expression, and increased apoptosis (Das et al., 2010; Segers et al., 2020). Taken together, these data suggest that $E R B B 4$ functions as a breast cancer tumor suppressor gene, particularly in ER/PR-positive/HER2-negative breast cancers (Bacus et al., 1996; Vogt et al., 1998; Suo et al., 2002; Witton et al., 2003; Zaczek et al., 2005; Muraoka-Cook et al., 2008; Sundvall et al., 2008; Koutras et al., 2010; Segers et al., 2020).

In contrast, there are numerous reports that ERBB4 ligands stimulate proliferation, malignant phenotypes, and chemoresistance in models of breast cancer (Karamouzis et al., 2007; Eccles, 2011; Xia et al., 2013; Feldinger and Kong, 2015). Similarly, BTC expression in breast tumor samples is associated with a poor clinical outcome (Olsen et al., 2012; Dahlhoff et al., 2014). ERBB4 underexpression is associated with improved responsiveness to endocrine therapies and longer relapse-free survival (Bieche et al., 2003; Wege et al., 2018; Brockhoff, 2019). Likewise, silencing endogenous ERBB4 expression in the ZR-75-1 human breast tumor cell line causes increased sensitivity to tamoxifen (Wege et al., 2018). Parenthetically, we postulate that this sensitivity is due to decreased signaling by ERBB4 heterodimers, as increased homotypic ERBB4 signaling also causes increased sensitivity to tamoxifen (Naresh et al., 2008). Another finding that indicates that increased ERBB4 signaling is coupled to tumorigenesis or tumor progression is that ERBB4 overexpression is associated with chemoresistance (including resistance to endocrine agents) and poorer prognosis (Lodge et al., 2003; Sutherland, 2011; Kim et al., 2016; Wege et al., 2018; Segers et al., 2020). Moreover, ectopic ERBB4 overexpression can stimulate proliferation and anchorage independence (Junttila et al., 2005).

The proliferative effects of ERBB4 have been observed in transgenic model systems. For example, in mice that exhibit high levels of canonical ERBB4 expression in the breast due to introduction of the MMTV-ERBB4 (JMa/CT-a) transgene, mammary terminal end bud differentiation is suppressed, and neoplastic mammary lesions form (Wali et al., 2014). These effects contrast those of the 4ICD CT-a transgene, which, as discussed earlier, causes terminal differentiation and suppresses proliferation (MuraokaCook et al., 2009). The functional difference between the full-length $E R B B 4 \mathrm{JMa} / \mathrm{CT}$-a transgene and the 4ICD CT-a transgene appears to be due to the fact that full-length ERBB4 can heterodimerize with another ERBB family receptor, whereas the 4ICD participates only in homotypic ERBB4 signaling.

It is well accepted that many triple-negative breast tumors (particularly those of the basal-like subtype of triple-negative breast cancer) exhibit elevated expression of EGFR and its ligands (Farnie et al., 2007; Kenny and Bissell, 2007; Gluz et al., 2009; Viale et al., 2009; Burness et al., 2010; Foley et al., 2010). Triple-negative breast cancers (TNBCs) exhibit significantly increased ADAM17 expression, which may stimulate ERBB4 signaling by enhancing the release of NRGs and BTC into the extracellular milieu. In TNBCs, ERBB4 overexpression is associated with a poorer prognosis, thereby supporting our hypothesis that ERBB4-EGFR heterodimers function as oncoproteins in TNBCs (McGowan et al., 2013; Feldinger and Kong, 2015; Kim et al., 2016; Wang et al., 2019).

$E R B B 2$ is a well established breast cancer oncogene. In transgenic mice that possess the MMTV-ERBB2 transgene, breast tumorigenesis occurs with relatively slow kinetics and is accompanied by overexpression of endogenous EGFR, ERBB3, and ERBB4 and phosphorylation of protein kinase B (PKB or AKT1). In contrast, in transgenic mice that possess the MMTV-ERBB2 transgene and a constitutively active $A K T 1$ allele under control of the MMTV promoter (MMTV-caAKT1), tumors form with rapid kinetics and exhibit elevated AKT1 phosphorylation but not overexpression of endogenous EGFR, ERBB3, and ERBB4. Thus, it appears that 
tumorigenesis driven by ERBB2 requires AKT1 phosphorylation, which occurs through overexpression of EGFR, ERBB3, and ERBB4 and heterodimerization of these receptors with ERBB2 (Young et al., 2008).

Thus, it seems plausible to hypothesize that the elevated ERBB2 expression or activity frequently observed during acquired resistance to endocrine therapy may result in heterodimerization with ERBB4, enabling ERBB4 to contribute to this acquired resistance (Ghayad et al., 2010). Indeed, as we have stated elsewhere, we predict that functional differences between ERBB4 homodimers (tumor suppressors) and heterodimers (oncoproteins) account for the disparities in ERBB4 function observed in breast cancers.

Functional differences among the ERBB4 isoforms may also account for the fact that ERBB4 appears to function as a tumor suppressor and as an oncoprotein, particularly since the $\mathrm{JMb}$ isoforms cannot be processed into the 4ICD intracellular fragment and thereby cannot facilitate the trafficking of signaling proteins to the nucleus and mitochondria. There is also evidence that the Cyt1 and Cyt2 isoforms play distinct roles in breast cancers (Fujiwara et al., 2014; Segers et al., 2020). This functional distinction is likely due to differences in the coupling of the carboxyl terminus of ERBB4 to signaling effectors (see Section II.H and Section II.I for further details). The functional differences between ERBB4 homodimers (tumor suppressors) and heterodimers (oncoproteins) may also account for this apparent difference in ERBB4 functions.

Mutations in ERBB4 are observed in $1 \%-4 \%$ of all breast cancers (Mishra et al., 2017). However, this particular report failed to identify the individual $E R B B 4$ mutations. The ERBB4 E872K mutation was found in an unspecified breast cancer sample (Soung et al., 2006; Tvorogov et al., 2009). As will be discussed later, it has been reported that the E872K mutant exhibits a gain-of-function phenotype (Prickett et al., 2009). Based on the hypothesis that ERBB4 functions as both tumor suppressor gene and as an oncogene, we predict that ERBB4 loss-of-function mutants will be found in the context in which ERBB4 functions as a tumor suppressor protein and that $E R B B 4$ gain-of-function mutants will be found in the context in which ERBB4 functions as an oncoprotein.

\section{Melanoma}

ERBB4 is mutated in 15 of $79(19 \%)$ melanoma samples, accounting for 20 distinct mutations (L39F, Y111H, M313I, E317K, S341L, R393W, P409L, E452K, R491K, E542K, R544W, E563K, D609N, P700S, E836K, E872K, G936R, P1033S, R1174Q, and S1246N; Tables 1 and 2) (Prickett et al., 2009). The L39F, R393W, and E872K mutations have been described in other tumor types, suggesting that these mutations are functionally relevant (Soung et al., 2006; Prickett et al., 2009;
Tvorogov et al., 2009; Chen et al., 2015). Moreover, seven ERBB4 missense mutants (E317K, E452K, E542K, R544W, E563K, E836K, and E872K) found in these samples exhibit increased ERBB4 tyrosine phosphorylation and ERBB4 tyrosine kinase activity. Moreover, these seven ERBB4 missense mutants induce foci (loss of contact inhibition) in a monolayer of NIH 3T3 fibroblasts. The pan-ErbB tyrosine kinase inhibitor $N$-\{3-chloro-4-[(3-fluorobenzyl)oxy]phenyl\}-6-[5(\{[2-(methylsulfonyl)ethyl]amino $\}$ methyl)-2-furyl $]-4$-quinazolinamine (lapatinib) (Rusnak et al., 2001) inhibits the proliferation of melanoma cell lines that possess endogenous $E R B B 4$ mutant alleles but not cells that possess wild-type $E R B B 4$. The inhibition of proliferation by lapatinib is accompanied by reduced ERBB4 tyrosine phosphorylation but not reduced ERBB2 tyrosine phosphorylation, suggesting that reduced ERBB4 phosphorylation is the mechanism of this growth inhibition. Similarly, silencing endogenous $E R B B 4$ in melanoma cells that possess an ERBB4 mutant results in growth arrest and reduced AKT phosphorylation. Together, these data have led to the conclusion that ERBB4 functions as an oncogene in melanoma (Kurppa and Elenius, 2009; Prickett et al., 2009; Easty et al., 2011; Kunz, 2013, 2014, 2015; Mishra et al., 2017) and that gain-of-function ERBB4 mutations are one of the multiple mechanisms by which melanoma cells activate the PI3K pathway (Kurppa and Elenius, 2009). Moreover, given that lapatinib is a much more potent inhibitor of ERBB2 tyrosine kinase activity than of ERBB4 tyrosine kinase activity (Rusnak et al., 2001; Qiu et al., 2008), lapatinib inhibition of proliferation by ERBB4-mutant melanoma cell lines suggests that ERBB4-ERBB2 heterodimerization and ERBB4 phosphorylation by ERBB2 is responsible for PI3K activation and deregulated proliferation in melanoma cells that harbor gain-of-function ERBB4 mutants.

On the surface, the conclusion that these gain-of-function ERBB4 melanoma mutants function as oncogenes contradicts evidence that the synthetic gain-of-function Q646C and I658E ERBB4 mutants function as tumor suppressor genes (Penington et al., 2002; Williams et al., 2003; Gallo et al., 2006, 2013; Pitfield et al., 2006; Vidal et al., 2007; Mill et al., 2011a). However, recall that we have postulated that ERBB4 heterodimers function as oncoproteins, whereas homodimers function as tumor suppressors. Thus, one possible explanation for the apparent difference between the gain-of-function $E R B B 4$ melanoma mutants and the synthetic gain-of-function ERBB4 mutants is that Q646C is constitutively homodimerized and $\mathrm{I} 658 \mathrm{E}$ is presumed to be constitutively homodimerized. In contrast, the gain-of-function $E R B B 4$ melanoma mutants may cause increased heterodimerization with EGFR or ERBB2 in addition to or instead of increased ERBB4 homodimerization. 
Another critique of these gain-of-function ERBB4 melanoma mutants is that they have not been useful in directing the use of lapatinib in a clinical trial for the treatment of advanced melanoma (Gonzalez-Cao et al., 2015; Mishra et al., 2017; Rudloff and Samuels, 2010). One potential explanation is that no group has replicated the finding that the E317K, E452K, E542K, R544W, E563K, E836K, and E872K ERBB4 mutants exhibit increased ligand-dependent or -independent phosphorylation nor the finding that these mutants cause loss of contact inhibition (focus formation) in a fibroblast cell line. Given that we postulate that gain-of-function ERBB4 melanoma mutants cause increased signaling by ERBB4 heterodimers but not by ERBB4 homodimers, differences in EGFR and ERBB2 expression in model systems could account for the apparent failure to replicate initial findings.

Another complication is that subsequent studies of melanoma genomes have either failed to detect the presumed seven gain-of-function ERBB4 alleles or have detected $E R B B 4$ mutations at a greatly reduced frequency in melanoma (Manca et al., 2013; Zhou et al., 2013; Segers et al., 2020). On the other hand, after in silico filtering for functional relevance, ERBB4 is mutated in 12 of 100 (12\%) melanoma samples, and 18 missense mutant alleles (16 distinct alleles) are found in these samples. Functional analyses of these mutants have not been performed. Only 2 of these 16 alleles correspond to the gain-of-function ERBB4 melanoma mutants described in the prior analysis of melanoma samples (E452K and E872K) (Prickett et al., 2009; de Unamuno Bustos et al., 2017). Similarly, these mutations are distributed across the entire $E R B B 4$ coding sequence, and this study failed to reveal the profound ERBB4 mutational hot spots characteristic of many gain-of-function mutant alleles in oncogenes, including gain-of-function mutations in $E G F R, B R A F$, and the neuroblastoma RAS viral oncogene homolog (NRAS) gene. Thus, it is possible that at least some of these 16 ERBB4 mutations cause a loss of function in the context of a homodimeric ERBB4 tumor suppressor (de Unamuno Bustos et al., 2017). Indeed, there have been calls for additional studies into the mechanisms by which ERBB4 melanoma mutants drive malignancies, in apparent recognition of the possibility that some ERBB4 melanoma mutants drive malignancies by disrupting the activity of homodimeric ERBB4 tumor suppressors (Rudloff and Samuels, 2010; Mishra et al., 2017).

\section{Implications for Staging and Treating Human Tumors}

\section{A. Determination of whether ERBB4 Functions as a Tumor Suppressor or as an Oncoprotein}

Our hypothesis that ERBB4 homodimers function as tumor suppressors, whereas ERBB4 heterodimers possess oncogenic activity, has profound implications the potential utility of ERBB4 as a biomarker and therapeutic target (Fig. 7). The most profound implication is the obvious need to assess the contribution of ERBB4 to the malignant phenotype for each tumor type of interest. Multiple approaches will need to be deployed.

Relative to normal samples, ERBB4 overexpression or elevated $E R B B 4$ copy number in tumor samples will be a preliminary indication that $E R B B 4$ functions as an oncogene in those samples. Because ERBB4 heterodimers are oncogenic, ERBB4 may also function as an oncogene in some EGFR-dependent or ERBB2-dependent tumors. These hypotheses will need to be confirmed through overexpression studies in normal tissues to confirm that ERBB4 is sufficient for malignant growth transformation. The hypothesis will also need to be confirmed through knockdown/silencing studies in tumor cells to confirm that ERBB4 is necessary for malignant phenotypes.

Relative to normal samples, ERBB4 underexpression or loss of $E R B B 4$ copy number in tumor samples will be a preliminary indication that $E R B B 4$ functions as a tumor suppressor gene in those samples. Such a hypothesis will need to be confirmed through knockdown/silencing studies in normal cells to demonstrate that loss of ERBB4 expression is sufficient for malignant growth transformation. The hypothesis will also need to be confirmed through overexpression studies in tumor cells to demonstrate that loss of ERBB4 expression is necessary for malignant phenotypes.

\section{B. Identification of ERBB4 Mutants that Serve as Biomarkers through Their Function as Bona Fide Tumor Drivers}

As noted in Table 1 and elsewhere, ERBB4 polymorphisms (most notably, missense mutations) are found in a wide variety of human malignancies. Strategies for ascertaining the functional significance of particular ERBB4 missense mutations in a specific type of tumor must account for the possibility that $E R B B 4$ functions either as an oncogene or as a tumor suppressor gene in that particular tumor type. Thus, the general question of whether ERBB4 functions as a tumor suppressor gene or as an oncogene in a specific type of tumor must precede the determination of whether particular ERBB4 missense mutations function as bona fide tumor drivers.

In tumors in which $E R B B 4$ functions as an oncogene, ERBB4 missense mutations that act as bona fide tumor drivers are anticipated to exhibit a gain-offunction phenotype. In other words, relative to wildtype $E R B B 4$, the $E R B B 4$ missense mutants will encode proteins that exhibit elevated tyrosine phosphorylation and coupling to downstream signaling effectors. To demonstrate that these mutants function as bona fide tumor drivers, the expression of the 


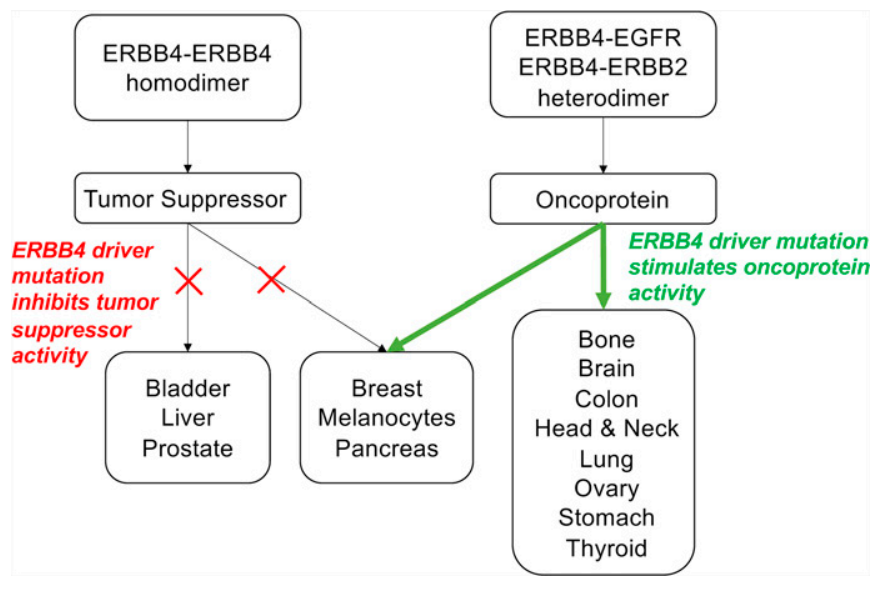

Fig. 7. A proposed role for ERBB4 in human malignancies.

ERBB4 missense mutants in normal cells must induce malignant phenotypes to a greater extent than does wild-type ERBB4. Furthermore, knockdown/ silencing of endogenous ERBB4 mutants in tumor cells must inhibit malignant phenotypes, and these malignant phenotypes must not be rescued through reintroduction of wild-type ERBB4 at endogenous levels of expression.

In tumors in which $E R B B 4$ functions as a tumor suppressor, $E R B B 4$ missense mutations that act as bona fide tumor drivers are anticipated to exhibit a loss-of-function phenotype. In other words, relative to wild-type $E R B B 4$, the $E R B B 4$ missense mutants will encode proteins that exhibit decreased tyrosine phosphorylation and coupling to downstream signaling effectors. To demonstrate that these mutants function as bona fide tumor drivers, the ERBB4 missense mutations must disrupt the growth inhibitory activity of wild-type $E R B B 4$. In particular, knockdown/silencing of endogenous ERBB4 mutants in tumor cells must inhibit malignant phenotypes, and these malignant phenotypes must not be rescued through reintroduction of wild-type $E R B B 4$.

Note that we predict that $E R B B 4$ gain-of-function tumor driver mutations will potentiate the phosphorylation and oncogenic signaling of ERBB4 heterodimers to a greater extent than they will potentiate the phosphorylation and tumor suppressor signaling of ERBB4 homodimers. Likewise, we predict that ERBB4 loss-of-function tumor driver mutations will disrupt the phosphorylation and tumor suppressor signaling by ERBB4 homodimers to a greater extent than they will disrupt oncogenic signaling by ERBB4 heterodimers. Therefore, significant forethought must go into the choice of model systems used to evaluate the activity of ERBB4 mutants, particularly with respect to the expression of other ERBB family receptors.

Likewise, the characterization of ERBB4 mutants must avoid using ERBB4 tyrosine phosphorylation as the sole indication of ERBB4 signaling activity. As noted elsewhere, the synthetic ERBB4 Q646C mutant exhibits ligand-independent homodimerization, tyrosine phosphorylation, and tumor suppressor activity. On the other hand, the synthetic ERBB4 H647C and A648C mutants exhibit ligand-independent homodimerization and tyrosine phosphorylation but do not possess tumor suppressor activity. It has been hypothesized that the $\mathrm{H} 647 \mathrm{C}$ and $\mathrm{A} 648 \mathrm{C}$ mutants do not homodimerize in the same conformation as the Q646C mutant, resulting in differences in the sites of ERBB4 tyrosine phosphorylation and differential coupling to effectors and growth inhibitory signaling (Penington et al., 2002; Williams et al., 2003; Pitfield et al., 2006).

\section{Potential Therapeutic Approaches for Tumors that Harbor Tumor Driver Mutations in ERBB4}

The use of ERBB4 tumor driver mutants as biomarkers for therapeutic intervention must reflect whether such mutants potentiate the oncogenic activity of ERBB4 or disrupt the tumor suppressor activity of ERBB4. This is because ERBB4 itself is not considered druggable in contexts in which it functions as a homodimeric tumor suppressor. In contrast, the wealth of United States Food and Drug Administration-approved agents that target EGFR and ERBB2 suggest that ERBB4 is quite druggable in contexts in which it functions as a heterodimeric oncoprotein. Some small-molecule inhibitors for other kinases nonetheless have reasonable potency against ERBB4 (Qiu et al., 2008; Ahammad et al., 2020). Moreover, classic medicinal chemistry approaches could be employed to improve the selectivity of these existing inhibitors for ERBB4.

On the other hand, here we propose that the observation that ERBB4 kinase activity is dispensable for the growth stimulatory activity of ERBB4 heterodimers (Pitfield et al., 2006; Mill et al., 2011a,b; Wilson et al., 2012b) is generally applicable to tumors in which ERBB4 heterodimers function as oncoproteins. If this holds true, then agents that disrupt EGFR or ERBB2 signaling possess more promise for the treatment of tumors that are dependent on ERBB4 heterodimers than small-molecule ERBB4 tyrosine kinase inhibitors. Indeed, inhibiting ERBB4 homodimeric signaling by small-molecule ERBB4 tyrosine kinase inhibitors is predicted to be deleterious.

ERBB4 mutants that function as bona fide tumor drivers by potentiating signaling by oncogenic ERBB4EGFR or ERBB4-ERBB2 heterodimers may indicate sensitivity to inhibitors of effectors of these ERBB4 heterodimers. As discussed earlier, the PI3K/AKT pathway appears to be a frequent mediator of oncogenic ERBB4 signaling. Section II.D describes other ERBB4 effectors that may be appealing targets for therapy. 
It is much less apparent how to treat tumors that harbor $E R B B 4$ (loss-of-function) tumor driver mutations that disrupt the tumor suppressor activity of ERBB4 homodimers. Section II.H describes mechanisms of homotypic ERBB4 signaling through the 4ICD, including mechanisms that lead to apoptosis and cell cycle arrest. Therefore, in tumors in which 4ICD signaling is lost due to a loss-of-function tumor driver mutation in $E R B B 4$, therapeutics that promote apoptosis or cell cycle arrest may be effective.

\section{Authorship Contributions}

Wrote or contributed to the writing of the manuscript: Lucas, Dwivedi, Senfeld, Cullum, Mill, Piazza, Bryant, Cook, Miller, Lott, Kelley, Knerr, Markham, Kaufmann, Jacobi, Shen, Riese.

\section{Acknowledgments}

The authors thank Profs. David Stern and Mark Lemmon of the Yale Cancer Center for decades of insightful conversations regarding ERBB4 function.

\section{References}

Abu-Odeh M, Salah Z, Herbel C, Hofmann TG, and Aqeilan RI (2014) WWOX, the common fragile site FRA16D gene product, regulates ATM activation and the DNA damage response. Proc Natl Acad Sci USA 111:E4716-E4725.

Ahammad I, Sarker MRI, Khan AM, Islam S, and Hossain M (2020) Virtual screening to identify novel inhibitors of pan ERBB family of proteins from natural products with known anti-tumorigenic properties. Int $J$ Pept Res Ther 26:1923-1938.

Ahsan A, Hiniker SM, Ramanand SG, Nyati S, Hegde A, Helman A, Menawat R, Bhojani MS, Lawrence TS, and Nyati MK (2010) Role of epidermal growth factor receptor degradation in cisplatin-induced cytotoxicity in head and neck cancer Cancer Res 70:2862-2869.

Alaoui-Jamali MA, Morand GB, and da Silva SD (2015) ErbB polymorphisms: insights and implications for response to targeted cancer therapeutics. Front Genet 6:17.

Alimandi M, Wang LM, Bottaro D, Lee CC, Kuo A, Frankel M, Fedi P, Tang C, Lippman M, and Pierce JH (1997) Epidermal growth factor and betacellulin mediate signal transduction through co-expressed ErbB2 and ErbB3 receptors. EMBO J 16:5608-5617.

Allison JG, Das PM, Ma J, Inglis FM, and Jones FE (2011) The ERBB4 intracellular domain (4ICD) regulates NRG1-induced gene expression in hippocampal neurons. Neurosci Res 70:155-163.

Anderson NG and Ahmad T (2002) ErbB receptor tyrosine kinase inhibitors as therapeutic agents. Front Biosci 7:d1926-d1940.

Andersson U, Guo D, Malmer B, Bergenheim AT, Brännström T, Hedman H, and Henriksson R (2004) Epidermal growth factor receptor family (EGFR, ErbB2-4) in gliomas and meningiomas. Acta Neuropathol 108:135-142.

Appert-Collin A, Hubert P, Crémel G, and Bennasroune A (2015) Role of ErbB receptors in cancer cell migration and invasion. Front Pharmacol 6:283.

Aqeilan RI, Abu-Remaileh M, and Abu-Odeh M (2014) The common fragile site FRA16D gene product WWOX: roles in tumor suppression and genomic stability. Cell Mol Life Sci 71:4589-4599.

Aqeilan RI, Donati V, Gaudio E, Nicoloso MS, Sundvall M, Korhonen A, Lundin J, Isola J, Sudol M, Joensuu H, et al. (2007) Association of Wwox with ErbB4 in breast cancer. Cancer Res 67:9330-9336.

Aqeilan RI, Donati V, Palamarchuk A, Trapasso F, Kaou M, Pekarsky Y, Sudol M, and Croce CM (2005) WW domain-containing proteins, WWOX and YAP, compete for interaction with ErbB-4 and modulate its transcriptional function. Cancer Res 65:6764-6772.

Arasada RR and Carpenter G (2005) Secretase-dependent tyrosine phosphorylation of Mdm2 by the ErbB-4 intracellular domain fragment. J Biol Chem 280:30783-30787.

Arienti C, Pignatta S, and Tesei A (2019) Epidermal growth factor receptor family and its role in gastric cancer. Front Oncol 9:1308.

Arteaga CL and Engelman JA (2014) ERBB receptors: from oncogene discovery to basic science to mechanism-based cancer therapeutics. Cancer Cell 25:282-303.

Bacus SS, Chin D, Yarden Y, Zelnick CR, and Stern DF (1996) Type 1 receptor tyrosine kinases are differentially phosphorylated in mammary carcinoma and differentially associated with steroid receptors. Am J Pathol 148:549-558.

Bae JA, Kho DH, Sun EG, Ko YS, Yoon S, Lee KH, Ahn KY, Lee JH, Joo YE, Chung IJ, et al. (2016) Elevated coexpression of KITENIN and the ErbB4 CYT-2 isoform promotes the transition from colon adenoma to carcinoma following APC loss. Clin Cancer Res 22:1284-1294.

Bae JA, Yoon S, Park SY, Lee JH, Hwang JE, Kim H, Seo YW, Cha YJ, Hong SP, Kim H, et al. (2014) An unconventional KITENIN/ErbB4-mediated downstream signal of EGF upregulates c-Jun and the invasiveness of colorectal cancer cells. Clin Cancer Res 20:4115-4128.

Baiocchi G, Lopes A, Coudry RA, Rossi BM, Soares FA, Aguiar S, Guimarães GC, Ferreira FO, and Nakagawa WT (2009) ErbB family immunohistochemical expression in colorectal cancer patients with higher risk of recurrence after radical surgery. Int $J$ Colorectal Dis 24:1059-1068.

Barnes NL, Khavari S, Boland GP, Cramer A, Knox WF, and Bundred NJ (2005) Absence of HER4 expression predicts recurrence of ductal carcinoma in situ of the breast. Clin Cancer Res 11:2163-2168.

Beerli RR, Graus-Porta D, Woods-Cook K, Chen X, Yarden Y, and Hynes NE (1995) Neu differentiation factor activation of ErbB-3 and ErbB-4 is cell specific and displays a differential requirement for ErbB-2. Mol Cell Biol 15:6496-6505.

Berezowska S and Schlegel J (2011) Targeting ErbB receptors in high-grade glioma. Curr Pharm Des 17:2468-2487.

Bessman NJ, Freed DM, and Lemmon MA (2014) Putting together structures of epidermal growth factor receptors. Curr Opin Struct Biol 29:95-101.

Bièche I, Onody P, Tozlu S, Driouch K, Vidaud M, and Lidereau R (2003) Prognostic value of ERBB family mRNA expression in breast carcinomas. Int $J$ Cancer 106:758-765.

Black LE, Longo JF, and Carroll SL (2019) Mechanisms of receptor tyrosineprotein kinase ErbB-3 (ERBB3) action in human neoplasia. Am J Pathol 189:1898-1912.

Black PC and Dinney CP (2008) Growth factors and receptors as prognostic markers in urothelial carcinoma. Curr Urol Rep 9:55-61.

Blaine SA, Ray KC, Branch KM, Robinson PS, Whitehead RH, and Means AL (2009) Epidermal growth factor receptor regulates pancreatic fibrosis. Am J Physiol Gastrointest Liver Physiol 297:G434-G441.

Blobel CP, Carpenter G, and Freeman M (2009) The role of protease activity in ErbB biology. Exp Cell Res 315:671-682.

Bose R and Zhang X (2009) The ErbB kinase domain: structural perspectives into kinase activation and inhibition. Exp Cell Res 315:649-658.

Bossy-Wetzel E, Newmeyer DD, and Green DR (1998) Mitochondrial cytochrome c release in apoptosis occurs upstream of DEVD-specific caspase activation and independently of mitochondrial transmembrane depolarization. EMBO J 17:37-49.

Bouyain S, Longo PA, Li S, Ferguson KM, and Leahy DJ (2005) The extracellular region of ErbB4 adopts a tethered conformation in the absence of ligand. Proc Natl Acad Sci USA 102:15024-15029.

Bowers G, Reardon D, Hewitt T, Dent P, Mikkelsen RB, Valerie K, Lammering G, Amir C, and Schmidt-Ullrich RK (2001) The relative role of ErbB1-4 receptor tyrosine kinases in radiation signal transduction responses of human carcinoma cells. Oncogene 20:1388-1397.

Breuleux M (2007) Role of heregulin in human cancer. Cell Mol Life Sci 64:2358-2377.

Britsch S (2007) The neuregulin-I/ErbB signaling system in development and disease. Adv Anat Embryol Cell Biol 190:1-65.

Brockhoff G (2019) Target HER four in breast cancer? Oncotarget 10:3147-3150

Burgess AW (2008) EGFR family: structure physiology signalling and therapeutic targets. Growth Factors 26:263-274.

Burgess AW, Cho HS, Eigenbrot C, Ferguson KM, Garrett TP, Leahy DJ, Lemmon MA, Sliwkowski MX, Ward CW, and Yokoyama S (2003) An open-and-shut case? Recent insights into the activation of EGF/ErbB receptors. Mol Cell 12:541-552.

Burke CL and Stern DF (1998) Activation of Neu (ErbB-2) mediated by disulfide bond-induced dimerization reveals a receptor tyrosine kinase dimer interface. Mol Cell Biol 18:5371-5379.

Burness ML, Grushko TA, and Olopade OI (2010) Epidermal growth factor receptor in triple-negative and basal-like breast cancer: promising clinical target or only a marker? Cancer J 16:23-32.

Cao GD, Chen K, Xiong MM, and Chen B (2016) HER3, but not HER4, plays an essential role in the clinicopathology and prognosis of gastric cancer: a metaanalysis. PLoS One 11:e0161219.

Carpenter G (2003a) ErbB-4: mechanism of action and biology. Exp Cell Res 284:66-77.

Carpenter G (2003b) Nuclear localization and possible functions of receptor tyrosine kinases. Curr Opin Cell Biol 15:143-148.

Carraway 3rd KL (2010) E3 ubiquitin ligases in ErbB receptor quantity control. Semin Cell Dev Biol 21:936-943.

Carraway 3rd KL and Cantley LC (1994) A neu acquaintance for erbB3 and erbB4: a role for receptor heterodimerization in growth signaling. Cell 78:5-8.

Carraway 3rd KL and Sweeney C (2001) Localization and modulation of ErbB receptor tyrosine kinases. Curr Opin Cell Biol 13:125-130.

Carraway KL, Carraway CA, and Carraway 3rd KL (1997) Roles of ErbB-3 and ErbB-4 in the physiology and pathology of the mammary gland. $J$ Mammary Gland Biol Neoplasia 2:187-198.

Carrión-Salip D, Panosa C, Menendez JA, Puig T, Oliveras G, Pandiella A, De Llorens R, and Massaguer A (2012) Androgen-independent prostate cancer cells circumvent EGFR inhibition by overexpression of alternative HER receptors and ligands. Int $J$ Oncol 41:1128-1138.

Chang H, Riese 2nd DJ, Gilbert W, Stern DF, and McMahan UJ (1997) Ligands for ErbB-family receptors encoded by a neuregulin-like gene. Nature 387:509-512.

Chen K, Yang D, Li X, Sun B, Song F, Cao W, Brat DJ, Gao Z, Li H, Liang H, et al. (2015) Mutational landscape of gastric adenocarcinoma in Chinese: implications for prognosis and therapy. Proc Natl Acad Sci USA 112:1107-1112.

Cheng QC, Tikhomirov O, Zhou W, and Carpenter G (2003) Ectodomain cleavage of ErbB-4: characterization of the cleavage site and m80 fragment. J Biol Chem 278:38421-38427.

Cho HS and Leahy DJ (2002) Structure of the extracellular region of HER3 reveals an interdomain tether. Science 297:1330-1333.

Chuu CP, Chen RY, Barkinge JL, Ciaccio MF, and Jones RB (2008) Systems-level analysis of ErbB4 signaling in breast cancer: a laboratory to clinical perspective. Mol Cancer Res 6:885-891.

Citri A and Yarden Y (2006) EGF-ERBB signalling: towards the systems level. Nat Rev Mol Cell Biol 7:505-516. 
Cohen BD, Kiener PA, Green JM, Foy L, Fell HP, and Zhang K (1996) The relationship between human epidermal growth-like factor receptor expression and cellular transformation in NIH3T3 cells. J Biol Chem 271:30897-30903.

Cote GM, Miller TA, Lebrasseur NK, Kuramochi Y, and Sawyer DB (2005) Neuregulin-1alpha and beta isoform expression in cardiac microvascular endothelial cells and function in cardiac myocytes in vitro. Exp Cell Res 311:135-146.

Culouscou JM, Carlton GW, and Aruffo A (1995) HER4 receptor activation and phosphorylation of Shc proteins by recombinant heregulin-Fc fusion proteins. $J$ Biol Chem 270:12857-12863.

Dahlhoff M, Wolf E, and Schneider MR (2014) The ABC of BTC: structural properties and biological roles of betacellulin. Semin Cell Dev Biol 28:42-48.

Das PM, Thor AD, Edgerton SM, Barry SK, Chen DF, and Jones FE (2010) Reactivation of epigenetically silenced HER4/ERBB4 results in apoptosis of breast tumor cells. Oncogene 29:5214-5219.

Dawson JP, Berger MB, Lin CC, Schlessinger J, Lemmon MA, and Ferguson KM (2005) Epidermal growth factor receptor dimerization and activation require ligand-induced conformational changes in the dimer interface. Mol Cell Biol 25:7734-7742.

de Unamuno Bustos B, Murria Estal R, Pérez Simó G, de Juan Jimenez I, Escutia Muñoz B, Rodríguez Serna M, Alegre de Miquel V, Llavador Ros M, Ballester Sánchez R, Nagore Enguídanos E, et al. (2017) Towards personalized medicine in melanoma: implementation of a clinical next-generation sequencing panel. Sci Rep 7:495.

Desai MD, Saroya BS, and Lockhart AC (2013) Investigational therapies targeting the ErbB (EGFR, HER2, HER3, HER4) family in GI cancers. Expert Opin Investig Drugs 22:341-356.

Ding L, Getz G, Wheeler DA, Mardis ER, McLellan MD, Cibulskis K, Sougnez C, Greulich H, Muzny DM, Morgan MB, et al. (2008) Somatic mutations affect key pathways in lung adenocarcinoma. Nature 455:1069-1075.

Donoghue JF, Kerr LT, Alexander NW, Greenall SA, Longano AB, Gottardo NG, Wang R, Tabar V, Adams TE, Mischel PS, et al. (2018) Activation of ERBB4 in glioblastoma can contribute to increased tumorigenicity and influence therapeutic response. Cancers (Basel) 10:10.

Dunbar AJ and Goddard C (2000) Structure-function and biological role of betacellulin. Int J Biochem Cell Biol 32:805-815.

Earp 3rd HS, Calvo BF, and Sartor CI (2003) The EGF receptor family-multiple roles in proliferation, differentiation, and neoplasia with an emphasis on HER4. Trans Am Clin Climatol Assoc 114:315-333, discussion 333-334.

Easty DJ, Gray SG, O'Byrne KJ, O'Donnell D, and Bennett DC (2011) Receptor tyrosine kinases and their activation in melanoma. Pigment Cell Melanoma Res 24:446-461.

Eccles SA (2011) The epidermal growth factor receptor/Erb-B/HER family in normal and malignant breast biology. Int J Dev Biol 55:685-696.

Eckert JM, Byer SJ, Clodfelder-Miller BJ, and Carroll SL (2009) Neuregulin-1 beta and neuregulin-1 alpha differentially affect the migration and invasion of malignant peripheral nerve sheath tumor cells. Glia 57:1501-1520.

Edlich F (2015) The great migration of Bax and Bak. Mol Cell Oncol 2:e995029.

Edwards DP (2000) The role of coactivators and corepressors in the biology and mechanism of action of steroid hormone receptors. J Mammary Gland Biol Neoplasia 5:307-324.

Elenius K, Choi CJ, Paul S, Santiestevan E, Nishi E, and Klagsbrun M (1999) Characterization of a naturally occurring ErbB4 isoform that does not bind or activate phosphatidyl inositol 3-kinase. Oncogene 18:2607-2615

Elenius K, Corfas G, Paul S, Choi CJ, Rio C, Plowman GD, and Klagsbrun M (1997a) A novel juxtamembrane domain isoform of HER4/ErbB4. Isoform-specific tissue distribution and differential processing in response to phorbol ester. J Biol Chem 272:26761-26768.

Elenius K, Paul S, Allison G, Sun J, and Klagsbrun M (1997b) Activation of HER4 by heparin-binding EGF-like growth factor stimulates chemotaxis but not proliferation. EMBO J 16:1268-1278.

Engelman JA and Cantley LC (2006) The role of the ErbB family members in nonsmall cell lung cancers sensitive to epidermal growth factor receptor kinase inhibitors. Clin Cancer Res 12:4372s-4376

Farnie G, Clarke RB, Spence K, Pinnock N, Brennan K, Anderson NG, and Bundred NJ (2007) Novel cell culture technique for primary ductal carcinoma in situ: role of Notch and epidermal growth factor receptor signaling pathways. $J$ Natl Cancer Inst 99:616-627.

Feldinger K and Kong A (2015) Profile of neratinib and its potential in the treatment of breast cancer. Breast Cancer (Dove Med Press) 7:147-162.

Ferguson KM, Berger MB, Mendrola JM, Cho HS, Leahy DJ, and Lemmon MA (2003) EGF activates its receptor by removing interactions that autoinhibit ectodomain dimerization. Mol Cell 11:507-517.

Ferguson KM, Hu C, and Lemmon MA (2020) Insulin and epidermal growth factor receptor family members share parallel activation mechanisms. Protein Sci 29:1331-1344.

Fiddes RJ, Campbell DH, Janes PW, Sivertsen SP, Sasaki H, Wallasch C, and Daly RJ (1998) Analysis of Grb7 recruitment by heregulin-activated erbB receptors reveals a novel target selectivity for erbB3. J Biol Chem 273:7717-7724.

Fitzpatrick VD, Pisacane PI, Vandlen RL, and Sliwkowski MX (1998) Formation of a high affinity heregulin binding site using the soluble extracellular domains of ErbB2 with ErbB3 or ErbB4. FEBS Lett 431:102-106.

Fluge O, Akslen LA, Haugen DR, Varhaug JE, and Lillehaug JR (2000) Expression of heregulins and associations with the ErbB family of tyrosine kinase receptors in papillary thyroid carcinomas. Int $J$ Cancer 87:763-770.

Foley J, Nickerson NK, Nam S, Allen KT, Gilmore JL, Nephew KP, and Riese 2nd DJ (2010) EGFR signaling in breast cancer: bad to the bone. Semin Cell Dev Bio 21:951-960.

Forget A, Martignetti L, Puget S, Calzone L, Brabetz S, Picard D, Montagud A, Liva S, Sta A, Dingli F, et al. (2018) Aberrant ERBB4-SRC signaling as a hallmark of group 4 medulloblastoma revealed by integrative phosphoproteomic profiling. Cancer Cell 34:379-395.e7.

Freed DM, Bessman NJ, Kiyatkin A, Salazar-Cavazos E, Byrne PO, Moore JO Valley CC, Ferguson KM, Leahy DJ, Lidke DS, et al. (2017) EGFR ligands differentially stabilize receptor dimers to specify signaling kinetics. Cell 171:683-695.e18.

Frey MR, Edelblum KL, Mullane MT, Liang D, and Polk DB (2009) The ErbB4 growth factor receptor is required for colon epithelial cell survival in the presence of TNF. Gastroenterology 136:217-226.

Frey MR, Hilliard VC, Mullane MT, and Polk DB (2010) ErbB4 promotes cyclooxygenase- 2 expression and cell survival in colon epithelial cells. Lab Invest 90:1415-1424

Fujiwara S, Hung M, Yamamoto-Ibusuk CM, Yamamoto Y, Yamamoto S, Tomiguchi M, Takeshita T, Hayashi M, Sueta A, and Iwase H (2014) The localization of HER4 intracellular domain and expression of its alternately-spliced isoforms have prognostic significance in ER+ HER2- breast cancer. Oncotarget 5:3919-3930.

Gala K and Chandarlapaty S (2014) Molecular pathways: HER3 targeted therapy. Clin Cancer Res 20:1410-1416.

Gallo RM, Bryant I, Fry R, Williams EE, and Riese 2nd DJ (2006) Phosphorylation of ErbB4 on Tyr1056 is critical for inhibition of colony formation by prostate tumor cell lines. Biochem Biophys Res Commun 349:372-382.

Gallo RM, Bryant IN, Mill CP, Kaverman S, and Riese 2nd DJ (2013) Multiple functional motifs are required for the tumor suppressor activity of a constitutivelyactive ErbB4 mutant. J Cancer Res Ther Oncol 1:10

Gao J, Ulekleiv CH, and Halstensen TS (2016) Epidermal growth factor (EGF) receptor-ligand based molecular staging predicts prognosis in head and neck squamous cell carcinoma partly due to deregulated EGF- induced amphiregulin expression. J Exp Clin Cancer Res 35:151.

Garcia RA, Vasudevan K, and Buonanno A (2000) The neuregulin receptor ErbB-4 interacts with PDZ-containing proteins at neuronal synapses. Proc Natl Acad Sci USA 97:3596-3601.

Garrett TP, McKern NM, Lou M, Elleman TC, Adams TE, Lovrecz GO, Kofler M, Jorissen RN, Nice EC, Burgess AW, et al. (2003) The crystal structure of a truncated ErbB2 ectodomain reveals an active conformation, poised to interact with other ErbB receptors. Mol Cell 11:495-505.

Garrett TP, McKern NM, Lou M, Elleman TC, Adams TE, Lovrecz GO, Zhu HJ, Walker F, Frenkel MJ, Hoyne PA, et al. (2002) Crystal structure of a truncated epidermal growth factor receptor extracellular domain bound to transforming growth factor alpha. Cell 110:763-773.

Garrido C, Galluzzi L, Brunet M, Puig PE, Didelot C, and Kroemer G (2006) Mechanisms of cytochrome c release from mitochondria. Cell Death Differ 13:1423-1433.

Gassmann M, Casagranda F, Orioli D, Simon H, Lai C, Klein R, and Lemke G (1995) Aberrant neural and cardiac development in mice lacking the ErbB4 neuregulin receptor. Nature 378:390-394.

Gaulard P and de Leval L (2016) ALK-negative anaplastic large-cell lymphoma. Blood 127:175-177.

Gerber TS, Schad A, Hartmann N, Springer E, Zechner U, and Musholt TJ (2018) Targeted next-generation sequencing of cancer genes in poorly differentiated thyroid cancer. Endocr Connect 7:47-55.

Ghayad SE, Vendrell JA, Ben Larbi S, Dumontet C, Bieche I, and Cohen PA (2010) Endocrine resistance associated with activated ErbB system in breast cancer cells is reversed by inhibiting MAPK or PI3K/Akt signaling pathways. Int $J$ Cancer 126:545-562

Giam M, Huang DC, and Bouillet P (2008) BH3-only proteins and their roles in programmed cell death. Oncogene 27 (Suppl 1):S128-S136.

Gilbertson R, Hernan R, Pietsch T, Pinto L, Scotting P, Allibone R, Ellison D, Perry R, Pearson A, and Lunec J (2001) Novel ERBB4 juxtamembrane splice variants are frequently expressed in childhood medulloblastoma. Genes Chromosomes Cancer 31:288-294.

Gilbertson RJ, Bentley L, Hernan R, Junttila TT, Frank AJ, Haapasalo H, Connelly M, Wetmore C, Curran T, Elenius K, et al. (2002) ERBB receptor signaling promotes ependymoma cell proliferation and represents a potential novel therapeutic target for this disease. Clin Cancer Res 8:3054-3064.

Gilbertson RJ, Clifford SC, MacMeekin W, Meekin W, Wright C, Perry RH, Kelly P, Pearson AD, and Lunec $J$ (1998) Expression of the ErbB-neuregulin signaling network during human cerebellar development: implications for the biology of medulloblastoma. Cancer Res 58:3932-3941.

Gilbertson RJ, Perry RH, Kelly PJ, Pearson AD, and Lunec J (1997) Prognostic significance of HER2 and HER4 coexpression in childhood medulloblastoma. Cancer Res 57:3272-3280.

Gilmore JL, Gallo RM, and Riese 2nd DJ (2006) The epidermal growth factor receptor (EGFR)-S442F mutant displays increased affinity for neuregulin-2beta and agonist-independent coupling with downstream signalling events. Biochem $J$ 396:79-88.

Gilmore JL, Gonterman RM, Menon K, Lorch G, Riese 2nd DJ, Robling A, and Foley J (2009) Reconstitution of amphiregulin-epidermal growth factor receptor signaling in lung squamous cell carcinomas activates PTHrP gene expression and contributes to cancer-mediated diseases of the bone. Mol Cancer Res 7:1714-1728

Gilmore JL and Riese 2nd DJ (2004) secErbB4-26/549 antagonizes ligand-induced ErbB4 tyrosine phosphorylation. Oncol Res 14:589-602.

Gilmore JL, Scott JA, Bouizar Z, Robling A, Pitfield SE, Riese 2nd DJ, and Foley J (2008) Amphiregulin-EGFR signaling regulates PTHrP gene expression in breast cancer cells. Breast Cancer Res Treat 110:493-505.

Gilmore-Hebert M, Ramabhadran R, and Stern DF (2010) Interactions of ErbB4 and Kap1 connect the growth factor and DNA damage response pathways. Mol Cancer Res 8:1388-1398. 
Gluz O, Liedtke C, Gottschalk N, Pusztai L, Nitz U, and Harbeck N (2009) Triplenegative breast cancer-current status and future directions. Ann Oncol 20:1913-1927.

González-Cao M, Rodón J, Karachaliou N, Sánchez J, Santarpia M, Viteri S, Pilotto $\mathrm{S}$, Teixidó C, Riso A, and Rosell R (2015) Other targeted drugs in melanoma. Ann Transl Med 3:266.

Grasso AW, Wen D, Miller CM, Rhim JS, Pretlow TG, and Kung HJ (1997) ErbB kinases and NDF signaling in human prostate cancer cells. Oncogene 15:2705-2716

Graus-Porta D, Beerli RR, Daly JM, and Hynes NE (1997) ErbB-2, the preferred heterodimerization partner of all ErbB receptors, is a mediator of lateral signaling. EMBO $J$ 16:1647-1655.

Greenwald I and Kovall R (2013) Notch signaling: genetics and structure. WormBook Jan 17:1-28.

Gullick WJ and Srinivasan R (1998) The type 1 growth factor receptor family: new ligands and receptors and their role in breast cancer. Breast Cancer Res Treat 52:43-53.

Han W, Sfondouris ME, and Jones FE (2016) Direct coupling of the HER4 intracellular domain (4ICD) and STAT5A signaling is required to induce mammary epithelial cell differentiation. Biochem Biophys Rep 7:323-327.

Haryuni RD, Watabe S, Yamaguchi A, Fukushi Y, Tanaka T, Kawasaki Y, Zhou Y, Yokoyama S, and Sakurai H (2019) Negative feedback regulation of ErbB4 tyrosine kinase activity by ERK-mediated non-canonical phosphorylation. Biochem Biophys Res Commun 514:456-461.

Haugen DR, Akslen LA, Varhaug JE, and Lillehaug JR (1996) Expression of c-erbB-3 and c-erbB-4 proteins in papillary thyroid carcinomas. Cancer Res 56:1184-1188.

He XX, Ding L, Lin Y, Shu M, Wen JM, and Xue L (2015) Protein expression of HER2, 3, 4 in gastric cancer: correlation with clinical features and survival. $J$ Clin Pathol 68:374-380.

Hedegger K, Algül H, Lesina M, Blutke A, Schmid RM, Schneider MR, and Dahlhoff M (2020) Unraveling ERBB network dynamics upon betacellulin signaling in pancreatic ductal adenocarcinoma in mice. Mol Oncol 14:1653-1669.

Heery DM, Kalkhoven E, Hoare S, and Parker MG (1997) A signature motif in transcriptional co-activators mediates binding to nuclear receptors. Nature 387:733-736.

Hobbs SS, Cameron EM, Hammer RP, Le AT, Gallo RM, Blommel EN, Coffing SL, Chang H, and Riese 2nd DJ (2004) Five carboxyl-terminal residues of neuregulin2 are critical for stimulation of signaling by the ErbB4 receptor tyrosine kinase. Oncogene 23:883-893.

Hobbs SS, Coffing SL, Le AT, Cameron EM, Williams EE, Andrew M, Blommel EN, Hammer RP, Chang H, and Riese 2nd DJ (2002) Neuregulin isoforms exhibit distinct patterns of ErbB family receptor activation. Oncogene 21:8442-8452.

Hoeing K, Zscheppang K, Mujahid S, Murray S, Volpe MV, Dammann CE, and Nielsen HC (2011) Presenilin-1 processing of ErbB4 in fetal type II cells is necessary for control of fetal lung maturation. Biochim Biophys Acta 1813:480-491.

Holbro T and Hynes NE (2004) ErbB receptors: directing key signaling networks throughout life. Annu Rev Pharmacol Toxicol 44:195-217.

Hollmén M and Elenius K (2010) Potential of ErbB4 antibodies for cancer therapy. Future Oncol 6:37-53.

Huang YZ, Wang Q, Won S, Luo ZG, Xiong WC, and Mei L (2002) Compartmentalized NRG signaling and PDZ domain-containing proteins in synapse structure and function. Int $J$ Dev Neurosci 20:173-185.

Huang YZ, Won S, Ali DW, Wang Q, Tanowitz M, Du QS, Pelkey KA, Yang DJ, Xiong WC, Salter MW, et al. (2000) Regulation of neuregulin signaling by PSD95 interacting with ErbB4 at CNS synapses. Neuron 26:443-455.

Hughes DP, Thomas DG, Giordano TJ, Baker LH, and McDonagh KT (2004) Cell surface expression of epidermal growth factor receptor and Her-2 with nuclear expression of Her-4 in primary osteosarcoma. Cancer Res 64:2047-2053.

Hughes DP, Thomas DG, Giordano TJ, McDonagh KT, and Baker LH (2006) Essential erbB family phosphorylation in osteosarcoma as a target for CI-1033 inhibition. Pediatr Blood Cancer 46:614-623.

Hynes NE, Horsch K, Olayioye MA, and Badache A (2001) The ErbB receptor tyrosine family as signal integrators. Endocr Relat Cancer 8:151-159.

Hynes NE and Lane HA (2005) ERBB receptors and cancer: the complexity of targeted inhibitors. Nat Rev Cancer 5:341-354.

Hynes NE and Schlange T (2006) Targeting ADAMS and ERBBs in lung cancer. Cancer Cell 10:7-11.

Hynes NE and Stern DF (1994) The biology of erbB-2/neu/HER-2 and its role in cancer. Biochim Biophys Acta 1198:165-184.

Ishibashi K, Fukumoto Y, Hasegawa H, Abe K, Kubota S, Aoyama K, Kubota S, Nakayama Y, and Yamaguchi N (2013) Nuclear ErbB4 signaling through H3K9me3 is antagonized by EGFR-activated c-Src. J Cell Sci 126:625-637.

Ito Y, Takeda T, Sakon M, Tsujimoto M, Higashiyama S, Noda K, Miyoshi E, Monden M, and Matsuura N (2001a) Expression and clinical significance of erb-B receptor family in hepatocellular carcinoma. Br J Cancer 84:1377-1383.

Ito Y, Takeda T, Sasaki Y, Sakon M, Yamada T, Ishiguro S, Imaoka S, Tsujimoto M, Higashiyama S, Monden M, et al. (2001b) Expression and clinical significance of the erbB family in intrahepatic cholangiocellular carcinoma. Pathol Res Pract 197:95-100.

Jansen SM, Sleumer LS, Damen E, Meijer IM, van Zoelen EJ, and van Leeuwen JE (2009) ErbB2 and ErbB4 Cbl binding sites can functionally replace the ErbB1 Cbl binding site. Cell Signal 21:810-818.

Jeffrey PD, Russo AA, Polyak K, Gibbs E, Hurwitz J, Massagué J, and Pavletich NP (1995) Mechanism of CDK activation revealed by the structure of a cyclinACDK2 complex. Nature 376:313-320.

Jones DC, Scanteianu A, DiStefano M, Bouhaddou M, and Birtwistle MR (2018) Analysis of copy number loss of the ErbB4 receptor tyrosine kinase in glioblastoma. PLoS One 13:e0190664.
Jones FE (2008) HER4 intracellular domain (4ICD) activity in the developing mammary gland and breast cancer. J Mammary Gland Biol Neoplasia 13:247-258.

Jones FE, Welte T, Fu XY, and Stern DF (1999) ErbB4 signaling in the mammary gland is required for lobuloalveolar development and Stat5 activation during lactation. J Cell Biol 147:77-88.

Jones RB, Gordus A, Krall JA, and MacBeath G (2006) A quantitative protein interaction network for the ErbB receptors using protein microarrays. Nature 439:168-174

Jordan EJ, Patil K, Suresh K, Park JH, Mosse YP, Lemmon MA, and Radhakrishnan $\mathrm{R}$ (2019) Computational algorithms for in silico profiling of activating mutations in cancer. Cell Mol Life Sci 76:2663-2679.

Joslin EJ, Opresko LK, Wells A, Wiley HS, and Lauffenburger DA (2007) EGFreceptor-mediated mammary epithelial cell migration is driven by sustained ERK signaling from autocrine stimulation. J Cell Sci 120:3688-3699.

Junttila TT, Sundvall M, Lundin M, Lundin J, Tanner M, Härkönen P, Joensuu H, Isola J, and Elenius K (2005) Cleavable ErbB4 isoform in estrogen receptorregulated growth of breast cancer cells. Cancer Res 65:1384-1393.

Kainulainen V, Sundvall M, Määttä JA, Santiestevan E, Klagsbrun M, and Elenius K (2000) A natural ErbB4 isoform that does not activate phosphoinositide 3-kinase mediates proliferation but not survival or chemotaxis. $J$ Biol Chem 275:8641-8649.

Kalyankrishna S and Grandis JR (2006) Epidermal growth factor receptor biology in head and neck cancer. $J$ Clin Oncol 24:2666-2672.

Karamouzis MV, Badra FA, and Papavassiliou AG (2007) Breast cancer: the upgraded role of HER-3 and HER-4. Int J Biochem Cell Biol 39:851-856.

Karunagaran D, Tzahar E, Beerli RR, Chen X, Graus-Porta D, Ratzkin BJ, Seger R, Hynes NE, and Yarden Y (1996) ErbB-2 is a common auxiliary subunit of NDF and EGF receptors: implications for breast cancer. EMBO J 15:254-264

Kassouf W, Black PC, Tuziak T, Bondaruk J, Lee S, Brown GA, Adam L, Wei C, Baggerly K, Bar-Eli M, et al. (2008) Distinctive expression pattern of ErbB family receptors signifies an aggressive variant of bladder cancer. $J$ Urol 179:353-358.

Kato S, Kobayashi T, Yamada K, Nishii K, Sawada H, Ishiguro H, Itoh M, Funahashi H, and Nagasaka A (2004) Expression of erbB receptors mRNA in thyroid tissues. Biochim Biophys Acta 1673:194-200.

Kaushansky A, Gordus A, Budnik BA, Lane WS, Rush J, and MacBeath G (2008) System-wide investigation of ErbB4 reveals 19 sites of Tyr phosphorylation that are unusually selective in their recruitment properties. Chem Biol 15:808-817.

Kawaguchi M, Hosotani R, Kogire M, Ida J, Doi R, Koshiba T, Miyamoto Y, Tsuji S, Nakajima S, Kobayashi H, et al. (2000) Auto-induction and growth stimulatory effect of betacellulin in human pancreatic cancer cells. Int J Oncol 16:37-41.

Kennedy SP, Hastings JF, Han JZ, and Croucher DR (2016) The under-appreciated promiscuity of the epidermal growth factor receptor family. Front Cell Dev Biol 4:88

Kenny PA and Bissell MJ (2007) Targeting TACE-dependent EGFR ligand shedding in breast cancer. $J$ Clin Invest 117:337-345.

Khanal S, Strickley JD, Ha T, Demehri S, Ghim SJ, Jenson AB, Redman RA, and Joh JJ (2020) Human papillomavirus-positivity is associated with EREG downregulation and promoter hypermethylation in head and neck squamous cell carcinoma. Exp Mol Pathol 117:104549.

Khelwatty SA, Essapen S, Seddon AM, and Modjtahedi H (2013) Prognostic significance and targeting of HER family in colorectal cancer. Front Biosci 18:394-421.

Kim JY, Jung HH, Do IG, Bae S, Lee SK, Kim SW, Lee JE, Nam SJ, Ahn JS, Park $\mathrm{YH}$, et al. (2016) Prognostic value of ERBB4 expression in patients with triple negative breast cancer. BMC Cancer 16:138.

Kinney MA, Vo LT, Frame JM, Barragan J, Conway AJ, Li S, Wong KK, Collins JJ, Cahan P, North TE, et al. (2019a) Author correction: a systems biology pipeline identifies regulatory networks for stem cell engineering. Nat Biotechnol 37:962.

Kinney MA, Vo LT, Frame JM, Barragan J, Conway AJ, Li S, Wong KK, Collins JJ, Cahan P, North TE, et al. (2019b) A systems biology pipeline identifies regulatory networks for stem cell engineering. Nat Biotechnol 37:810-818.

Kiuchi T, Ortiz-Zapater E, Monypenny J, Matthews DR, Nguyen LK, Barbeau J, Coban O, Lawler K, Burford B, Rolfe DJ, et al. (2014) The ErbB4 CYT2 variant protects EGFR from ligand-induced degradation to enhance cancer cell motility Sci Signal 7:ra78.

Klijn JG, Berns PM, Schmitz PI, and Foekens JA (1992) The clinical significance of epidermal growth factor receptor (EGF-R) in human breast cancer: a review on 5232 patients. Endocr Rev 13:3-17.

Knowlden JM, Gee JM, Seery LT, Farrow L, Gullick WJ, Ellis IO, Blamey RW, Robertson JF, and Nicholson RI (1998) c-erbB3 and c-erbB4 expression is a feature of the endocrine responsive phenotype in clinical breast cancer. Oncogene 17:1949-1957.

Komurasaki T, Toyoda H, Uchida D, and Nemoto N (2002) Mechanism of growth promoting activity of epiregulin in primary cultures of rat hepatocytes. Growth Factors 20:61-69.

Komuro A, Nagai M, Navin NE, and Sudol M (2003) WW domain-containing protein YAP associates with ErbB-4 and acts as a co-transcriptional activator for the carboxyl-terminal fragment of ErbB-4 that translocates to the nucleus. J Biol Chem 278:33334-33341.

Kountourakis P, Pavlakis K, Psyrri A, Rontogianni D, Xiros N, Patsouris E, Pectasides D, and Economopoulos T (2006) Prognostic significance of HER3 and HER4 protein expression in colorectal adenocarcinomas. BMC Cancer 6:46.

Kourie HR, El Rassy E, Clatot F, de Azambuja E, and Lambertini M (2017) Emerging treatments for HER2-positive early-stage breast cancer: focus on neratinib. OncoTargets Ther 10:3363-3372.

Koutras AK, Fountzilas G, Kalogeras KT, Starakis I, Iconomou G, and Kalofonos HP (2010) The upgraded role of HER3 and HER4 receptors in breast cancer. Crit Rev Oncol Hematol 74:73-78. 
Koutras AK, Kalogeras KT, Dimopoulos MA, Wirtz RM, Dafni U, Briasoulis E, Pectasides D, Gogas H, Christodoulou C, Aravantinos G, et al.; Hellenic Cooperative Oncology Group (HeCOG) (2008) Evaluation of the prognostic and predictive value of HER family mRNA expression in high-risk early breast cancer: a Hellenic Cooperative Oncology Group (HeCOG) study. $\mathrm{Br} J$ Cancer 99:1775-1785.

Kovacs E, Das R, Wang Q, Collier TS, Cantor A, Huang Y, Wong K, Mirza A, Barros T, Grob P, et al. (2015) Analysis of the role of the C-terminal tail in the regulation of the epidermal growth factor receptor. Mol Cell Biol 35:3083-3102.

Krishnamurthy S, Poornima R, Challa VR, and Goud YG (2012) Triple negative breast cancer - our experience and review. Indian J Surg Oncol 3:12-16.

Kunz M (2013) New developments in dermatological oncogenetics. J Dtsch Dermatol Ges 11:831-836.

Kunz M (2014) Oncogenes in melanoma: an update. Eur J Cell Biol 93:1-10.

Kunz M (2015) The genetic basis of new treatment modalities in melanoma. Curr Drug Targets 16:233-248.

Kurppa K and Elenius K (2009) Mutated ERBB4: a novel drug target in metastatic melanoma? Pigment Cell Melanoma Res 22:708-710.

Kurppa KJ, Denessiouk K, Johnson MS, and Elenius K (2016) Activating ERBB4 mutations in non-small cell lung cancer. Oncogene 35:1283-1291.

Kuwana T, Mackey MR, Perkins G, Ellisman MH, Latterich M, Schneiter R, Green DR, and Newmeyer DD (2002) Bid, Bax, and lipids cooperate to form supramolecular openings in the outer mitochondrial membrane. Cell 111:331-342.

Lafky JM, Wilken JA, Baron AT, and Maihle NJ (2008) Clinical implications of the ErbB/epidermal growth factor (EGF) receptor family and its ligands in ovarian cancer. Biochim Biophys Acta 1785:232-265.

Landau M, Fleishman SJ, and Ben-Tal N (2004) A putative mechanism for downregulation of the catalytic activity of the EGF receptor via direct contact between its kinase and C-terminal domains. Structure 12:2265-2275.

Lee D, Yu M, Lee E, Kim H, Yang Y, Kim K, Pannicia C, Kurie JM, and Threadgill DW (2009) Tumor-specific apoptosis caused by deletion of the ERBB3 pseudokinase in mouse intestinal epithelium. J Clin Invest 119:2702-2713.

Lee HJ, Jung KM, Huang YZ, Bennett LB, Lee JS, Mei L, and Kim TW (2002a) Presenilin-dependent gamma-secretase-like intramembrane cleavage of ErbB4. $J$ Biol Chem 277:6318-6323.

Lee JC, Wang ST, Chow NH, and Yang HB (2002b) Investigation of the prognostic value of coexpressed erbB family members for the survival of colorectal cancer patients after curative surgery. Eur J Cancer 38:1065-1071.

Lee TY, Kim KT, and Han SY (2007) Expression of ErbB receptor proteins and TGF-alpha during diethylnitrosamine-induced hepatocarcinogenesis in the rat liver. Korean J Hepatol 13:70-80.

Lemmon MA (2009) Ligand-induced ErbB receptor dimerization. Exp Cell Res 315:638-648.

Lemmon MA, Bu Z, Ladbury JE, Zhou M, Pinchasi D, Lax I, Engelman DM, and Schlessinger J (1997) Two EGF molecules contribute additively to stabilization of the EGFR dimer. EMBO J 16:281-294.

Lemmon MA, Freed DM, Schlessinger J, and Kiyatkin A (2016) The dark side of cell signaling: positive roles for negative regulators. Cell 164:1172-1184.

Lemmon MA and Schlessinger J (2010) Cell signaling by receptor tyrosine kinases. Cell 141:1117-1134.

Lemmon MA, Schlessinger J, and Ferguson KM (2014) The EGFR family: not so prototypical receptor tyrosine kinases. Cold Spring Harb Perspect Biol 6:a020768.

Letai A, Bassik MC, Walensky LD, Sorcinelli MD, Weiler S, and Korsmeyer SJ (2002) Distinct BH3 domains either sensitize or activate mitochondrial apoptosis, serving as prototype cancer therapeutics. Cancer Cell 2:183-192.

Levkowitz G, Waterman H, Zamir E, Kam Z, Oved S, Langdon WY, Beguinot L, Geiger B, and Yarden Y (1998) c-Cbl/Sli-1 regulates endocytic sorting and ubiquitination of the epidermal growth factor receptor. Genes Dev 12:3663-3674.

$\mathrm{Li}$ J, Liu J, Ren Y, and Liu P (2015) Roles of the WWOX in pathogenesis and endocrine therapy of breast cancer. Exp Biol Med (Maywood) 240:324-328.

Li L, Seno M, Yamada H, and Kojima I (2003) Betacellulin improves glucose metabolism by promoting conversion of intraislet precursor cells to beta-cells in streptozotocin-treated mice. Am J Physiol Endocrinol Metab 285:E577-E583.

Li Y, Zhou Z, Alimandi M, and Chen C (2009) WW domain containing E3 ubiquitin protein ligase 1 targets the full-length ErbB4 for ubiquitin-mediated degradation in breast cancer. Oncogene 28:2948-2958.

Lindet C, Révillion F, Lhotellier V, Hornez L, Peyrat JP, and Bonneterre J (2012) Relationships between progesterone receptor isoforms and the HER/ErbB receptors and ligands network in 299 primary breast cancers. Int J Biol Markers 27:e111-e117.

Linggi B and Carpenter G (2006) ErbB-4 s80 intracellular domain abrogates ETO2dependent transcriptional repression. J Biol Chem 281:25373-25380.

Linggi B, Cheng QC, Rao AR, and Carpenter G (2006) The ErbB-4 s80 intracellular domain is a constitutively active tyrosine kinase. Oncogene 25:160-163.

Liu W, Purevdorj E, Zscheppang K, von Mayersbach D, Behrens J, Brinkhaus M.J, Nielsen HC, Schmiedl A, and Dammann CE (2010) ErbB4 regulates the timely progression of late fetal lung development. Biochim Biophys Acta 1803:832-839.

Liu Y, Song L, Ni H, Sun L, Jiao W, Chen L, Zhou Q, Shen T, Cui H, Gao T, et al. (2017) ERBB4 acts as a suppressor in the development of hepatocellular carcinoma. Carcinogenesis 38:465-473.

Ljuslinder I, Malmer B, Isaksson-Mettävainio M, Oberg A, Henriksson R, Stenling $\mathrm{R}$, and Palmqvist R (2009) ErbB 1-4 expression alterations in primary colorectal cancers and their corresponding metastases. Anticancer Res 29:1489-1494.

Lodge AJ, Anderson JJ, Gullick WJ, Haugk B, Leonard RC, and Angus B (2003) Type 1 growth factor receptor expression in node positive breast cancer: adverse prognostic significance of c-erbB-4. J Clin Pathol 56:300-304

Long W, Wagner KU, Lloyd KC, Binart N, Shillingford JM, Hennighausen L, and Jones FE (2003) Impaired differentiation and lactational failure of Erbb4deficient mammary glands identify ERBB4 as an obligate mediator of STAT5. Development 130:5257-5268.
Lupu R, Cardillo M, Harris L, Hijazi M, and Rosenberg K (1995) Interaction between erbB-receptors and heregulin in breast cancer tumor progression and drug resistance. Semin Cancer Biol 6:135-145.

Lupu R, Dickson RB, and Lippman ME (1992) The role of erbB-2 and its ligands in growth control of malignant breast epithelium. J Steroid Biochem Mol Biol 43:229-236.

Lyu H, Han A, Polsdofer E, Liu S, and Liu B (2018) Understanding the biology of HER3 receptor as a therapeutic target in human cancer. Acta Pharm Sin B 8:503-510.

Ma J, Lyu H, Huang J, and Liu B (2014) Targeting of erbB3 receptor to overcome resistance in cancer treatment. Mol Cancer 13:105.

Määttä JA, Sundvall M, Junttila TT, Peri L, Laine VJ, Isola J, Egeblad M, and Elenius K (2006) Proteolytic cleavage and phosphorylation of a tumor-associated ErbB4 isoform promote ligand-independent survival and cancer cell growth. Mol Biol Cell 17:67-79.

Macdonald-Obermann JL and Pike LJ (2014) Different epidermal growth factor (EGF) receptor ligands show distinct kinetics and biased or partial agonism for homodimer and heterodimer formation. J Biol Chem 289:26178-26188.

Maennling AE, Tur MK, Niebert M, Klockenbring T, Zeppernick F, Gattenlöhner S, Meinhold-Heerlein I, and Hussain AF (2019) Molecular targeting therapy against EGFR family in breast cancer: progress and future potentials. Cancers (Basel) 11:11.

Manca A, Lissia A, Cossu A, Rubino C, Ascierto PA, Stanganelli I, and Palmieri G (2013) Mutations in ERBB4 may have a minor role in melanoma pathogenesis. $J$ Invest Dermatol 133:1685-1687.

Mashima H, Ohnishi H, Wakabayashi K, Mine T, Miyagawa J, Hanafusa T, Seno M, Yamada H, and Kojima I (1996) Betacellulin and activin A coordinately convert amylase-secreting pancreatic AR42J cells into insulin-secreting cells. $J$ Clin Invest 97:1647-1654.

McGowan PM, Mullooly M, Caiazza F, Sukor S, Madden SF, Maguire AA, Pierce A McDermott EW, Crown J, O'Donovan N, et al. (2013) ADAM-17: a novel therapeutic target for triple negative breast cancer. Ann Oncol 24:362-369.

Mei L and Xiong WC (2008) Neuregulin 1 in neural development, synaptic plasticity and schizophrenia. Nat Rev Neurosci 9:437-452.

Memon AA, Sorensen BS, Meldgaard P, Fokdal L, Thykjaer T, and Nexo E (2006) The relation between survival and expression of HER1 and HER2 depends on the expression of HER3 and HER4: a study in bladder cancer patients. $\mathrm{Br} J$ Cancer 94:1703-1709.

Memon AA, Sorensen BS, Melgard P, Fokdal L, Thykjaer T, and Nexo E (2004) Expression of HER3, HER4 and their ligand heregulin-4 is associated with better survival in bladder cancer patients. Br J Cancer 91:2034-2041.

Mill CP, Gettinger KL, and Riese 2nd DJ (2011a) Ligand stimulation of ErbB4 and a constitutively-active ErbB4 mutant result in different biological responses in human pancreatic tumor cell lines. Exp Cell Res 317:392-404.

Mill CP, Zordan MD, Rothenberg SM, Settleman J, Leary JF, and Riese 2nd DJ (2011b) ErbB2 is necessary for ErbB4 ligands to stimulate oncogenic activities in models of human breast cancer. Genes Cancer 2:792-804.

Miller MA, Sullivan RJ, and Lauffenburger DA (2017) Molecular pathways: receptor ectodomain shedding in treatment, resistance, and monitoring of cancer. Clin Cancer Res 23:623-629.

Mishra R, Hanker AB, and Garrett JT (2017) Genomic alterations of ERBB receptors in cancer: clinical implications. Oncotarget 8:114371-114392

Mitsui K, Yonezawa M, Tatsuguchi A, Shinji S, Gudis K, Tanaka S, Fujimori S, and Sakamoto C (2014) Localization of phosphorylated ErbB1-4 and heregulin in colorectal cancer. BMC Cancer 14:863.

Modjtahedi H, Cho BC, Michel MC, and Solca F (2014) A comprehensive review of the preclinical efficacy profile of the ErbB family blocker afatinib in cancer. Naunyn Schmiedebergs Arch Pharmacol 387:505-521.

Mota JM, Collier KA, Barros Costa RL, Taxter T, Kalyan A, Leite CA, Chae YK, Giles FJ, and Carneiro BA (2017) A comprehensive review of heregulins, HER3, and HER4 as potential therapeutic targets in cancer. Oncotarget 8:89284-89306.

Muraoka-Cook RS, Caskey LS, Sandahl MA, Hunter DM, Husted C, Strunk KE, Sartor CI, Rearick Jr WA, McCall W, Sgagias MK, et al. (2006) Heregulindependent delay in mitotic progression requires HER4 and BRCA1. Mol Cell Biol 26:6412-6424.

Muraoka-Cook RS, Feng SM, Strunk KE, and Earp 3rd HS (2008) ErbB4/HER4 role in mammary gland development, differentiation and growth inhibition. $J$ Mammary Gland Biol Neoplasia 13:235-246.

Muraoka-Cook RS, Sandahl MA, Strunk KE, Miraglia LC, Husted C, Hunter DM, Elenius K, Chodosh LA, and Earp 3rd HS (2009) ErbB4 splice variants Cyt1 and Cyt2 differ by 16 amino acids and exert opposing effects on the mammary epithelium in vivo. Mol Cell Biol 29:4935-4948.

Muthuswamy SK, Gilman M, and Brugge JS (1999) Controlled dimerization of ErbB receptors provides evidence for differential signaling by homo- and heterodimers. Mol Cell Biol 19:6845-6857.

Naresh A, Long W, Vidal GA, Wimley WC, Marrero L, Sartor CI, Tovey S, Cooke TG, Bartlett JM, and Jones FE (2006) The ERBB4/HER4 intracellular domain 4ICD is a BH3-only protein promoting apoptosis of breast cancer cells. Cancer Res 66:6412-6420.

Naresh A, Thor AD, Edgerton SM, Torkko KC, Kumar R, and Jones FE (2008) The HER4/4ICD estrogen receptor coactivator and BH3-only protein is an effector of tamoxifen-induced apoptosis. Cancer Res 68:6387-6395.

Ni CY, Murphy MP, Golde TE, and Carpenter G (2001) gamma -Secretase cleavage and nuclear localization of ErbB-4 receptor tyrosine kinase. Science 294:2179-2181. Ni CY, Yuan H, and Carpenter G (2003) Role of the ErbB-4 carboxyl terminus in gamma-secretase cleavage. J Biol Chem 278:4561-4565.

Nicholas MK, Lukas RV, Jafri NF, Faoro L, and Salgia R (2006) Epidermal growth factor receptor - mediated signal transduction in the development and therapy of gliomas. Clin Cancer Res 12:7261-7270. 
Nicholson BE, Frierson HF, Conaway MR, Seraj JM, Harding MA, Hampton GM, and Theodorescu D (2004) Profiling the evolution of human metastatic bladder cancer. Cancer Res 64:7813-7821.

Nie FR, Li QX, Wei HF, and Ma Y (2020) miR-326 inhibits the progression of papillary thyroid carcinoma by targeting MAPK1 and ERBB4. Neoplasma 67:604-613.

Northcott PA, Jones DT, Kool M, Robinson GW, Gilbertson RJ, Cho YJ, Pomeroy SL, Korshunov A, Lichter P, Taylor MD, et al. (2012) Medulloblastomics: the end of the beginning. Nat Rev Cancer 12:818-834.

Olayioye MA, Beuvink I, Horsch K, Daly JM, and Hynes NE (1999) ErbB receptorinduced activation of stat transcription factors is mediated by Src tyrosine kinases. J Biol Chem 274:17209-17218.

Olayioye MA, Graus-Porta D, Beerli RR, Rohrer J, Gay B, and Hynes NE (1998) ErbB-1 and ErbB-2 acquire distinct signaling properties dependent upon their dimerization partner. Mol Cell Biol 18:5042-5051.

Olayioye MA, Neve RM, Lane HA, and Hynes NE (2000) The ErbB signaling network: receptor heterodimerization in development and cancer. $E M B O \mathrm{~J}$ 19:3159-3167.

Olsen DA, Bechmann T, łstergaard B, Wamberg PA, Jakobsen EH, and Brandslund I (2012) Increased concentrations of growth factors and activation of the EGFR system in breast cancer. Clin Chem Lab Med 50:1809-1818.

Omerovic J, Puggioni EM, Napoletano S, Visco V, Fraioli R, Frati L, Gulino A, and Alimandi M (2004) Ligand-regulated association of ErbB-4 to the transcriptional co-activator YAP65 controls transcription at the nuclear level. Exp Cell Res 294:469-479.

Omerovic J, Santangelo L, Puggioni EM, Marrocco J, Dall'Armi C, Palumbo C, Belleudi F, Di Marcotullio L, Frati L, Torrisi MR, et al. (2007) The E3 ligase Aip4/ Itch ubiquitinates and targets ErbB-4 for degradation. FASEB $J$ 21:2849-2862.

Ota I, Higashiyama S, Masui T, Yane K, Hosoi H, and Matsuura N (2013) Heparinbinding EGF-like growth factor enhances the activity of invasion and metastasis in thyroid cancer cells. Oncol Rep 30:1593-1600.

Ozcan F, Klein P, Lemmon MA, Lax I, and Schlessinger J (2006) On the nature of low- and high-affinity EGF receptors on living cells. Proc Natl Acad Sci USA 103:5735-5740.

Paatero I and Elenius K (2008) ErbB4 and its isoforms: patentable drug targets? Recent Pat DNA Gene Seq 2:27-33.

Paatero I, Lassus H, Junttila TT, Kaskinen M, Bützow R, and Elenius K (2013) CYT-1 isoform of ErbB4 is an independent prognostic factor in serous ovarian cancer and selectively promotes ovarian cancer cell growth in vitro. Gynecol Oncol 129:179-187.

Parsons DW, Wang TL, Samuels Y, Bardelli A, Cummins JM, DeLong L, Silliman N, Ptak J, Szabo S, Willson JK, et al. (2005) Colorectal cancer: mutations in a signalling pathway. Nature 436:792.

Pawlowski V, Révillion F, Hebbar M, Hornez L, and Peyrat JP (2000) Prognostic value of the type I growth factor receptors in a large series of human primary breast cancers quantified with a real-time reverse transcription-polymerase chain reaction assay. Clin Cancer Res 6:4217-4225.

Pellat A, Vaquero J, and Fouassier L (2018) Role of ErbB/HER family of receptor tyrosine kinases in cholangiocyte biology. Hepatology 67:762-773.

Penington DJ, Bryant I, and Riese 2nd DJ (2002) Constitutively active ErbB4 and ErbB2 mutants exhibit distinct biological activities. Cell Growth Differ 13:247-256.

Pinkas-Kramarski R, Lenferink AE, Bacus SS, Lyass L, van de Poll ML, Klapper LN, Tzahar E, Sela M, van Zoelen EJ, and Yarden Y (1998a) The oncogenic ErbB-2/ErbB-3 heterodimer is a surrogate receptor of the epidermal growth factor and betacellulin. Oncogene 16:1249-1258.

Pinkas-Kramarski R, Shelly M, Guarino BC, Wang LM, Lyass L, Alroy I, Alimandi M, Kuo A, Moyer JD, Lavi S, et al. (1998b) ErbB tyrosine kinases and the two neuregulin families constitute a ligand-receptor network. Mol Cell Biol 18:6090-6101.

Pitfield SE, Bryant I, Penington DJ, Park G, and Riese 2nd DJ (2006) Phosphorylation of ErbB4 on tyrosine 1056 is critical for ErbB4 coupling to inhibition of colony formation by human mammary cell lines. Oncol Res 16:179-193.

Pospiech K, Płuciennik E, and Bednarek AK (2018) WWOX tumor suppressor gene in breast cancer, a historical perspective and future directions. Front Oncol 8:345.

Prickett TD, Agrawal NS, Wei X, Yates KE, Lin JC, Wunderlich JR, Cronin JC, Cruz P, Rosenberg SA, and Samuels Y (2009) Analysis of the tyrosine kinome in melanoma reveals recurrent mutations in ERBB4. Nat Genet 41:1127-1132.

Puricelli L, Proietti CJ, Labriola L, Salatino M, Balañá ME, Aguirre Ghiso J, Lupu R, Pignataro OP, Charreau EH, Bal de Kier Joffé E, et al. (2002) Heregulin inhibits proliferation via ERKs and phosphatidyl-inositol 3-kinase activation but regulates urokinase plasminogen activator independently of these pathways in metastatic mammary tumor cells. Int $J$ Cancer 100:642-653.

Qiu C, Tarrant MK, Choi SH, Sathyamurthy A, Bose R, Banjade S, Pal A, Bornmann WG, Lemmon MA, Cole PA, et al. (2008) Mechanism of activation and inhibition of the HER4/ErbB4 kinase. Structure 16:460-467.

Qu Y, Dang S, and Hou P (2013) Gene methylation in gastric cancer. Clin Chim Acta 424:53-65.

Rahmann EP and Gilbertson RJ (2018) Multiomic Medulloblastomas. Cancer Cell 34:351-353.

Rauf F, Festa F, Park JG, Magee M, Eaton S, Rinaldi C, Betanzos CM, GonzalezMalerva L, and LaBaer J (2018) Ibrutinib inhibition of ERBB4 reduces cell growth in a WNT5A-dependent manner. Oncogene 37:2237-2250.

Rickert CH (2004) Prognosis-related molecular markers in pediatric central nervous system tumors. J Neuropathol Exp Neurol 63:1211-1224.

Rickert CH and Paulus W (2005) Prognosis-related histomorphological and immunohistochemical markers in central nervous system tumors of childhood and adolescence. Acta Neuropathol 109:69-92.

Riese 2nd DJ, Bermingham Y, van Raaij TM, Buckley S, Plowman GD, and Stern DF (1996a) Betacellulin activates the epidermal growth factor receptor and erbB-4, and induces cellular response patterns distinct from those stimulated by epidermal growth factor or neuregulin-beta. Oncogene 12:345-353.
Riese 2nd DJ and Cullum RL (2014) Epiregulin: roles in normal physiology and cancer Semin Cell Dev Biol 28:49-56.

Riese 2nd DJ, Gallo RM, and Settleman J (2007) Mutational activation of ErbB family receptor tyrosine kinases: insights into mechanisms of signal transduction and tumorigenesis. BioEssays 29:558-565.

Riese 2nd DJ, Komurasaki T, Plowman GD, and Stern DF (1998) Activation of ErbB4 by the bifunctional epidermal growth factor family hormone epiregulin is regulated by ErbB2. J Biol Chem 273:11288-11294.

Riese 2nd DJ and Stern DF (1998) Specificity within the EGF family/ErbB receptor family signaling network. BioEssays 20:41-48.

Riese 2nd DJ, van Raaij TM, Plowman GD, Andrews GC, and Stern DF (1995) The cellular response to neuregulins is governed by complex interactions of the erbB receptor family. Mol Cell Biol 15:5770-5776.

Riese DJ, Kim ED, Elenius K, Buckley S, Klagsbrun M, Plowman GD, and Stern DF (1996b) The epidermal growth factor receptor couples transforming growth factoralpha, heparin-binding epidermal growth factor-like factor, and amphiregulin to Neu, ErbB-3, and ErbB-4. J Biol Chem 271:20047-20052.

Rio C, Buxbaum JD, Peschon JJ, and Corfas G (2000) Tumor necrosis factoralpha-converting enzyme is required for cleavage of erbB4/HER4. J Biol Chem 275:10379-10387.

Roepstorff K, Grandal MV, Henriksen L, Knudsen SL, Lerdrup M, Grøvdal L, Willumsen BM, and van Deurs B (2009) Differential effects of EGFR ligands on endocytic sorting of the receptor. Traffic 10:1115-1127.

Roepstorff K, Grøvdal L, Grandal M, Lerdrup M, and van Deurs B (2008) Endocytic downregulation of ErbB receptors: mechanisms and relevance in cancer. Histochem Cell Biol 129:563-578.

Rokicki J, Das PM, Giltnane JM, Wansbury O, Rimm DL, Howard BA, and Jones FE (2010) The ERalpha coactivator, HER4/4ICD, regulates progesterone receptor expression in normal and malignant breast epithelium. Mol Cancer 9:150.

Roskoski Jr R (2004) The ErbB/HER receptor protein-tyrosine kinases and cancer Biochem Biophys Res Commun 319:1-11.

Roskoski Jr R (2014) The ErbB/HER family of protein-tyrosine kinases and cancer. Pharmacol Res 79:34-74.

Røtterud R, Fosså SD, and Nesland JM (2007) Protein networking in bladder cancer: immunoreactivity for FGFR3, EGFR, ERBB2, KAI1, PTEN, and RAS in normal and malignant urothelium. Histol Histopathol 22:349-363.

Rudloff UNCT01264081 - Lapatinib in stage IV melanoma with ERBB4 mutations. https://ClinicalTrialsgov/show/NCT01264081 NCT01264081.

Rudloff U and Samuels Y (2010) A growing family: adding mutated Erbb4 as a novel cancer target. Cell Cycle 9:1487-1503.

Rusnak DW, Lackey K, Affleck K, Wood ER, Alligood KJ, Rhodes N, Keith BR, Murray DM, Knight WB, Mullin RJ, et al. (2001) The effects of the novel, reversible epidermal growth factor receptor/ErbB-2 tyrosine kinase inhibitor, GW2016, on the growth of human normal and tumor-derived cell lines in vitro and in vivo. Mol Cancer Ther 1:85-94.

Sacco AG and Worden FP (2016) Molecularly targeted therapy for the treatment of head and neck cancer: a review of the ErbB family inhibitors. OncoTargets Ther 9:1927-1943

Sardi SP, Murtie J, Koirala S, Patten BA, and Corfas G (2006) Presenilindependent ErbB4 nuclear signaling regulates the timing of astrogenesis in the developing brain. Cell 127:185-197.

Sartor CI, Zhou H, Kozlowska E, Guttridge K, Kawata E, Caskey L, Harrelson J, Hynes N, Ethier S, Calvo B, et al. (2001) Her4 mediates ligand-dependent antiproliferative and differentiation responses in human breast cancer cells. Mol Cell Biol 21:4265-4275.

Sassen A, Rochon J, Wild P, Hartmann A, Hofstaedter F, Schwarz S, and Brockhoff G (2008) Cytogenetic analysis of HER1/EGFR, HER2, HER3 and HER4 in 278 breast cancer patients. Breast Cancer Res 10:R2.

Sato Y, Yashiro M, and Takakura N (2013) Heregulin induces resistance to lapatinib-mediated growth inhibition of HER2-amplified cancer cells. Cancer Sci 104:1618-1625

Savkur RS and Burris TP (2004) The coactivator LXXLL nuclear receptor recognition motif. J Pept Res 63:207-212.

Scarfò I, Pellegrino E, Mereu E, Kwee I, Agnelli L, Bergaggio E, Garaffo G, Vitale N, Caputo M, Machiorlatti R, et al.; European T-Cell Lymphoma Study Group (2016) Identification of a new subclass of ALK-negative ALCL expressing aberrant levels of ERBB4 transcripts. Blood 127:221-232.

Scheck RA, Lowder MA, Appelbaum JS, and Schepartz A (2012) Bipartite tetracysteine display reveals allosteric control of ligand-specific EGFR activation. ACS Chem Biol 7:1367-1376.

Schlessinger J (2000) Cell signaling by receptor tyrosine kinases. Cell 103:211-225.

Schlessinger J and Lemmon MA (2003) SH2 and PTB domains in tyrosine kinase signaling. Sci STKE 2003:RE12.

Schlessinger J and Lemmon MA (2006) Nuclear signaling by receptor tyrosine kinases: the first robin of spring. Cell 127:45-48.

Schroeder JA and Lee DC (1998) Dynamic expression and activation of ERBB receptors in the developing mouse mammary gland. Cell Growth Differ 9:451-464

Schuchardt BJ, Bhat V, Mikles DC, McDonald CB, Sudol M, and Faroog A (2013) Molecular origin of the binding of WWOX tumor suppressor to ErbB4 receptor tyrosine kinase. Biochemistry 52:9223-9236.

Schug ZT and Gottlieb E (2009) Cardiolipin acts as a mitochondrial signalling platform to launch apoptosis. Biochim Biophys Acta 1788:2022-2031.

Schulten HJ, Alotibi R, Al-Ahmadi A, Ata M, Karim S, Huwait E, Gari M, Al-Ghamdi $\mathrm{K}$, Al-Mashat F, Al-Hamour O, et al. (2015) Effect of BRAF mutational status on expression profiles in conventional papillary thyroid carcinomas. BMC Genomics $\mathbf{1 6}$ (Suppl 1):S6.

Schulze WX, Deng L and Mann M (2005) Phosphotyrosine interactome of the ErbB-receptor kinase family. Mol Syst Biol 1:2005 0008 . 
Schumacher MA, Hedl M, Abraham C, Bernard JK, Lozano PR, Hsieh JJ, Almohazey D, Bucar EB, Punit S, Dempsey PJ, et al. (2017) ErbB4 signaling stimulates proinflammatory macrophage apoptosis and limits colonic inflammation. Cell Death Dis 8:e2622.

Segers VFM, Dugaucquier L, Feyen E, Shakeri H, and De Keulenaer GW (2020) The role of ErbB4 in cancer. Cell Oncol (Dordr) 43:335-352.

Sepp-Lorenzino L, Eberhard I, Ma Z, Cho C, Serve H, Liu F, Rosen N, and Lupu R (1996) Signal transduction pathways induced by heregulin in MDA-MB-453 breast cancer cells. Oncogene 12:1679-1687.

Shelly M, Pinkas-Kramarski R, Guarino BC, Waterman H, Wang LM, Lyass L, Alimandi M, Kuo A, Bacus SS, Pierce JH, et al. (1998) Epiregulin is a potent pan-ErbB ligand that preferentially activates heterodimeric receptor complexes. $J$ Biol Chem 273:10496-10505.

Shi J, Yao D, Liu W, Wang N, Lv H, He N, Shi B, Hou P, and Ji M (2012) Frequent gene amplification predicts poor prognosis in gastric cancer. Int $\mathrm{J} \mathrm{Mol} S \mathrm{Sci}$ 13:4714-4726

Song G, Zhang H, Chen C, Gong L, Chen B, Zhao S, Shi J, Xu J, and Ye Z (2017) miR-551b regulates epithelial-mesenchymal transition and metastasis of gastric cancer by inhibiting ERBB4 expression. Oncotarget 8:45725-45735.

Sorkin A and Goh LK (2008) Endocytosis and intracellular trafficking of ErbBs. Exp Cell Res 314:3093-3106.

Soung YH, Lee JW, Kim SY, Wang YP, Jo KH, Moon SW, Park WS, Nam SW, Lee JY, Yoo NJ, et al. (2006) Somatic mutations of the ERBB4 kinase domain in human cancers. Int $J$ Cancer 118:1426-1429.

Srinivasan R, Benton E, McCormick F, Thomas H, and Gullick WJ (1999) Expression of the c-erbB-3/HER-3 and c-erbB-4/HER-4 growth factor receptors and their ligands, neuregulin-1 alpha, neuregulin-1 beta, and betacellulin, in normal endometrium and endometrial cancer. Clin Cancer Res 5:2877-2883.

Srinivasan R, Gillett CE, Barnes DM, and Gullick WJ (2000) Nuclear expression of the c-erbB-4/HER-4 growth factor receptor in invasive breast cancers. Cancer Res 60:1483-1487.

Steffensen KD, Waldstrøm M, Andersen RF, Olsen DA, Jeppesen U, Knudsen HJ, Brandslund I, and Jakobsen A (2008) Protein levels and gene expressions of the epidermal growth factor receptors, HER1, HER2, HER3 and HER4 in benign and malignant ovarian tumors. Int $J$ Oncol 33:195-204.

Stern DF (2008) ERBB3/HER3 and ERBB2/HER2 duet in mammary development and breast cancer. J Mammary Gland Biol Neoplasia 13:215-223.

Stern DF and Kamps MP (1988) EGF-stimulated tyrosine phosphorylation of p185neu: a potential model for receptor interactions. EMBO $J$ 7:995-1001.

Stern KA, Place TL, and Lill NL (2008) EGF and amphiregulin differentially regulate $\mathrm{Cbl}$ recruitment to endosomes and EGF receptor fate. Biochem $J$ 410:585-594.

Strunk KE, Husted C, Miraglia LC, Sandahl M, Rearick WA, Hunter DM, Earp 3rd HS, and Muraoka-Cook RS (2007) HER4 D-box sequences regulate mitotic progression and degradation of the nuclear HER4 cleavage product s80HER4. Cancer Res 67:6582-6590.

Sun EG, Lee KH, Ko YS, Choi HJ, Yang JI, Lee JH, Chung IJ, Paek YW, Kim H, Bae JA, et al. (2017) KITENIN functions as a fine regulator of ErbB4 expression level in colorectal cancer via protection of ErbB4 from E3-ligase Nrdp1-mediated degradation. Mol Carcinog 56:1068-1081.

Sunaga N and Kaira K (2015) Epiregulin as a therapeutic target in non-small-cell lung cancer. Lung Cancer (Auckl) 6:91-98.

Sunaga N, Kaira K, Imai H, Shimizu K, Nakano T, Shames DS, Girard L, Soh J, Sato M, Iwasaki Y, et al. (2013) Oncogenic KRAS-induced epiregulin overexpression contributes to aggressive phenotype and is a promising therapeutic target in nonsmall-cell lung cancer. Oncogene 32:4034-4042

Sundvall M, Iljin K, Kilpinen S, Sara H, Kallioniemi O-P, and Elenius K (2008) Role of ErbB4 in breast cancer. J Mammary Gland Biol Neoplasia 13:259-268.

Sundvall M, Veikkolainen V, Kurppa K, Salah Z, Tvorogov D, van Zoelen EJ, Aqeilan R, and Elenius K (2010) Cell death or survival promoted by alternative isoforms of ErbB4. Mol Biol Cell 21:4275-4286.

Suo Z, Risberg B, Kalsson MG, Willman K, Tierens A, Skovlund E, and Nesland JM (2002) EGFR family expression in breast carcinomas. c-erbB-2 and c-erbB-4 receptors have different effects on survival. J Pathol 196:17-25.

Sutherland RL (2011) Endocrine resistance in breast cancer: new roles for ErbB3 and ErbB4. Breast Cancer Res 13:106.

Sweeney C, Lai C, Riese 2nd DJ, Diamonti AJ, Cantley LC, and Carraway 3rd KL (2000) Ligand discrimination in signaling through an ErbB4 receptor homodimer. J Biol Chem 275:19803-19807.

te Velde EA, Franke AC, van Hillegersberg R, Elshof SM, de Weger RW, Borel Rinkes IH, and van Diest PJ (2009) HER-family gene amplification and expression in resected pancreatic cancer. Eur J Surg Oncol 35:1098-1104.

Thøgersen VB, Sørensen BS, Poulsen SS, Orntoft TF, Wolf H, and Nexo E (2001) A subclass of HER1 ligands are prognostic markers for survival in bladder cancer patients. Cancer Res 61:6227-6233.

Thybusch-Bernhardt A, Beckmann S, and Juhl H (2001) Comparative analysis of the EGF-receptor family in pancreatic cancer: expression of HER-4 correlates with a favourable tumor stage. Int $J$ Surg Investig 2:393-400.

Tidcombe H, Jackson-Fisher A, Mathers K, Stern DF, Gassmann M, and Golding JP (2003) Neural and mammary gland defects in ErbB4 knockout mice genetically rescued from embryonic lethality. Proc Natl Acad Sci USA 100:8281-8286.

Tripathy D and Benz CC (1992) Activated oncogenes and putative tumor suppressor genes involved in human breast cancers. Cancer Treat Res 63:15-60.

Tvorogov D, Sundvall M, Kurppa K, Hollmén M, Repo S, Johnson MS, and Elenius K (2009) Somatic mutations of ErbB4: selective loss-of-function phenotype affecting signal transduction pathways in cancer. J Biol Chem 284:5582-5591.

Uberall I, Kolár Z, Trojanec R, Berkovcová J, and Hajdúch M (2008) The status and role of ErbB receptors in human cancer. Exp Mol Pathol 84:79-89.

Vecchi M and Carpenter G (1997) Constitutive proteolysis of the ErbB-4 receptor tyrosine kinase by a unique, sequential mechanism. J Cell Biol 139:995-1003.
Veikkolainen V, Vaparanta K, Halkilahti K, Iljin K, Sundvall M, and Elenius K (2011) Function of ERBB4 is determined by alternative splicing. Cell Cycle 10:2647-2657.

Viale G, Rotmensz N, Maisonneuve P, Bottiglieri L, Montagna E, Luini A, Veronesi $\mathrm{P}$, Intra M, Torrisi R, Cardillo A, et al. (2009) Invasive ductal carcinoma of the breast with the "triple-negative" phenotype: prognostic implications of EGFR immunoreactivity. Breast Cancer Res Treat 116:317-328.

Vidal GA, Clark DE, Marrero L, and Jones FE (2007) A constitutively active ERBB4/HER4 allele with enhanced transcriptional coactivation and cell-killing activities. Oncogene 26:462-466.

Vidal GA, Naresh A, Marrero L, and Jones FE (2005) Presenilin-dependent gamma-secretase processing regulates multiple ERBB4/HER4 activities. J Biol Chem 280:19777-19783.

Vogt U, Bielawski K, Schlotter CM, Bosse U, Falkiewicz B, and Podhajska AJ (1998) Amplification of erbB-4 oncogene occurs less frequently than that of erbB2 in primary human breast cancer. Gene 223:375-380.

Wada T, Qian XL, and Greene MI (1990) Intermolecular association of the p185neu protein and EGF receptor modulates EGF receptor function. Cell 61:1339-1347.

Wali VB, Gilmore-Hebert M, Mamillapalli R, Haskins JW, Kurppa KJ, Elenius K Booth CJ, and Stern DF (2014) Overexpression of ERBB4 JM-a CYT-1 and CYT2 isoforms in transgenic mice reveals isoform-specific roles in mammary gland development and carcinogenesis. Breast Cancer Res 16:501.

Wang H, Sun W, Sun M, Fu Z, Zhou C, Wang C, Zuo D, Zhou Z, Wang G, Zhang $\mathrm{T}$, et al. (2018) HER4 promotes cell survival and chemoresistance in osteosarcoma via interaction with NDRG1. Biochim Biophys Acta Mol Basis Dis 1864 (5 Pt A):1839-1849.

Wang J, Yin J, Yang Q, Ding F, Chen X, Li B, and Tian X (2016) Human epidermal growth factor receptor 4 (HER4) is a favorable prognostic marker of breast cancer: a systematic review and meta-analysis. Oncotarget 7:76693-76703.

Wang LM, Kuo A, Alimandi M, Veri MC, Lee CC, Kapoor V, Ellmore N, Chen XH, and Pierce JH (1998) ErbB2 expression increases the spectrum and potency of ligand-mediated signal transduction through ErbB4. Proc Natl Acad Sci USA 95:6809-6814.

Wang W, Zhao H-F, Yao T-F, and Gong H (2019) Advanced development of ErbB family-targeted therapies in osteosarcoma treatment. Invest New Drugs 37:175-183. Wang Z (2017) ErbB receptors and cancer. Methods Mol Biol 1652:3-35.

Wee P and Wang Z (2018) Regulation of EGFR endocytosis by CBL during mitosis. Cells 7:7.

Wege AK, Chittka D, Buchholz S, Klinkhammer-Schalke M, Diermeier-Daucher S, Zeman F, Ortmann O, and Brockhoff G (2018) HER4 expression in estrogen receptor-positive breast cancer is associated with decreased sensitivity to tamoxifen treatment and reduced overall survival of postmenopausal women. Breast Cancer Res 20:139.

Weiss FU, Wallasch C, Campiglio M, Issing W, and Ullrich A (1997) Distinct characteristics of heregulin signals mediated by HER3 or HER4. J Cell Physiol 173:187-195.

Wilfling F, Weber A, Potthoff S, Vögtle FN, Meisinger C, Paschen SA, and Häcker G (2012) BH3-only proteins are tail-anchored in the outer mitochondrial membrane and can initiate the activation of Bax. Cell Death Differ 19:1328-1336.

Williams CC, Allison JG, Vidal GA, Burow ME, Beckman BS, Marrero L, and Jones FE (2004) The ERBB4/HER4 receptor tyrosine kinase regulates gene expression by functioning as a STAT5A nuclear chaperone. J Cell Biol 167:469-478.

Williams CS, Bernard JK, Demory Beckler M, Almohazey D, Washington MK, Smith JJ, and Frey MR (2015) ERBB4 is over-expressed in human colon cance and enhances cellular transformation. Carcinogenesis 36:710-718.

Williams EE, Trout LJ, Gallo RM, Pitfield SE, Bryant I, Penington DJ, and Riese 2nd DJ (2003) A constitutively active ErbB4 mutant inhibits drug-resistant colony formation by the DU-145 and PC-3 human prostate tumor cell lines. Cancer Lett 192:67-74.

Willis SN, Fletcher JI, Kaufmann T, van Delft MF, Chen L, Czabotar PE, Ierino H, Lee EF, Fairlie WD, Bouillet P, et al. (2007) Apoptosis initiated when BH3 ligands engage multiple Bcl-2 homologs, not Bax or Bak. Science 315:856-859.

Willmarth NE, Baillo A, Dziubinski ML, Wilson K, Riese 2nd DJ, and Ethier SP (2009) Altered EGFR localization and degradation in human breast cancer cells with an amphiregulin/EGFR autocrine loop. Cell Signal 21:212-219.

Wilson KJ, Gilmore JL, Foley J, Lemmon MA, and Riese 2nd DJ (2009) Functiona selectivity of EGF family peptide growth factors: implications for cancer. Pharmacol Ther 122:1-8

Wilson KJ, Mill C, Lambert S, Buchman J, Wilson TR, Hernandez-Gordillo V, Gallo RM, Ades LM, Settleman J, and Riese 2nd DJ (2012a) EGFR ligands exhibit functional differences in models of paracrine and autocrine signaling. Growth Factors 30:107-116.

Wilson KJ, Mill CP, Cameron EM, Hobbs SS, Hammer RP, and Riese 2nd DJ (2007) Inter-conversion of neuregulin2 full and partial agonists for ErbB4. Biochem Biophys Res Commun 364:351-357.

Wilson KJ, Mill CP, Gallo RM, Cameron EM, VanBrocklin H, Settleman J, and Riese DJ (2012b) The Q43L mutant of neuregulin $2 \beta$ is a pan-ErbB receptor antagonist. Biochem J 443:133-144.

Wiseman SM, Griffith OL, Melck A, Masoudi H, Gown A, Nabi IR, and Jones SJ (2008) Evaluation of type 1 growth factor receptor family expression in benign and malignant thyroid lesions. Am J Surg 195:667-673, discussion 673.

Witton CJ, Reeves JR, Going JJ, Cooke TG, and Bartlett JM (2003) Expression of the HER1-4 family of receptor tyrosine kinases in breast cancer. J Pathol 200:290-297.

Xia W, Petricoin 3rd EF, Zhao S, Liu L, Osada T, Cheng Q, Wulfkuhle JD, Gwin WR, Yang X, Gallagher RI, et al. (2013) An heregulin-EGFR-HER3 autocrine signaling axis can mediate acquired lapatinib resistance in HER2+ breast cancer models. Breast Cancer Res 15:R85. 
Yamano Y, Uzawa K, Saito K, Nakashima D, Kasamatsu A, Koike H, Kouzu Y, Shinozuka K, Nakatani K, Negoro K, et al. (2010) Identification of cisplatinresistance related genes in head and neck squamous cell carcinoma. Int $J$ Cancer 126:437-449.

Yang X, Wang W, Wang C, Wang L, Yang M, Qi M, Su H, Sun X, Liu Z, Zhang J, et al. (2014) Characterization of EGFR family gene aberrations in cholangiocarcinoma. Oncol Rep 32:700-708.

Yarden Y and Sliwkowski MX (2001) Untangling the ErbB signalling network. Nat Rev Mol Cell Biol 2:127-137.

Yokoyama M, Funatomi H, Kobrin M, Ebert M, Friess H, Buchler M, and Korc M (1995) Betacellulin, a member of the epidermal growth-factor family, is overexpressed in human pancreatic-cancer. Int J Oncol 7:825-829.

Young CD, Nolte EC, Lewis A, Serkova NJ, and Anderson SM (2008) Activated Akt1 accelerates MMTV-c-ErbB2 mammary tumourigenesis in mice without activation of ErbB3. Breast Cancer Res 10:R70.

Zaczek A, Brandt B, and Bielawski KP (2005) The diverse signaling network of EGFR, HER2, HER3 and HER4 tyrosine kinase receptors and the consequences for therapeutic approaches. Histol Histopathol 20:1005-1015.

Zang ZJ, Cutcutache I, Poon SL, Zhang SL, McPherson JR, Tao J, Rajasegaran V, Heng HL, Deng N, Gan A, et al. (2012) Exome sequencing of gastric adenocarcinoma identifies recurrent somatic mutations in cell adhesion and chromatin remodeling genes. Nat Genet 44:570-574.

Zhang K, Sun J, Liu N, Wen D, Chang D, Thomason A, and Yoshinaga SK (1996) Transformation of NIH 3T3 cells by HER3 or HER4 receptors requires the presence of HER1 or HER2. J Biol Chem 271:3884-3890.
Zhang M, Ding D, and Salvi R (2002) Expression of heregulin and ErbB/Her receptors in adult chinchilla cochlear and vestibular sensory epithelium. Hear Res 169:56-68.

Zhang TT, Qu N, Sun GH, Zhang L, Wang YJ, Mu XM, Wei WJ, Wang YL, Wang Y, Ji QH, et al. (2018) NRG1 regulates redox homeostasis via NRF2 in papillary thyroid cancer. Int J Oncol 53:685-693.

Zhang X, Gureasko J, Shen K, Cole PA, and Kuriyan J (2006) An allosteric mechanism for activation of the kinase domain of epidermal growth factor receptor. Cell 125:1137-1149.

Zhou QM, Li W, Guan YX, Zhang X, Chen XC, Ding Y, Wen XZ, Peng RQ, Yan SM, and Zhang XS (2013) The absence of the ERBB4 hotspot mutations in melanomas in patients from southern China. Chin J Cancer 32:410-414.

Zhou W and Carpenter G (2000) Heregulin-dependent trafficking and cleavage of ErbB-4. J Biol Chem 275:34737-34743.

Zhou W and Carpenter G (2002) ErbB-4: a receptor tyrosine kinase. Inflamm Res 51:91-101.

Zhu Y, Sullivan LL, Nair SS, Williams CC, Pandey AK, Marrero L, Vadlamudi RK, and Jones FE (2006) Coregulation of estrogen receptor by ERBB4/HER4 establishes a growth-promoting autocrine signal in breast tumor cells. Cancer Res 66:7991-7998.

Zou H, Li Y, Liu X, and Wang X (1999) An APAF-1.cytochrome c multimeric complex is a functional apoptosome that activates procaspase-9. J Biol Chem 274:11549-11556.

Zscheppang K, Liu W, Volpe MV, Nielsen HC, and Dammann CE (2007) ErbB4 regulates fetal surfactant phospholipid synthesis in primary fetal rat type II cells. Am J Physiol Lung Cell Mol Physiol 293:L429-L435. 